Mississippi State University

Scholars Junction

5-3-2019

\title{
Effects of a 28-day carbohydrate-restricted diet on metabolic and performance markers in professional firefighters
}

Hunter Scott Waldman

Follow this and additional works at: https://scholarsjunction.msstate.edu/td

\section{Recommended Citation}

Waldman, Hunter Scott, "Effects of a 28-day carbohydrate-restricted diet on metabolic and performance markers in professional firefighters" (2019). Theses and Dissertations. 5069.

https://scholarsjunction.msstate.edu/td/5069

This Dissertation - Open Access is brought to you for free and open access by the Theses and Dissertations at Scholars Junction. It has been accepted for inclusion in Theses and Dissertations by an authorized administrator of Scholars Junction. For more information, please contact scholcomm@msstate.libanswers.com. 
Effects of a 28-day carbohydrate-restricted diet on metabolic and performance markers in professional firefighters.

\title{
By
}

Hunter Scott Waldman

\author{
A Dissertation \\ Submitted to the Faculty of \\ Mississippi State University \\ in Partial Fulfillment of the Requirements \\ for the Degree of Doctor of Philosophy \\ in Exercise Science \\ in the Department of Kinesiology
}

Mississippi State, Mississippi

May 2019 
Copyright by

Hunter Scott Waldman

2019 
Effects of a 28-day carbohydrate-restricted diet on metabolic and performance markers in professional firefighters.

By

Hunter Scott Waldman

Approved:

\begin{tabular}{c}
\hline $\begin{array}{c}\text { Matthew J. McAllister } \\
\text { (Major Professor) }\end{array}$ \\
\hline $\begin{array}{c}\text { JohnEric William Smith } \\
\text { (Co-Major Professor) }\end{array}$ \\
\hline Brent J. Fountain \\
(Committee Member) \\
\hline John Lamberth \\
(Committee Member) \\
Adam C. Knight \\
(Graduate Coordinator) \\
\hline Richard L. Blackbourn \\
Dean \\
College of Education
\end{tabular}


Name: Hunter Scott Waldman

Date of Degree: May 2, 2019

Institution: Mississippi State University

Major Field: Exercise Science

Major Professor: Matthew J. McAllister

Title of Study: Effects of a 28-day carbohydrate-restricted diet on metabolic and performance markers in professional firefighters.

Pages in Study 132

Candidate for Degree of Doctor of Philosophy

Cardiovascular disease is the leading cause of death in firefighters $(\mathrm{FF})$ around the nation. Recent observational studies have emerged suggesting that FF consume calorically dense foods, high in sugar and fat, but low in nutritional value which can exacerbate heart diseases and impair performance. The potential to improve cardiometabolic and performance measurements when following a carbohydrate $(\mathrm{CHO})$ restricted diet (CRD) has gained interest in the literature. To date, only one study has employed a nutrition intervention in FF, yet its' focus was on nutrient dense foods and antioxidant supplements. Therefore, the purpose of this study was to examine the cardiometabolic and performance effects of a 28-day CRD in FF. 15 career FF participated and finished the present study. Participants reported to the laboratory on 9 separate occasions. Trial 1 consisted of participants having a blood draw performed for assessment of their heart disease risk followed by body composition, blood pressure, and a glucose challenge test (GCT) to assess glucose impairment following ingestion of a 75 g glucose beverage. Trial 2 consisted of a graded exercise cycling test with 5 stages followed by a maximal Wingate for $30 \mathrm{~s}$. Finally, the last trial included the FF physical 
performance assessment (FPPA) which consisted of a $2.41-\mathrm{km}$ run followed by $2 \mathrm{~min}$ of maximal pull-ups, push-ups, and sit-ups. The first 3 trials were used as familiarizations, the second 3 trials were used as baseline measurements, and the last 3 trials followed the 28-day CRD. The CRD consisted of ad-libitum consumption of fat and protein and keeping $\mathrm{CHO}<25 \%$ daily kilocalorie intake. Dependent variables measured pre- and post-diet included body composition, lipid profile, insulin, cortisol, c-reactive protein (CRP), GCT, substrate oxidation rates, Wingate variables, and the FPPA. Following the diet, participants had significant reductions in CRP, blood pressure, $2.41-\mathrm{km}$ run time, $\mathrm{CHO}$ oxidation rates, and fat mass. Participants also had significant increases in high density cholesterol count, fat oxidation rates, and pull-up repetitions. Overall, our results show that a CRD in a high-stress occupation can favorably change markers of heart disease and body composition without decrements to physical performance. 


\section{DEDICATION}

This dissertation is dedicated to the four women in my life who have provided support throughout my academic journey. My grandmother, Patricia Thomas, who "left me alone" for my academic studies and has always reminded me of how proud she is. My mother, Shannon Bumgardner, who has been my biggest role model and greatest source of inspiration. My sister, Hayley Waldman, who has kept me grounded, humbled, and never stopped encouraging her big brother. Finally, to my wife, Erica Waldman. You have sacrificed so much to see me bring this journey to an end and yet, you have never once complained or asked me to stop. Many times I came home disappointed and defeated, but you always encouraged me to keep going. This degree is as much yours as it is mine. I am thankful God placed you in my life and that we may now pursue other aspirations together. 


\section{ACKNOWLEDGEMENTS}

I would like to acknowledge and thank my committee members (Drs. Matthew McAllister, JohnEric Smith, Brent Fountain, and John Lamberth) for their guidance and feedback to this dissertation and all previous projects. Dr. Matthew McAllister, thank you for instilling in me the want to become a producer of knowledge rather than just a consumer. Thank you for teaching me to see things for what they could be and not for what they are. I have always strived to match your drive, dedication, and knowledge in our field. I will forever be proud to say I was your first doctoral student. Dr. JohnEric Smith, thank you for reminding me to not always be such a scientist and reminding me not to lose sight of the forest for the trees. Dr. Brent Fountain, thank you for your knowledge and guidance on all of our projects we have collaborated on. Your knowledge of nutrition is humbling and where I strive to be one day. Dr. John Lamberth, thank you for our afternoon talks about your farm, school politics, and Navy life. You always reminded me there is more to this life than merely school. I also want to acknowledge Dr. Eric O’Neal and Dr. Benjamin Krings. Dr. O’ was my first academic mentor and unknowingly kept me from dropping out of school as an undergraduate with his course: HPE 225, Human Performance and Nutrition. It was this course that I found my love for exercise science and nutrition. Dr. Benjamin Krings was my office mate and doctoral colleague during our Ph.D. years together. Dr. Krings and I maintained a healthy competition as friends, students, and researchers which has played a significant role in 
my success today. Finally, thank you to all the other undergraduates, graduates, and faculty members who have assisted with this project as it would not have been possible without your help. 


\section{TABLE OF CONTENTS}

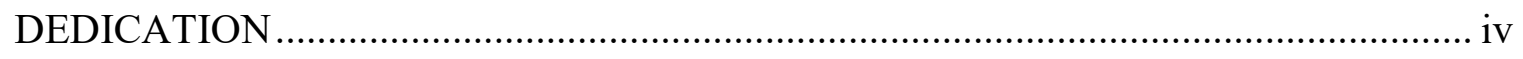

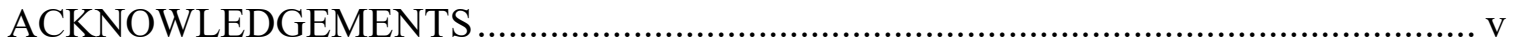

TABLE OF CONTENTS ..................................................................................... vii

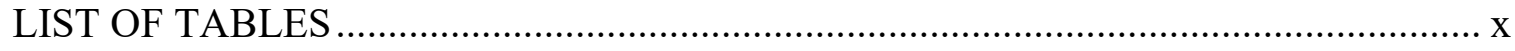

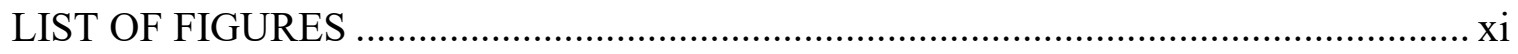

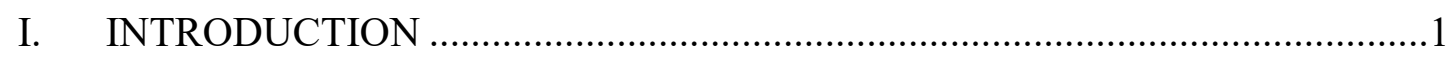

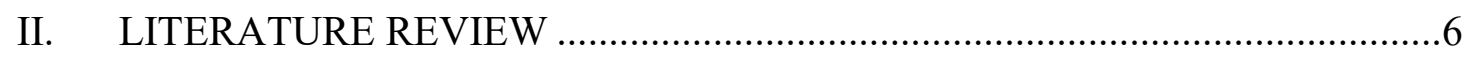

An Introduction to Cardiovascular Disease ............................................................

Cardiovascular Disease and Nutrition .........................................................6

Origin of the Current Dietary Guidelines .......................................................

Problems in the Current Research Paradigm............................................

Calories In vs. Calories Out............................................................

An Overview of Dietary Lipids .....................................................................

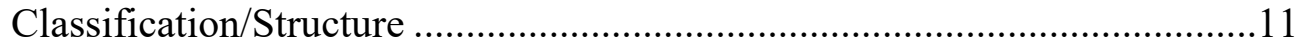

Organization of Triacylglycerols .............................................................12

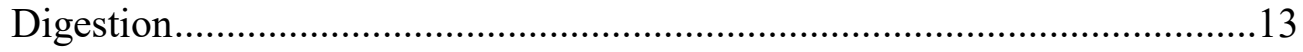

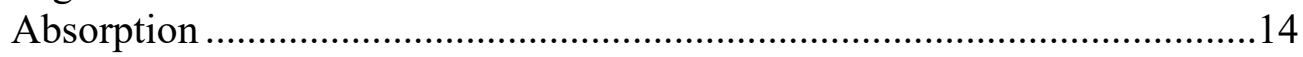

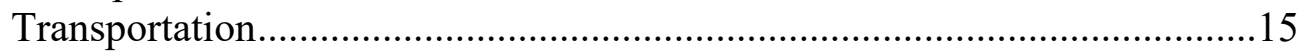

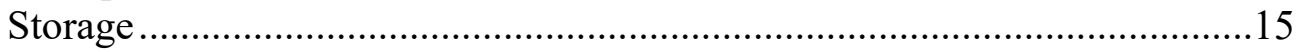

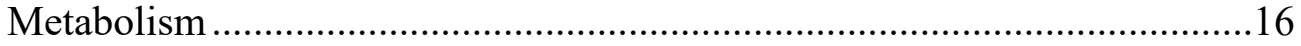

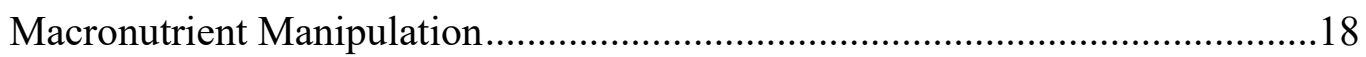

Characteristics of a Carbohydrate Restricted Diet ........................................19

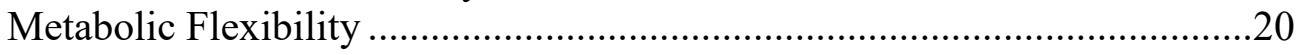

Cardiometabolic Responses to Carbohydrate Restriction ...................................22

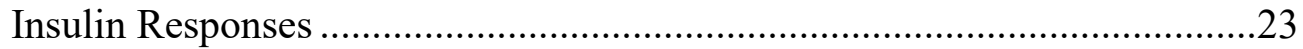

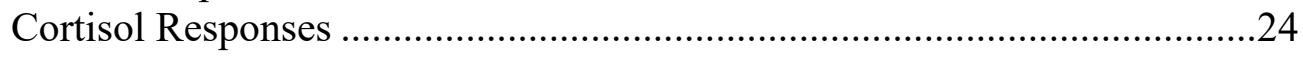

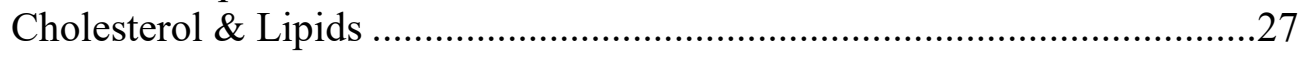

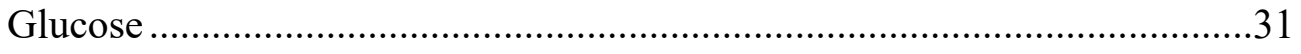

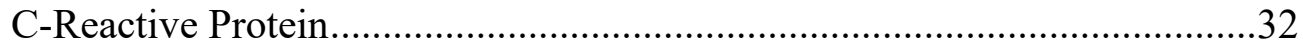

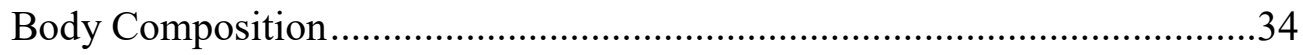

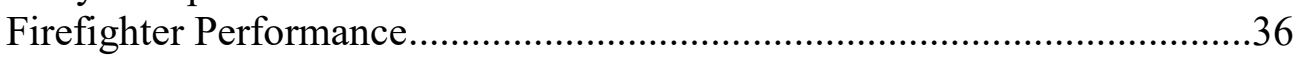

vii 


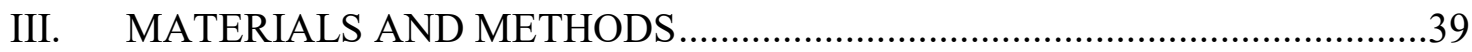

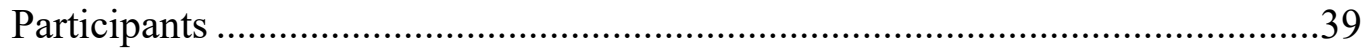

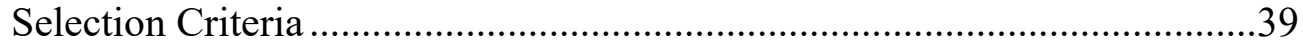

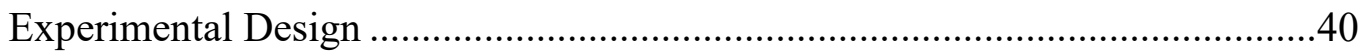

Experimental Procedures ............................................................................... 41

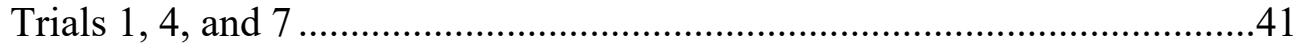

Blood Sampling and Glucose Challenge Test ..........................................41

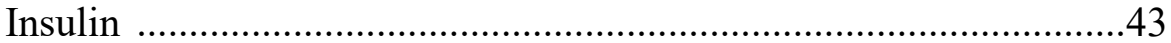

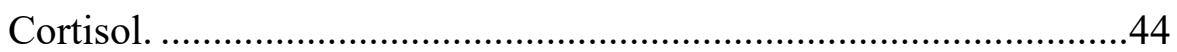

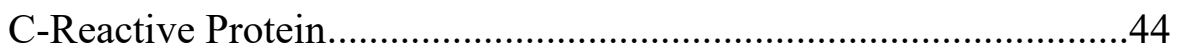

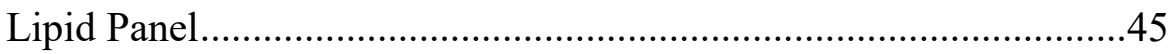

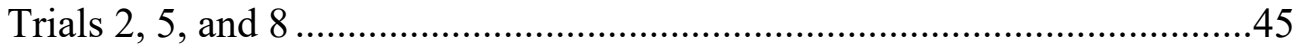

Graded Exercise and Wingate Testing .................................................45

Substrate Metabolism Calculations ……………………….....................46

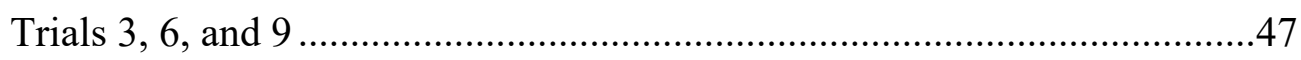

Firefighter Physical Performance Assessment ........................................47

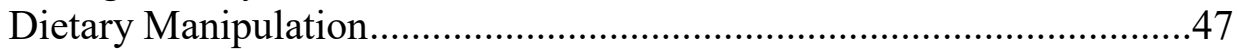

Physical Fitness Regimen .....................................................................49

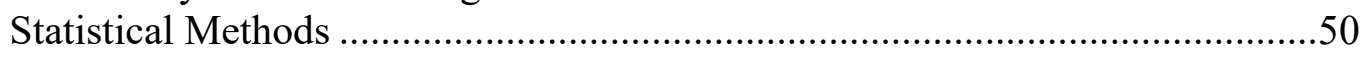

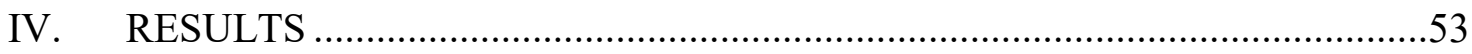

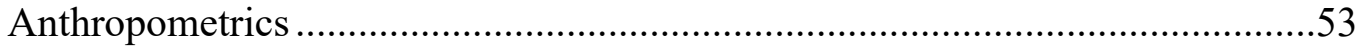

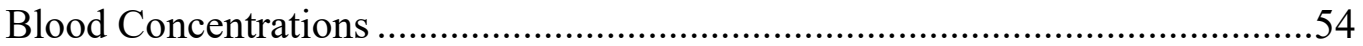

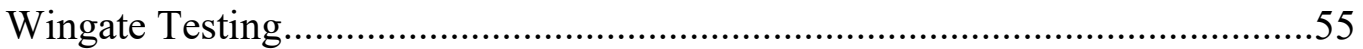

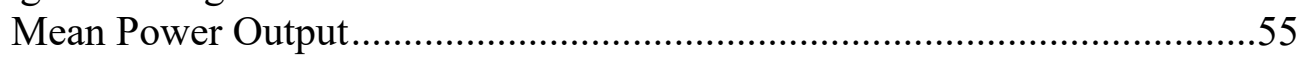

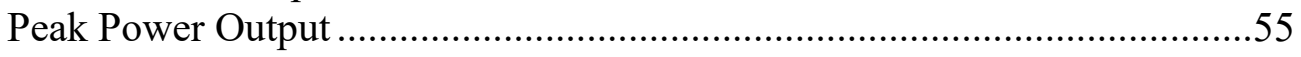

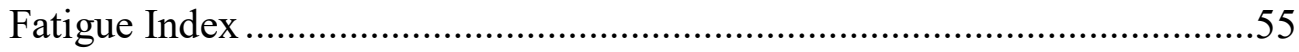

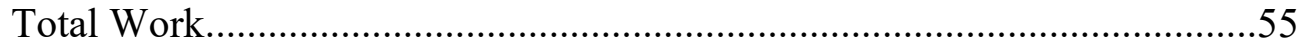

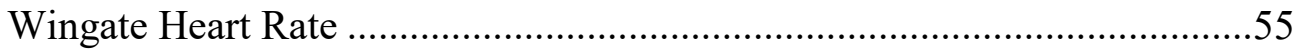

Firefighter Physical Performance Assessment ...................................................56

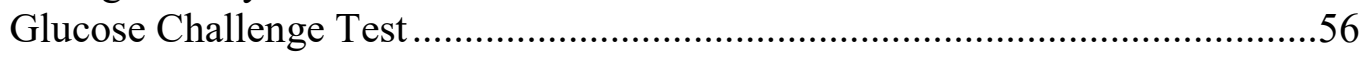

Graded Exercise Testing ...............................................................................5

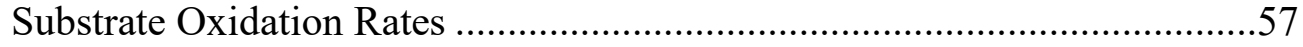

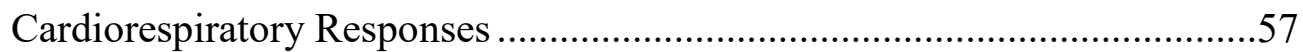

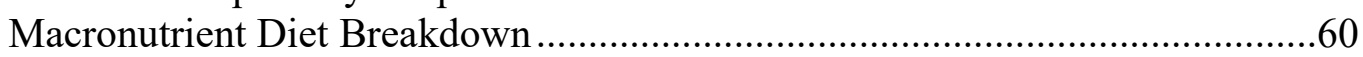

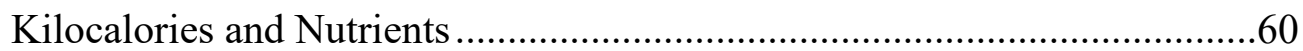

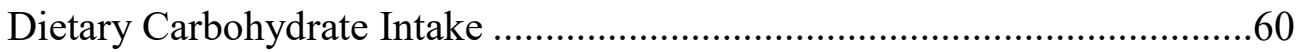

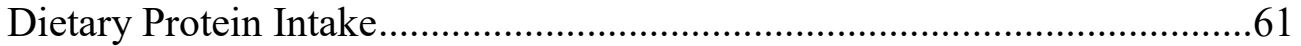

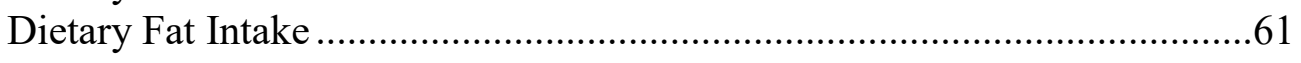

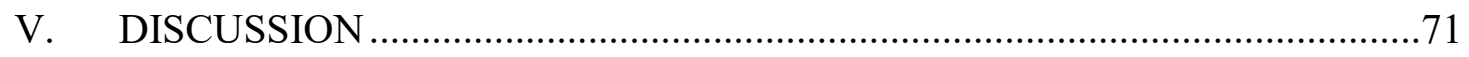

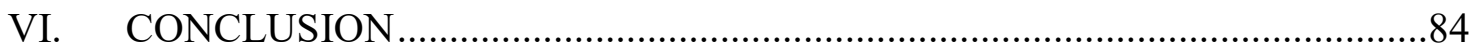

viii 


\section{APPENDIX}
A. IRB APPROVAL
124
B. INFORMED CONSENT
126 


\section{LIST OF TABLES}

1. Body Composition and Lipid Responses .................................................68

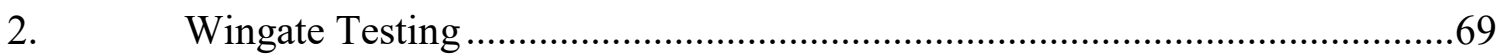

3. Macronutrient Composition Breakdown................................................... 70 


\section{LIST OF FIGURES}

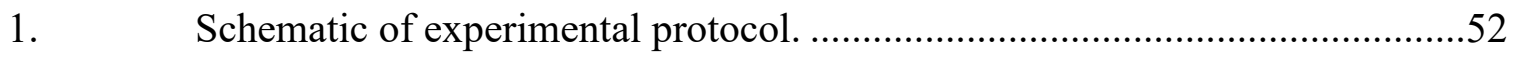

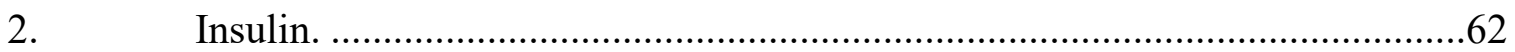

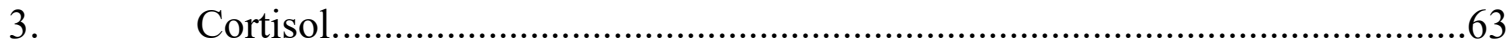

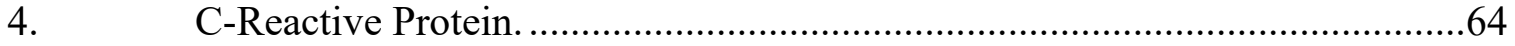

5. Firefighter physical performance assessment. .......................................65

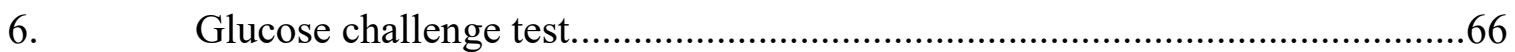

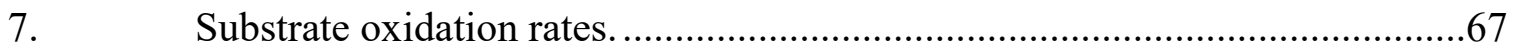




\section{CHAPTER I}

\section{INTRODUCTION}

Firefighters (FF) exhibit some of the highest rates of obesity and cardiovascular disease (CVD) in North America (Dobson et al., 2013; Gordon \& Larivière, 2014; Huang, Webb, Zourdos, \& Acevedo, 2013). FF are also exposed to a variety of stressors such as disturbed sleep patterns, frequent snacking of calorically dense foods, smoke exposure, intense physical exertion, all of which can exacerbate the progression of CVD and lead to possible sudden cardiac death (Soteriades, Smith, Tsismenakis, Baur, \& Kales, 2011; Superko et al., 2011). Further, FF express a spectrum of risk factors for the development of CVD collectively known as Syndrome X or metabolic syndrome. The components which make up metabolic syndrome (i.e. insulin resistance, excess adipose tissue, hypercholesterolemia, etc.) are considered preventable risk factors through the proper modification of an individual's diet and incorporation of an exercise regime. While the research is extensive with regard to FF health, performance, and exercise (Abel, Mortara, \& Pettitt, 2011; Dennison, Mullineaux, Yates, \& Abel, 2012; Smith, 2011), to date, most studies on FF eating patterns are observational as opposed to randomized control trials (Haddock, Day, Poston, Jahnke, \& Jitnarin, 2015; Poston, Haddock, Jahnke, Jitnarin, \& Day, 2013). Similar to westernized diets, FF consume excessive amounts of sodium, processed sugars, fatty snacks, and alcohol (Haddock et al., 2015; Poston et al., 2013). This eating behavior is partly due to the demands of the FF 
work schedule which consists of sporadic night shifts and the need for quick, on-the-go snacks. However, there is also reason to believe that most FF, like many Americans, are uneducated as to healthy eating patterns and the positive effects proper nutrition can have on health and performance. A recent study showed that most FF ( 71\%) do not follow any specific dietary plan and over $75 \%$ of FF were interested in developing healthier eating patterns (Yang, Farioli, Korre, \& Kales, 2015). However, a large majority of the FF questioned were unsure of the proper steps for implementing healthier eating patterns into their professional and everyday lives. Provided these data, research is needed to examine how proper nutrition counseling and a diet intervention could potentially mitigate the components of metabolic syndrome and reduce the prevalence of CVD expressed in FF.

Carbohydrate restricted diets (CRD) are diet alternatives being considered by national health and nutrition organizations, such as the American Diabetes Association and Academy of Nutrition and Dietetics, as a treatment for the metabolic components of Syndrome X (Feinman et al., 2015; Franz et al., 2002). Although the scope of how a CRD specifically impacts these metabolic markers is detailed further below; in short, when an individual restricts carbohydrates ( $\mathrm{CHO})$, ingestion of both dietary protein and fat increases, leading to an overall increase in satiety (Hu et al., 2016). A common observation during CRD is decreases in total body mass and improvements in lipid profiles, regardless of calories being held at requirements to maintain body mass or in an ad-lib caloric fashion that results in a caloric deficit (Heatherly et al., 2017; Volek, Fernandez, Feinman, \& Phinney, 2008; Volk et al., 2014). Adherence is also a strong component of any successful diet, given that a diet only has potential for success if an 
individual can follow the provided guidelines. Research has consistently shown that adherence to a $\mathrm{CRD}$, ranging in customized prescription of allotted daily $\mathrm{CHO}$ intake, is overall higher than other diets such as low fat, high $\mathrm{CHO}$ diets (Feinman et al., 2015). Although many current $\mathrm{CRD}$ require severe $\mathrm{CHO}$ restriction resulting in a light to moderate elevation in endogenous ketones, a CRD is technically defined as any diet restricting $\mathrm{CHO}$ to below $26 \%$ of total caloric intake (Volek \& Feinman, 2005; Volek et al., 2008) or below 130 grams of $\mathrm{CHO}$ per day when advanced dietary tracking software is not available to participants (Sato et al., 2017).

Present evidence suggests that a CRD could be a diet that FF would adhere to and benefit from in regard to overall health. Specifically, one study recently surveyed over 3,500 FF concerning their dietary preferences and found diets (e.g. Mediterranean and Paleo) low in $\mathrm{CHO}$ and high in animal meats were viewed more favorably ( $\sim 5 \%)$ by FF than diets based solely on vegetables or were extremely low in fat or $\mathrm{CHO}(<10 \%$ for either macronutrient) (Yang et al., 2015). Ideally, a caloric restricted diet might be the overall best option for this particular occupation due to its simplistic nature and brief duration. However, research has shown individuals in the presence of "trigger" foods, specifically sugar (Avena, Rada, \& Hoebel, 2008), then restriction of those trigger foods (Astrup, Larsen, \& Harper, 2004) along with healthy food choice counseling (A. D. Association, 2002) is required for successful adherence to any diet. This is due to a particular food "addiction" known as hedonic hunger and is commonly observed during caloric restricted diets, resulting in low success rates pertaining to chronic weight-loss and adherence (Appelhans, 2009; Berthoud, Münzberg, \& Morrison, 2017; Lowe \& Butryn, 2007; Stroebe, Papies, \& Aarts, 2008). A CRD, by its macronutrient 
requirements, removes the overconsumption of highly processed sugars that have been observed in FF (Haddock et al., 2015). By comparison, restricting calories expresses only one major limitation: another limitation is the eventual regain in bodyweight, as observed in the TODAY study where individuals followed a caloric restricted diet for over a 2-year period and regained all of their original bodyweight back (Diabetes Prevention Program Research Group, 2002). As detailed by Hall and Guo (2017), even when calories are reduced, the body compensates by not only reducing caloric expenditure through other processes (detailed further below), but also by upregulating hunger hormones and initiating a feeding response (Hall \& Guo, 2017). The end results are individuals who eat more and move less due to the hypothalamic signaling processes recognizing the caloric deficit the diet creates. Rather than slowly reintroducing calories back to the body, calories are usually introduced quickly in a binge fashion and all while the metabolic regulating hormones such as thyroxin are still significantly low. This combination results in the individual obtaining a weight higher than when they first started the diet, known as the rebound effect (Sumithran \& Proietto, 2013). A recent review paper examining dietary macronutrient composition and loss of fat mass found increasing dietary protein intake is the key macronutrient for maintaining lean muscle mass and reducing adipose tissue (Campbell et al., 2007). Thus, the last variable remains the manipulation of either decreasing $\mathrm{CHO}$ or fats. Given genotype research has shown that a majority $(\sim 70 \%)$ of the population responds metabolically (i.e. lipid and inflammation markers) more favorably to a CRD than a low fat diet (Krauss, 2005), the present study will aim to utilize a CRD to improve cardiometabolic markers in FF. 
Therefore, provided these findings, the purpose of the present investigation is to examine the effects of a 28-day CRD on metabolic and performance markers in career male FF. These findings might offer insight into new dietary approaches for combating and mitigating the number one cause of death among the nation's FF. 


\section{CHAPTER II}

\section{LITERATURE REVIEW}

\section{An Introduction to Cardiovascular Disease}

By the year 2030, heart disease is projected to be the third leading cause of mortality rates worldwide with over 23 million individuals dying from CVD-related risk factors (Mathers \& Loncar, 2006). In agreement with current statistics, the American Heart Association (AHA), a leading organization for CVD risk prevention, found nearly $70 \%$ of all American adults over 20 years old are overweight and of that population, $35 \%$ are obese (body mass index $(\mathrm{BMI}) \geq 30 \mathrm{~kg} / \mathrm{m}^{2}$; Go et al., 2014). Aside from a high BMI, the AHA has identified common risk factors related to CVD, to include the following: elevated serum cholesterol $(\geq 240 \mathrm{mg} \cdot \mathrm{dL})$, hypertension $(>120 / 80 \mathrm{~mm} \mathrm{Hg})$, fasting plasma glucose $\left(\geq 100 \mathrm{mg} \cdot \mathrm{dL}^{-1}\right)$, use of tobacco, and/or leading a sedentary lifestyle (Go et al., 2014).

\section{Cardiovascular Disease and Nutrition}

Current recommendations from the AHA for preventing and mitigating CVD involve individuals working toward a variety of goals to maintain a healthy lifestyle. The AHA and American College of Sports Medicine (ACSM) defined these goals in 2013, to include: individuals burning more calories than calories consumed, following a dietary approach to stop hypertension (DASH) diet, participating in (75-150 min) a week of 
moderate-to-vigorous intensity aerobic exercise, respectively, and eliminating smoking or secondhand smoking (Eckel et al., 2014). However, the recent HELENA study found the allotted ACSM physical activity requirements (both duration and intensity) to be not stringent enough to make noticeable changes on markers of cardiovascular health, as the findings claimed that physical activity of low intensity, as measured by accelerometer, did not differ significantly from television viewing in terms of cardiometabolic risk factors (Barker et al., 2017). Further, organizations such as the AHA, the National Heart, Lung, and Blood Institute, and the United States Department of Health and Human Services all recommend a similar set of dietary guidelines which places emphasis on reducing total caloric intake of dietary fats, especially those consisting of saturated fats (SFAs; DeSalvo, Olson, \& Casavale, 2016; Larosa et al., 1990). Similar to the physical activity recommendations, the growing work of scientific literature is showing discrepancies among emerging data and the current dietary guidelines; this discrepancy may be exhibited most notably the high-fat DASH study (Chiu et al., 2015). Chiu and team randomized participants to either a low-fat or high-fat DASH diet. Although both diets significantly reduced both systolic (SBP) and diastolic blood pressure (DBP), it was only the high-fat DASH diet which yielded significant improvements in plasma triacylglycerols (TAG) and very-low density lipoprotein (VLDL-c) particle size. These data, among others, are in disagreement with the Framingham Heart Study and Seven Countries Study of Ancel Keyes from the early 1950's which form the cornerstones for dietary guidelines today and the diet-heart hypothesis. 


\section{Origin of the Current Dietary Guidelines}

The Framingham Heart Study set out to determine common CVD characteristics among adult men and women. After collecting data from over 5,000 participants and with the Framingham study still ongoing today, some common risk factors found were high $\mathrm{BP}$, high cholesterol, excess adipose tissue, and physical inactivity. Although the Framingham Study provided science with the important role that high density lipoproteins (HDL-c) play in reducing CVD, researchers also concluded heart disease and consumption of dietary fat were significantly increased in individuals due to the relationship between the participants' cholesterol levels, circulating plasma levels of TAG, and risk for developing heart disease (Castelli, 1984; Castelli, 1986; Wilson, 1994). Following the Framingham Study, the Seven Countries Study set out to examine the association of diets and corresponding risks for developing CVD across a multitude of cultures. In a similar manner as the Framingham Study, the findings of the Seven Countries Study showed blood cholesterol and SFAs ingestion followed a linear path and subsequently increased the risk for developing any form of coronary heart disease (CHD; Keys et al., 1984; Keys et al., 1986; Verschuren et al., 1995). It was these findings the AHA then implored in developing its heart healthy nutritional guidelines for minimizing dietary fat and cholesterol-containing foods in order to mitigate hypercholesterolemia. Although both studies have been instrumental in providing evidence for the prevention of $\mathrm{CHD}$, recent literature shows there were also incorrect conclusions drawn from the findings of both studies. 
Problems in the Current Research Paradigm. Specifically, research from the University of California Los Angeles monitored total cholesterol (TC), BMI, HDL-c and LDL-c, as well as total TAG in 1,134 hospitalized patients, and found that low TC $(<129$ $\mathrm{mg} / \mathrm{dL}$ ) was most closely associated, although not causative, with an increased risk for heart failure (Horwich, Hamilton, MacLellan, \& Fonarow, 2002). Moreover, a recent meta-analysis called to question the current dietary guidelines when the relationship between dietary fat, serum cholesterol, and CHD was examined in ten separate, randomized controlled dietary intervention trials, and found no relationship for reducing dietary fat and CHD risk (Harcombe, Baker, DiNicolantonio, Grace, \& Davies, 2016). Further, the AHA has recommended the replacement of SFAs with polyunsaturated fats (PUFAs) and CHO. However, the data are clear that replacement of SFAs with $\mathrm{CHO}$ generally results in minimal changes for CHD risk and can even increase an individual's risk for developing CVD (Siri-Tarino, Chiu, Bergeron, \& Krauss, 2015).

Calories In vs. Calories Out. A current dietary protocol of the AHA and ACSM for improving CHD risk factors is an emphasis on weight reduction via "calories in vs. calories out." Given the higher caloric load of a TAG (9 kcals/gram) versus both protein and $\mathrm{CHO}$ (4 kcals/gram), leading health organizations have implemented guidelines reducing dietary fats to meet the need for creating a greater energy deficit in Americans. With regard to successful and sustainable weight-loss, caloric expenditure must exceed caloric intake, regardless of diet macronutrient composition (Buchholz \& Schoeller, 2004; Schoeller \& Buchholz, 2005; Wing \& Hill, 2001; Wing \& Phelan, 2005). In contrast to the beneficial aspects demonstrated by calorie monitoring (Hartmann-Boyce, Johns, Jebb, \& Aveyard, 2014), the approach of calorie counting and recommended 
reductions in dietary fat have not slowed the steadily increasing number of overweight and obese individuals (Chan, 2017). The prevalence of weight gain can be partially attributed to the misconception that the aforementioned guideline implies, which is all calories are created equal. A sole focus on caloric density ignores the neuroregulation different macronutrients have on the hypothalamic and hedonic regions of the brain. Although removal of dietary fats for $\mathrm{CHO}$ can reduce total caloric load acutely, chronically, an increase in $\mathrm{CHO}$ in an individual's diet can alter the dopamine-mediated responses to food as well as the chemical-hormonal messaging taking place during digestion. Specifically, when individuals consume meals of high glycemic load and minimal dietary fat or protein content, secretion of glucagon-like peptide 1 (GLP-1) signals for the production of insulin and is represented with an inverse relationship to insulin (Norouzy, Leeds, Emery, \& Bayat, 2009). Aside from leptin and insulin, intestinal secretion of GLP-1 and cholecystokinin (CCK) are the immediate satiety hormones, given the ability of both hormones to mitigate gastric emptying. However, the diminished response from GLP-1 and reactive hypoglycemic crash following a high glycemic meal results in an attenuated feeling of fullness and, chronically, is a potent appetite stimulus leading to excessive caloric consumption and eventual weight gain (Waldman, Krings, Smith, \& McAllister, 2018). With regard to dietary fat, research has shown a moderate bolus of TAG to cause an increase in CCK levels, which is known to immediately induce satiety, reduce meal size, and decrease total caloric consumption (Lee, Schiffman, \& Pappas, 1994). Satiety scales developed by examining the caloric requirements for the gastric emptying rates of different macronutrients, rank protein as the most filling macronutrient followed by fibrous $\mathrm{CHO}$, then $\mathrm{TAG}$, and lastly, highly processed $\mathrm{CHO}$ 
(Kessler, 2010). The Centers for Disease Control and Prevention showed most Americans are consuming $\mathrm{CHO}$ from highly processed foods such as cereals, granola bars, and soda drinks (Ervin \& Ogden, 2013). Therefore, given the strong correlation between excessive adiposity and CHD as shown by the AHA (Eckel \& Krauss, 1998) and the calorie in vs. calorie out model that the AHA recommends for the prevention of CVD, it can be hypothesized macronutrient composition -- specifically protein and fat, not just caloric expenditure -- does matter in the prevention and treatment of CHD.

\section{An Overview of Dietary Lipids}

\section{Classification/Structure}

Molecularly, lipids are a diverse group of hydrophobic, organic-solvent-soluble compounds that are generally not water-soluble. Their primary structure consists of a hydrocarbon core (i.e. fatty acids and steroids) which can also possess a polar, hydrophilic group or head [R-( $\left.\left.\mathrm{CH}^{2}\right)_{\mathrm{n}} \mathrm{COO}-\right]$. Unlike proteins and $\mathrm{CHO}$, which both form covalent interactions, lipids associate through non-covalent forces (Palsdottir \& Hunte, 2004). Non-covalent forces and the Van der Waals interaction between two or more hydrocarbon regions allow lipids to participate in a multitude of roles such as energy storage, membrane integrity, cell signaling, and hormone regulation (Mougios, 2006).

Fatty acids are classified by a hierarchical process, the first of which begins with the length (i.e., short, medium, long, or very long) of a fatty acids chain (C:2 to C:24) and can occur naturally in two forms: saturated or unsaturated. The degree of unsaturation is dependent on the number of double bonds occurring between carbon molecules and are grouped as saturated (SFA; no double bonds), mono-unsaturated (MUFA; 1 double bond), and poly-unsaturated (PUFA; 2 or more double bonds). Moreover, the orientation 
of double bonds can further classify a fatty acid to either a cis or trans group. Unlike a trans fatty acid where the functional group occurs on the opposite side, a cis fatty acid has its functional group on the same side, allowing for the insertion of a bend into the hydrocarbon tail -- generally the fatty acids found in nature (Mougios, 2006). Lastly, fatty acids are classified on esterification status to glycerol and availability for oxidation, either as a glyceride (glycerol attached) or as a non-esterified fatty acid (NEFA) (glycerol absent), also known as a free fatty acid (FFA) (Mougios, 2006). Within the scientific literature, fatty acids are referred to by a system of abbreviations such as: $18: 3 \mathrm{c} \Delta 9$, where 18 designates the total number of carbons, 3 designates the number of double bonds, followed by a "c" or "t" denoting either cis or trans fatty acid, respectively, and then a final number (9) representing where the double bond starts within the fatty acid chain (Mead, 1986).

\section{Organization of Triacylglycerols}

Complex lipids known as a TAG are characterized by three separate fatty acid chains attached to a glycerol backbone. Rarely are the three fatty acid chains of the same carbon length, but are usually composed of three mixed fats, including saturated and unsaturated fatty acids (Mead, 1986; Vance \& Vance, 2008). Among the three macronutrients, oxidation of TAG produces the greatest quantity of energy because unlike either $\mathrm{CHO}$ or proteins, the carbons of a TAG predominately exist in a reduced state and therefore, are efficient in the storage of energy (Mead, 1986). Quantitative analysis in previous literature has shown most of the carbons found in TAG are more highly reduced than those of $\mathrm{CHO}$, due to their placement near the reduced methyl level; thus, oxidation of a TAG consumes more oxygen than a $\mathrm{CHO}$, resulting in a greater 
release of metabolic energy (Mead, 1986; Vance \& Vance, 2008). It is due to this vast difference in energy yield and storage that TAG are the primary substrate for energy while at rest and during low-moderate exercise intensities (50-65\%) of maximal oxygen consumption $\left(\dot{\mathrm{V}}_{2} \max \right)$ (Juul Achten, Gleeson, \& Jeukendrup, 2002; Coyle, 1995; van Loon, Greenhaff, Constantin-Teodosiu, Saris, \& Wagenmakers, 2001). Aside from energy production, TAG also serve the purpose of heat production, as found in brown adipose tissue, and for thermal insulation of organs (Cannon \& Nedergaard, 2004; R. A. Young, 1976).

\section{Digestion}

Dietary TAG digestion poses a problem unlike proteins or $\mathrm{CHO}$ due to its hydrophobic structure. Making lipids readily available for breakdown, absorption, and transportation requires the release of bile salts -- the amphipathic make-up of which can actively emulsify and expand the surface area for the digestion of dietary lipids. However, given the storage of bile salts in the gallbladder, a network of signals must exist to allow feedforward control of this compound. Upon entering the oral cavity, lipids are sensed by taste bud receptors lining the tongue and walls of the mouth. Salivary lipase, which initially begins the digestive process of a lipid, generates chemical signals to the brainstem which are then dispersed in a bidirectional system. Although the data are not fully clear on the final destinations of either neuronal signal, present literature speculates one set of chemical messengers travels by way of the gut-brain vagal nerve and signals for the release of cholecystokinin (CCK) and secretin, resulting in bile salt release and delayed gastric emptying (Froehlich, Gonvers, \& Fried, 1995; Green, Taguchi, Friestman, Chey, \& Liddle, 1989). The second set of messengers travels first to 
the caudal brainstem and then to the hypothalamic and hedonic regions where they merge with information from the gut and digestive organs to prompt neurotransmitters to initiate a satiety response, usually through the downregulation of Neuropeptide Y (Beck, Stricker-Krongrad, Burlet, Nicolas, \& Burlet, 1990). Upon entering the stomach, lingual lipase begins the process of lipolysis and conversion of an intact TAG to a mixture of glycerol, FFA, mono, and diacylglycerols (Liao, Hamosh, \& Hamosh, 1984). The remaining mixture then enters the lumen of the small intestine and -- because of the partly hydrophilic structure these particles now have due to bile salts -- micellar particles form to enable absorption through intestinal mucosal cells.

\footnotetext{
Absorption

Cellular uptake of micellar particles and TAG re-formation from the hydrolyzed products is dependent on the chain length of the FFA and takes place in the endoplasmic reticulum and Golgi complex of the intestinal cells. Re-esterification requires FFA of 10 carbon atoms or greater to be activated first by the enzyme acyl CoA synthetase, due to the high specificity for long chain fatty acids only (Mead, 1986). If the number of carbon atoms of a FFA is less than 10 (generally short and medium-chain FFA) the activation step is bypassed and the FFA enter directly into the portal vein, bound by the protein albumin, and are then facilitated to the liver. However, esterification of a long chain FFA into a TAG is then dumped into the lymphatic system, bound to a lipoprotein carrier known as a chylomicron.
} 


\section{Transportation}

All dietary lipids are transported in the circulatory system, from tissue to tissue, by a lipoprotein. Lipoproteins are classified with respect to their density, as determined by centrifugation, and are dependent on the concentration of lipids and specific polypeptides within a given protein carrier. Lipoproteins of high, moderate, and low lipid concentrations differ in their lipid-carrying roles with respect to the origin and synthesis (i.e. exogenous or endogenous) of each specific TAG (Mead, 1986). The primary lipoprotein carrier for exogenous dietary TAG are chylomicrons. Chylomicrons transport TAG to non-hepatic tissues -- specifically adipose tissue, the heart, and skeletal muscles - to be either immediately oxidized for cellular energy or stored for later utilization.

\section{Storage}

Lipogenesis predominately occurs within adipose tissue during periods of overnutrition. After a TAG has been transported by a chylomicron, apoprotein C-II activates lipoprotein lipase, which then catalyzes the hydrolysis of a TAG to glycerol and FFA (Mougios, 2006). Upon FFA entry into the adipocyte, a TAG is once again re-synthesized for storage while the glycerol is shuttled to the liver for glucose re-synthesis. However, due to adipose tissue's lack of the enzyme glycerol kinase, the backbone (i.e. glycerol-3phosphate) for a TAG must come from glycolysis (Mead, 1986). However, the expandability of adipose tissue is not an unlimited process and lipotoxicity, or the spillover of excessive TAG, can occur in response to a positive energy balance (Slawik \& Vidal-Puig, 2007). Therefore, given the average adipocyte of non-obese individuals is 0.1 $\mathrm{mm}$ in diameter and $0.05 \mu \mathrm{g}$ in mass (Salans, Cushman, \& Weismann, 1973), a typical fat 
cell is only capable of storing $0.7 \pm 0.2 \mu \mathrm{mol} \cdot \mathrm{kg}$ lipid (Ali et al., 2011) and anything exceeding this potentially leads to an increase in circulating fatty acids or hyperplasia.

\section{Metabolism}

During periods of energy generation, when caloric expenditure is exceeding caloric intake, organisms catabolize fat (i.e. lipolysis) to meet the energy demands. The complete hydrolysis of a TAG will yield a glycerol backbone, along with three fatty acids. Lipolysis is controlled hormonally by the enzyme hormone-sensitive lipase (HSL), adipose triglyceride lipase (ATGL), and monoacylglycerol lipase (MGL) whose activity is also significantly regulated by the hormone insulin (Strålfors, Björgell, \& Belfrage, 1984). Before oxidation of FFA can occur, mobilization must first take place. ATGL is the first enzyme to catalyze the lipolysis reaction by hydrolyzing the ester linkage between the FFA chains and glycerol backbone and generating a diacylglycerol. After the removal of perilipin by protein kinase A, phosphorylated HSL catalyzes the second step of mobilization by hydrolysis of the diacylglycerol and creating a monoacylglycerol. The last step of lipolysis is the enzyme MGL catalyzing hydrolysis and effectively releasing the final FFA. The release of the three FFA are passively diffused through the cell membrane where they are then bound to the plasma transporter albumin and carried to peripheral tissues for a process collectively known as $\beta$-oxidation.

$\beta$-oxidation occurs within the mitochondria of a cell; however, FFA must first be activated by the acetylation of coenzyme A, reducing FFA to fatty acyl CoA. Activation of a FFA to fatty acyl-CoA by coenzyme A requires two ATPs, due to the energy requirements of cytoplasmic fatty acyl-CoA synthetase, which initiates the reaction and is 
specific to the chain length of the FFA attempting to gain entry to the mitochondria (Gropper \& Smith, 2012). Aside from short-chain FFA, medium and long chain FFA must cross the mitochondrial membranes utilizing a transport system. The first step of transporting fatty acyl CoA across the mitochondrial membrane complex involves the covalent bonding of the fatty acyl moiety to a transporter known as carnitine. This step is initiated by the transferase enzyme carnitine acyltransferase I (CAT I) whose active site faces the cytoplasm of a cell (Mead, 1986). Following the translocation of CAT I from the outer mitochondrial membrane to the inner membrane, a second transferase known as carnitine acyltransferase II (CAT II) completes the transport process by exchanging the tightly bonded fatty acyl-carnitine for free carnitine and fatty acyl-CoA which is released into the mitochondrial matrix. Once in the matrix, oxidation takes place at the $\beta$-carbon, hence the term $\beta$-oxidation, and results in the fatty acyl-CoA chain being shortened by two-carbon units each time. Each two-carbon unit is released in the form of acetyl-CoA where it can then enter the tricarboxylic acid cycle (TCA) for further oxidation (Gropper \& Smith, 2012).

Furthermore, $\beta$-oxidation is tightly regulated by several rate-limiting enzymes (RLE). The first enzyme is known as acyl-CoA dehydrogenase which catalyzes the first rate-limiting step of $\beta$-oxidation and is responsible for the removal of two hydrogen atoms using the redox acceptor Flavin Adenine Dinucleotide (FAD). The second ratelimiting step to $\beta$-oxidation involves the enzyme $\beta$-hydroxyacyl-CoA dehydrogenase; this step removes one hydrogen and binds to the redox cofactor Nicotinamide Adenine Dinucleotide (NAD), which can then donate its hydrogen to the electron transport chain (ETC) to undergo oxidative phosphorylation. The final rate-limiting step to $\beta$-oxidation 
involves the enzyme thiolase which effectively cleaves the $\alpha-\beta$ bond from 3-ketoacylCoA, producing only acetyl-CoA for the TCA (Gropper \& Smith, 2012; Mead, 1986; Mougios, 2006; Vance \& Vance, 2008). All three RLE are regulated by several mediators including: elevated levels of ATP, hydrogen ions, acyl-CoA carboxylase (ACC), available NAD and FAD cofactors, and citrate levels (Gropper \& Smith, 2012; Mead, 1986).

\section{Macronutrient Manipulation}

With regard to metabolic health, a shift has occurred over the last decade in our understanding of dietary macronutrient manipulations and lipid metabolism (Liebman, 2014; Volek et al., 2008; Volek, Phinney, et al., 2009). Specifically, present ongoing investigations are examining the relationship between the reduction in exogenous $\mathrm{CHO}$ ingestion and its effects on CVD risk. Numerous studies have purported the benefits of light-moderate $\mathrm{CHO}$ restriction on improving variables such as weight-loss (Grieb et al., 2008; Volek et al., 2008; Volek et al., 2002), improvements in atherogenic dyslipidemia (Volek et al., 2008), hyperinsulinemia, and type II diabetes (Volek \& Feinman, 2005; Volek et al., 2002), as well as characteristics of the metabolic syndrome (Volek, Ballard, et al., 2009; Volek \& Feinman, 2005). Although similar findings have been found in investigations which have examined like dependent variables using caloric restriction and low-fat high-CHO diets as its model (Golay et al., 1996; Opie, 2009; Redman \& Ravussin, 2011), a previous study by Draznin and team showed a CRD was significantly more effective at increasing the cellular expression of the mitochondrial transcription factor peroxisome proliferator-activated receptor gamma coactivator 1-alpha (PGC-1 $\alpha)$ 
and cellular sensor adenosine monophosphate kinase (AMPK) in both a caloric surplus and caloric deficit, compared with a low-fat, high CHO diet (Draznin, Wang, Adochio, Leitner, \& Cornier, 2012). This finding suggests CHO restriction has benefits transcending merely skeletal substrate metabolism. In light of the current research, the physiological benefits to $\mathrm{CHO}$ restriction will be detailed further.

\section{Characteristics of a Carbohydrate Restricted Diet}

As of recently, agreement upon common parameters for defining a CRD has eluded the scientific community and resulted in a constant barrier for communication. This might be partly explained due to the severity of $\mathrm{CHO}$ restriction being implemented, as studies have shown a multitude of alterations in mitochondrial enzymatic expression with varying levels of $\mathrm{CHO}$ manipulations. Feinman et al. and others have proposed a set of definitions which were based on similar dietary parameters in multiple studies: 1) a very low $\mathrm{CHO}$ ketogenic diet is one limiting $\mathrm{CHO}$ intake to less than 50 grams per day $(\mathrm{g} / \mathrm{d})$ or less then $10 \%$ of the 2000 kilocalories per day (kcal/day); 2) a non-ketogenic, $\mathrm{CRD}$, also known as a low $\mathrm{CHO}$, high fat (LCHF) diet, is a diet which limits $\mathrm{CHO}$ intake to less than $26 \%$ of total caloric energy; 3 ) a moderate $\mathrm{CRD}$ allows for $\mathrm{CHO}$ intake between $26 \%$ and $45 \%$; 4 ) a high $\mathrm{CHO}$ diet or western diet (WD), as recommended by the ADA, allows $\mathrm{CHO}$ intake above $45 \%$ (Feinman et al., 2015; T. D. Noakes \& Windt, 2017). It should be pointed out that the term $\mathrm{CHO}$ restriction is becoming more acceptable within the literature, as opposed to LCHF. It has been observed from our own laboratory that fat intake is generally consumed at around $30-40 \%$ in a typical WD and rarely is there need for the individual to increase dietary fat in their own diet (Waldman et al., 2017). Therefore, during periods of $\mathrm{CHO}$ restriction, protein ingestion increases and 
dietary fat naturally becomes the dominant oxidized substrate and thus, is in agreement with the Law of Mass Action. It is important to note that although protein ingestion increases, dietary fat is the macronutrient which characterizes the greater percentage of the CRD given its higher calorie-per-gram content, and is why studies show an increase in oxidative and lipolytic enzymes -- not proteolytic enzymes -- within 5-days of reducing $\mathrm{CHO}$ intake (Goedecke et al., 1999).

\section{Metabolic Flexibility}

Previous research examining the interplay between macronutrients and components of the metabolic syndrome concluded that regardless of nutrient composition, excessive exposure of nutrients to cells results in what is termed mitochondrial dysfunction and metabolic inflexibility (Wisse, Kim, \& Schwartz, 2007). This inflexibility was first considered when a series of studies demonstrated the inefficiency with which the mitochondria of individuals displaying characteristics of the metabolic syndrome were unable to effectively use FFA as a fuel source and were "stuck" in a glycolytic flux cycle (Kelley, Goodpaster, Wing, \& Simoneau, 1999; Kelley, Mokan, Simoneau, \& Mandarino, 1993; Kelley \& Simoneau, 1994). It is known excessive lactate $\left(\mathrm{La}^{-}\right)$, referred to as lactatemia, is a product of continuous glycolysis and has been shown to effectively inhibit FFA oxidation by inhibiting the FFA transporter CAT 1 and by reducing lipolysis through a G-coupled receptor (GPR81; Cai et al., 2008; Liu et al., 2009). This was also recently demonstrated when a study attempted to show metabolic flexibility indirectly through correlation of blood $\mathrm{La}^{-}$levels, fat, and $\mathrm{CHO}$ oxidation responses during the peri-exercise window (San-Millán \& Brooks, 2017). Subjects expressed a spectrum of metabolic capabilities ranging from those with 
metabolic syndrome $\left(\dot{\mathrm{VO}}_{2 \max }=26.9 \pm 10.5 \mathrm{~mL} \cdot \mathrm{kg}^{-1} \cdot \mathrm{min}^{-1}\right)$ to elite, international-level cyclists $\left(\dot{\mathrm{V}}_{2 \max }=74.1 \pm 4.7 \mathrm{~mL} \cdot \mathrm{kg}^{-1} \cdot \mathrm{min}^{-1}\right)$. The findings showed two important concepts relevant to mitochondrial flexibility: 1) Individuals who expressed components of the metabolic syndrome had similar $\mathrm{La}^{-}$levels at rest compared to those of professional athletes when cycling at 300 Watts (W), 2.0 vs. $2.5 \mathrm{mmol} \cdot \mathrm{L}^{-1}$, respectively, (San-Millán $\&$ Brooks, 2017); 2) Individuals who were categorized with metabolic syndrome also showed a very strong inverse relationship $(\mathrm{r}=-0.97, p<0.01)$ between fat oxidation rates during exercise and La- levels (San-Millán \& Brooks, 2017). These findings further conclude individuals whom lack mitochondrial flexibility and express metabolic dysfunction are unable to adequately oxidize FFA due to a host of feedforward processes which effectively inhibit both the TCA and oxidative phosphorylation.

Moreover, there is current literature which argues the composition of macronutrients, specifically $\mathrm{CHO}$, does matter with regard to mitochondrial dysfunction, given its unique alterations to lipid metabolism and insulin when ingested (Volek et al., 2008). Among the three major macronutrients, $\mathrm{CHO}$ are the only major non-essential substrate, due to the physiological production of ketone bodies and regulatory hormones maintaining blood glucose during periods of low $\mathrm{CHO}$ availability. Rather, dietary $\mathrm{CHO}$ play a significant role in determining substrate availability and subsequently, oxidation rates. After ingestion, $\mathrm{CHO}$ signals for the secretion of insulin, a key storage and regulatory hormone for all three macronutrients (Saltiel \& Kahn, 2001). Insulin is a powerful hormone which affects multiple downstream pathways including peripheral glycolysis, lipolysis, lipogenesis, gluconeogenesis, and glycogenolysis. With regard to substrate oxidation, insulin is able to directly inhibit CAT I and CAT II, HSL, AMPK, 
and increase the activities of ACC and fatty acid synthase (FAS; Moustaid, Beyer, \& Sul, 1994; Stephens, Constantin-Teodosiu, \& Greenhaff, 2007; Witters \& Kemp, 1992). This is an important concept given that a reduction of $\mathrm{CHO}$ can result in a major perturbation to the regulatory mechanisms which attempt to maintain homeostasis; this disturbance signals for a multitude of transcriptional and enzymatic changes, which affectively shifts the mitochondria back to a state of flexibility. Additionally, these changes have even been observed at the molecular level in acute settings ( $<5$ days) where $\mathrm{CHO}$ was restricted from $49 \%$ of total energy intake to only 34\%. By Day 3, almost 400 out of 18,861 transcriptional genes involved in FFA oxidation were upregulated within skeletal muscle tissue (Sparks et al., 2006). Of these transcriptional factors, arguably the most significant two are $\mathrm{CHO}$ response element binding protein (ChREBP) and sterol response element binding protein 1c (SREBP-1c). An increase in TAG plasma appearance has been contributed to SREBP-1c as the primary de novo lipogenic transcription factor when high levels of glucose are in circulation (Lin et al., 2005). Furthermore, ChREBP exacerbates the effects of SREBP-1c by upregulating ACC and FAS, thus, further promoting de novo lipogenesis (Ishii, IIzuka, Miller, \& Uyeda, 2004). The research is clear in determining the existing links between excessive dietary $\mathrm{CHO}$ intake, insulin, and subsequent signaling in cellular health and function.

\section{Cardiometabolic Responses to Carbohydrate Restriction}

A cascade of metabolic and hormonal accommodations occurs to meet the decreased flux of glucose during a CRD. These changes are controlled and monitored by the higher hedonic centers and hypothalamic region (Ziauddeen, Alonso-Alonso, Hill, Kelley, \& Khan, 2015). Although the hormones insulin and cortisol are both directly 
affected by the lack of $\mathrm{CHO}$ intake, there is evidence for indirect adaptations which result in improved CVD risk factors such as TAG levels, lipid profiles, body composition, body mass index (BMI), resting blood glucose, CRP, and BP.

\section{Insulin Responses}

Insulin is a peptide hormone secreted by the $\beta$-cells of the pancreas in response to excess blood glucose. Insulin serves the body in a variety of roles: facilitating glucose uptake through the upregulation of GLUT-4, controlling of $\mathrm{CHO}$, FFA, and protein metabolism, as well as promoting cellular growth and division. In normal and healthy individuals, insulin is released in a biphasic manner following the ingestion of a meal (Bratanova-Tochkova et al., 2002). However, chronically elevated insulin levels produce a mitigated biological response known as insulin resistance (IR) (Cefalu, 2001). During IR, the receptor becomes resistant to the insulin polypeptide substrate, resulting in impaired sensitivity and an attenuated rate of glucose disposal (G. Reaven, 2004). Over time, IR will cause the $\beta$-cells of the pancreas to over secrete insulin in order to maintain proper glucose levels, resulting in a disrupted pathophysiological condition known as compensatory hyperinsulinemia (Wilcox, 2005).

Hyperinsulinemia and elevated blood glucose levels have both been suggested as the predominant mechanisms for the facilitation of all other metabolic markers which make up the metabolic syndrome (Syndrome X; Lakka et al., 2002; G. M. Reaven, 1993). Moreover, individuals whom have been diagnosed with hyperinsulinemia are at a significantly greater risk of developing some form of CHD, independent of diabetes diagnosis (Ginsberg, 2000). These findings are of particular interest given the Federal 
Emergency Management Agency (FEMA) showing in a previous study that sudden cardiac death is the leading cause of death in career FF; moreover, out of almost $300 \mathrm{FF}$, glucose and insulin levels were significantly correlated with coronary vascular lesions and artery calcium scoring suggesting participants who expressed these symptoms were at a higher risk for CHD (Superko et al., 2011). It is reasonable to assume the beneficial effects of $\mathrm{CHO}$ restriction used in studies with subjects exhibiting risk factors of the metabolic syndrome can be applied to FF as well, given similar metabolic characteristics (Donovan et al., 2009).

With regard to $\mathrm{CHO}$ restriction, hormone responses, and CVD risk, insulin is arguably the primary dependent variable observed among the literature. Given that a bolus of glucose ingestion raises blood glucose levels and subsequently insulin, the removal of dietary $\mathrm{CHO}$ should result in a decreased need for insulin secretion and improved insulin sensitivity. Medical practitioners have voiced these exact findings with utilizing $\mathrm{CHO}$ restriction in patients who have been diagnosed with metabolic syndrome and tapered those individuals off by as much as 150 units of insulin per day within an 8 day period (Westman \& Vernon, 2008). Therefore, it is reasonable to assume individuals who express metabolic syndrome characteristics, like FF, would show improvements in resting insulin levels within a 30-day duration period when following a CRD (Waldman et al., 2017).

\section{Cortisol Responses}

Cortisol is a glucocorticoid produced by the adrenal glands during times of stress and in response to low blood glucose levels. The primary pathways through which cortisol is secreted is the hypothalamus-pituitary-adrenal (HPA) axis and 
sympethoadrenal axis (SA) (Schaeffer \& Baum, 1984). Cortisol upregulates lipolysis, glycolysis, proteolysis, glycogenolysis, and gluconeogenesis when synthesized and ensures adequate substrates are available for oxidation depending on the stimulus from either the internal or external environment. Acutely, secretion of cortisol in healthy individuals plays an important role in maintaining metabolic homeostasis, the facilitation of recovery, and promotion of favorable skeletal and cellular adaptations for survival known as allostasis (Franklin, Saab, \& Mansuy, 2012; Selye, 1955). In an occupation such as firefighting, an acute stressor can result in secretion of cortisol, as well as other glucocorticoids and catecholamines, and is a beneficial process which prepares the body for "fight or flight" (Jansen, Van Nguyen, Karpitskiy, Mettenleiter, \& Loewy, 1995). However, chronic exposure to stress has been proposed as a major contributor to the development and progression of CVD (Walker, 2007). Although the degree of sensitivity differs among individuals, research shows peripheral tissues are highly receptive to glucocorticoid secretion by way of increasing vasoconstriction and substrate storage (Walker, Best, Shackleton, Padfield, \& Edwards, 1996; Walker et al., 1998). Metabolically, insulin and cortisol are antagonistic hormones, and during acute periods of CHO restriction ( $<5$ days), counteract one another (Waldman et al., 2017). In overweight or obese individuals who express symptoms of metabolic syndrome and insulin resistance, the chronic elevation of glucose and suppression of insulin can lead to cells starved of glucose. The net result is chronically elevated levels of cortisol which effectively makes available additional glucose molecules via its action as a glucocorticoid. (Stolk, Lamberts, De Jong, Pols, \& Grobbee, 1996). Further, chronic elevation in cortisol is a known mechanism for insulin resistance by way of decreasing 
the transcription, binding, and coding of the insulin receptor substrate (IRS) (Ferris \& Kahn, 2012). The net result is excessive weight-gain from chronic upregulation of fatty acid synthase, an increase in LPL activity, and excessive nutrient availability due to cortisol's ability to create lysis of all major macromolecules and metabolic pathways detailed earlier.

Caloric restriction from any macronutrient, acutely ( $\sim 3$ weeks), increases cortisol (Tomiyama et al., 2010). It has further been shown that a significant reduction in $\mathrm{CHO}$ will result in: increased cortisol output (McMahon, Gerich, \& Rizza, 1988), decreased thermogenesis using the adrenal hormone triiodothyronine (T3) as its marker (Spaulding, Chopra, Sherwin, \& Lyall, 1976), impaired mood (Brinkworth, Buckley, Noakes, Clifton, \& Wilson, 2009), and suppressed immune function (Gleeson \& Bishop, 2000). Cortisol and $\mathrm{T} 3$ are tightly regulated by one another and together are used as a marker for metabolic health. Elevated cortisol is known to lower thyroid stimulating hormone (TSH) and subsequently, inhibits the conversion of the inactive form of T4 from becoming active by way of reverse T3 (Walter et al., 2012). When researchers have restricted CHO or calories in subjects, $\mathrm{T} 3$ was significantly decreased, therefore suggesting the role of $\mathrm{CHO}$ in maintaining a properly functioning metabolism is essential (Kose, Guzel, Demir, \& Arslan, 2017; Spaulding et al., 1976). However, since the findings regarding CHO restriction and T3 from Phinney et al. (1983) demonstrating normal metabolic rates without associated hyperthyroidism, it has been argued that the reduced T3 levels observed in $\mathrm{CHO}$ restricted studies are not a result of a dysfunctional metabolic system, but rather a result of the cells becoming more metabolically efficient and requiring less T3 for thermogenesis (Phinney, Bistrian, Wolfe, \& Blackburn, 1983). While further 
studies are needed, it can be reasonably argued that $\mathrm{CHO}$ restriction induces a unique metabolic adaptation exceeding the current understanding of macronutrient manipulations on hormonal and biochemical responses. While only speculation, recent pilot data from our laboratory suggests acutely applied ( $<5$ days) a CRD will cause an increase in cortisol; however, once weight-loss becomes stable and cells have become "fat-adapted", cortisol will return to baseline values and insulin will remain significantly lower. Collectively, these data suggest the individuals are transitioning towards a state of metabolic flexibility without impairment to their metabolic rates.

\section{Cholesterol \& Lipids}

Cholesterol is an essential phospholipid providing rigidity to cell membranes and is a precursor to steroidal hormones. Synthesis of cholesterol occurs in the cytosol through the enzyme hydroxymethylglutaryl-CoA (HMG-CoA) synthase and HMG-CoA reductase which uses excess acetyl-CoA -- generally from excessive FFA availability -exported from the mitochondria and imported through either the Kandutsch-Russell pathway or Bloch pathway, resulting in a new zoosterol (Kresge, Simoni, \& Hill, 2005; Wu, 2014). Since the Key's study, much attention with regard to CVD has been given to cholesterol as a strong marker for future plaque development and atherosclerosis. Briefly, early studies demonstrated plasma levels of cholesterol and vascular adhesions were more prominent in the cholesterol containing-group when rabbits and chickens were fed either a high cholesterol or no cholesterol diet (Gould, 1951; Ignatowski, 1908). These findings, along with observations that dietary fat, specifically SFA, increased plasma LDL-c levels (Chiu, Williams, \& Krauss, 2017), led to current nutrition recommendations prescribing low-fat, low-cholesterol diets for individuals with 
components of the metabolic syndrome. However, the researchers which denounced dietary cholesterol due to its negative effects on the heart, later announced cholesterol in fact had little effect on cardiovascular health when examined in humans as opposed to animals -- although this went largely ignored by the scientific community (Keys, 1953). Although progress is currently being made, there is much debate as to how SFA might increase cholesterol levels.

With regard to cholesterol homeostasis, much attention has been given to the peroxisome proliferator-activated (PPAR) $\alpha, \beta / \delta, \gamma$ nuclear receptor transcription family and availability of FFA. Though it would seem the PPAR family is sensitive to all FFA, specifically SFA, myristic acid and stearic acid are both found to bind with especially low affinity to the PPARs ligand binding pocket, thus, upregulating the PPAR nuclear receptors (Varga, Czimmerer, \& Nagy, 2011). While PPARs are regarded as antiinflammatory enzymes (Kapadia, Yi, \& Vemuganti, 2008), excessive TAG synthesis in the cytoplasm, as a result of high efflux from malonyl-CoA and subsequent over expression of PPAR receptors, can result in ceramide production and essentially inhibit the PPAR nuclear family (Wymann \& Schneiter, 2008). These findings are important because the PPAR family regulates excessive cholesterol uptake through HDL-c by activation of the protein ATP-binding cassette transporter (ABCA1; Oram \& Lawn, 2001).

Regardless of the cholesterol increasing mechanism, what researchers do agree upon is LDL-c has the greatest capacity to be oxidized of all the lipoproteins (Parthasarathy, Raghavamenon, Garelnabi, \& Santanam, 2010). LDL-c are naturally covered by a sheath of antioxidants which act to protect their lipid contents (Bowry, 
Ingold, \& Stocker, 1992). During periods of LDL-c aggregation, this antioxidant system is quickly oxidized, leaving LDL-c exposed to oxidative damage. The oxidized apolipoprotein B (apo B) then becomes a chemical signal which is recognized by macrophages as an inflammatory process occurring. Macrophages are attracted to the damaged region and the collective gathering of LDL-c and its subsequent consumption by macrophages result in foam cells (Moore, Sheedy, \& Fisher, 2013). Foam cells then attach to the lesion and harden, forming a plaque. Over time, the plaque is weakened by the inflammatory process and eventually can break off resulting in a cardiac infarction. However, investigators and dieticians are finding dietary modifications with $\mathrm{CHO}$ restriction, regardless of the fat and cholesterol content, is proving a potent treatment for individuals whom express hypercholesterolemia.

In a dose-response relationship, when dietary fat is replaced with $\mathrm{CHO}$, hepatic lipogenesis increases, and has been observed even when the diet remains isocaloric (Aarsland \& Wolfe, 1998; Parks, 2002). In a seminal study by Schwarz and colleagues, de novo lipogenesis significantly increased when normoinsulinemic subjects confined to a metabolic ward switched from a 5 day LCHF diet to an isocaloric low-fat high-CHO diet (Schwarz, Linfoot, Dare, \& Aghajanian, 2003). The mechanism for these findings was attributed to insulin. When individuals are following a LCHF diet, insulin is naturally low and even though the diet is high in dietary fat, low insulin allows for the cells to become more lipolytic. However, when individuals switched over to a similarly calorically matched low-fat, high-CHO diet, insulin was increased, resulting in an increase in malonyl-CoA and excess glycerol backbones for TAG synthesis from the limited storage capacity for $\mathrm{CHO}$. These findings, along with earlier discussions about 
downregulation of PPARs due to excessive FFA binding and increased cholesterol markers, collectively suggest why a CRD can favorably alter hypercholesterolemia and dyslipidemia. Numerous studies have shown CRD differing in duration (1-12 mo) and ad lib and/or hypocaloric intake, generally outperform similar low-fat high-CHO diets in lipid variables, with the mean relative responses across the CRD resulting in differences of TAG (22\%), LDL-c (9\%), total cholesterol (7\%), and HDL-c (11\%) (Larosa, Fry, Muesing, \& Rosing, 1980; Newbold, 1988; Phinney et al., 1983; Phinney et al., 1980; Sharman et al., 2002; Volek, Gómez, \& Kraemer, 2000). Finally, Krauss and coworkers have identified cholesterol and lipid panel responses with respect to diet are also significantly correlated with genetics, grouped as either pattern B or pattern A (Krauss, 2005). Individuals falling into the pattern B group are predisposed to smaller LDL-c particle sizes and also respond more favorably to low-fat, higher-CHO diets. However, this makes up less than $30 \%$ of the population. All other individuals fall into pattern A, identified as individuals whom have larger, fluffier LDL-c particles and negatively respond to low-fat, high-CHO diets by shifting from a pattern $\mathrm{A}$ to a pattern $\mathrm{B}$ phenotype (D. Dreon, Fernstrom, Miller, \& Krauss, 1994; D. M. Dreon, Fernstrom, Williams, \& Krauss, 1999; Krauss, 2005). To illustrate, over $70 \%$ of the population responds to a lowfat, high-CHO diet by increasing LDL-c particle number and decreasing particle size which is a known risk for CVD and therefore, depicts how CRD can have beneficial effects on cholesterol and lipid panels in both healthy populations and individuals with metabolic syndrome. 


\section{Glucose}

Blood glucose is tightly regulated by human physiology and maintained at adequate levels by glucocorticoid hormones to stay within a teaspoon range of approximately four grams ( 100 mg/dL) at all times (Wasserman, 2009). However, a characteristic of an individual with metabolic syndrome are fasted glucose levels which exceed $100-110 \mathrm{mg} / \mathrm{dL}$, also known as hyperglycemic, and is also a prevalent risk factor for CHD (Ford, Giles, \& Dietz, 2002). As detailed earlier, insulin directly regulates glucose uptake into either muscle or adipose tissue. As seen in metabolic syndrome, hyperglycemic conditions occur when the IRS becomes unresponsive to the insulin substrate, resulting in unregulated glucose levels (Cefalu, 2001). Aside from pharmacological interventions, $\mathrm{CHO}$ restriction is being considered as a prominent method for improving glucose tolerance and insulin sensitivity.

Glucose tolerance and an individual's risk for developing type II diabetes is assessed via a standardized glucose challenge test (GCT) in which individuals consume a 50-75 g solution of glucose or dextrose and have blood sampled at baseline and again $1 \mathrm{~h}$ later (Ooshima, 1987; Stumvoll et al., 2000). Well-controlled isocaloric diets, in which meals were provided to healthy males and glucose responses assessed (but varying in CHO load) showed that glucose production was reduced in a dose-response relationship with a lower glycemic load (Bisschop et al., 2000). More chronic studies ( $>3$ weeks) have shown similar findings in that $\mathrm{CHO}$ restriction resulted in a significant decrease of plasma resting glucose values from 167 to $119 \mathrm{mg} / \mathrm{dL}$ (Gannon \& Nuttall, 2004). The evidence linking both glycemic load and index to the development of CVD (McKeown et al., 2004), metabolic syndrome (Franz et al., 2002), and diabetes (Salmeron et al., 1997) 
is compelling. Volek and colleagues have attributed the improved glucose control to enhanced translocation of GLUT-4 following CHO restriction. Specifically, GLUT-4 movement to the cell membrane is enhanced during exercise or during periods of low CHO availability due to low muscle glycogen availability (Hespel \& Richter, 1990). Therefore, as long as glycogen levels remain low, the muscle cell is essentially readily available for the uptake of glucose. Given the main source of calories for FF comes from heavily processed and simple sugars (Haddock et al., 2015; Poston et al., 2013) and that FF rank third in obesity prevalence among forty different male occupations (Caban et al., 2005) as well as the shared relationship between obesity and impaired glucose intolerance share (Ferrannini \& Camastra, 1998), CRD have a potential role for repairing dysfunctional GLUT-4 vesicles and improving overall systemic glucose sensitivity in FF.

\section{C-Reactive Protein}

C-reactive protein (CRP) is a marker of systemic inflammation produced by the liver during times of physiological stress, and elevated levels are strongly correlated with a risk of developing CVD (Prasad, 2003). When the allostatic load of cells have become overwhelmed, these cells start to die as part of the apoptosis process (Pepys \& Hirschfield, 2003). Dying cells are then bound to CRP which are signaled by the acute release of interleukin-6 (IL-6), an inflammatory cytokine produced by macrophages to begin the process of phagocytosis (Pepys \& Hirschfield, 2003). Further, while the aforementioned markers (insulin and cortisol) are both excellent indicators of the risk for developing CVD, CRP is considered the strongest independent predictor of CVD, even compared to IL-6 and cholesterol levels (Danesh et al., 2004; Ridker, Hennekens, Buring, \& Rifai, 2000). 
With regard to specific macronutrient effects on CRP, the literature has shown high consumption of trans fats or a large bolus of glucose/fructose to both directly increase systemic inflammation through mediation of reactive oxygen species (ROS) (Esposito et al., 2002; Lopez-Garcia et al., 2005; Mohanty et al., 2000). Moreover, there is evidence suggesting high fat diets and red meat will significantly increase CRP (Arya et al., 2006; Azadbakht \& Esmaillzadeh, 2008; Montonen et al., 2013). However, these same studies are extremely high in $\mathrm{CHO}$ as well, simulating a more westernized diet than a primarily high fat diet and are mostly self-reported rather than calorically controlled. Further, due to the enzymatic changes that occur within the mitochondria when $\mathrm{CHO}$ are restricted, it is reasonable to assume an acute duration ( $<3$ weeks) of meals containing higher amounts of fat and protein would place some level of stress on both the cell and liver. Regardless of macronutrient distribution, the research is clear that when diets are calorically controlled, CRP is mostly improved through a reduction in body weight, preferably loss of fat mass, rather than diet macronutrient composition (Noakes et al., 2006; Volek \& Sharman, 2004). CHO restriction demonstrated effectiveness in both dietary intervention for weight loss and outperforming similar isocaloric diets with respect to a loss in fat mass, as detailed further below (Bravata et al., 2003; Brehm, Seeley, Daniels, \& D’alessio, 2003; Brinkworth et al., 2009). Therefore, while it is not hypothesized that the macronutrient distribution found in CRD will directly influence CRP levels, it is reasonable to presume the body composition changes found in CRD will indirectly affect CRP values favorably. 


\section{Body Composition}

In simple terms, body composition is the relative percentage of body mass composed of either fat mass or fat free mass (i.e. muscle). Body composition is a wellestablished predictor for an individual developing a host of serious adverse health events. For example, the storage of excess adipose tissue around vital organs, known as android fat, increases the risk for sudden heart infarction, CVD, atherosclerosis, cancer, even more (Medicine, 2013). In males between the ages of 20 and 60 years old, elevated or high body fat percentages are present at rates of 20-27\% (American College of Medicine, 2013). In a 16-year follow up study, excess adipose tissue was consistently associated with metabolic dysfunction, hypertension, and increased rates of all-cause mortality (Zhang, Rexrode, Van Dam, Li, \& Hu, 2008). While the effects of being overweight are well understood as to circulatory, cardiovascular, and neuroregulatory systems, the underlying cellular causes of adipose storage are related to an overabundance of nutrient exposure to cells that contribute to ROS formation and increased rates of lipogenesis which subsequently lead to the development of metabolic disorders (Sankhla et al., 2012). It is this mechanism, the cell-nutrient exposure, which has made diets such as the ketogenic diet and intermittent fasting popular caloric deficit interventions for current researchers. However, both diets have been considered extreme approaches. Instead, a successful diet treatment plan for weight loss must not only create a caloric deficit, but also be a diet in which an individual can adhere.

An alternative dietary approach is one in which $\mathrm{CHO}$ are restricted, but not necessarily in such a way that induces endogenous ketones. Low $\mathrm{CHO}$ diets $(<25 \%$ total kcals) have been shown to be as effective, if not better, at inducing weight loss and 
improving metabolic variables than low-fat and low calorie diets (Bravata et al., 2003; Brehm et al., 2003; Brinkworth et al., 2009; Yudkin \& Carey, 1960). As detailed in earlier sections, both protein and fat have high satiety ratings. When combined during meals, it is the collectively higher satiation that results in caloric reduction and weight loss. Dietary fat aside, previous research demonstrates that reductions in $\mathrm{CHO}$ leads to protein ingestion naturally increasing (Waldman et al., 2017) thus promoting lean mass retention during weight loss. Therefore, a researcher could make a strong argument that a diet which induces weight loss primarily through adipose tissue and spares lean mass creates a metabolic advantage not found in other diets. This hypothesis has been demonstrated in the first systematic study on $\mathrm{CHO}$ restriction and body composition changes where Benoit and team placed individuals on a hypocaloric CRD for 10 days and reported an average body mass loss of $600 \mathrm{~g} /$ day, of which $97 \%$ was from fat mass (Benoit, Martin, \& Watten, 1965). Other investigations have demonstrated similar findings. Young and colleagues took college aged males and placed them on three different calorically matched diets differing in $\mathrm{CHO}$ content $(30 \mathrm{~g}, 60 \mathrm{~g}$, and $100 \mathrm{~g})$. After following the diets for nine weeks, subjects had body composition changes measured via underwater weighing and found that weight loss for the three diets was $16.2 \mathrm{~kg}, 12.8 \mathrm{~kg}$, and $11.9 \mathrm{~kg}$ and fat mass accounted for $95 \%, 84 \%$, and 75\%, respectively (Young, Scanlan, Im, \& Lutwak, 1971). Further, adherence to a chronic CRD is generally higher compared to low fat and low calorie diets (Brinkworth et al., 2009; Hu et al., 2016; Krebs, Gao, Gralla, Collins, \& Johnson, 2010; Nickols-Richardson, Coleman, Volpe, \& Hosig, 2005; Shai et al., 2008; Tay, Brinkworth, Noakes, Keogh, \& Clifton, 2008; Volek, Phinney, et al., 2009). Although satiety hormones will not be measured in the present 
study, some researchers have concluded adherence is greater in a CRD due to decreases in the appetite stimulant ghrelin and without the constant calorie counting and portion control is associated with many/the majority of other diets (McClernon, Yancy, Eberstein, Atkins, \& Westman, 2007; Nickols-Richardson et al., 2005).

\section{Firefighter Performance}

FF, by occupation, are required to maintain a higher level of cardiorespiratory fitness and musculoskeletal strength. Duties that FF might face during a field exercise or on-duty call include hose dragging, short distance $(<200-350 \mathrm{~m})$ sprints, long distance $(>$ $350 \mathrm{~m}$ ) runs, victim carries, room clear procedures, ladder climbing; and all while wearing personal protective equipment (PPE) which can weigh upwards of $35 \mathrm{~kg}$ (Gavhed \& Holmér, 1989) and while exposed to heat which can exceed $100^{\circ} \mathrm{C}$, thus exacerbating the metabolic demands required to complete a specific task (Dimri, Malhotra, Gupta, Kumar, \& Arora, 1980). Moreover, a higher thermal environment is known to accelerate muscle glycogen depletion, potentially impairing performance (Cheuvront, Kenefick, Montain, \& Sawka, 2010). However, firefighting has been proposed as predominately an aerobic occupation mixed with short bouts of anaerobic tasks (Lemon \& Hermiston, 1977; Perroni et al., 2010). When high-intensity tasks are required, lactate levels have been recorded at upwards of $13.1 \mathrm{mmol} \bullet \mathrm{L}^{-1}$ (Lemon $\&$ Hermiston, 1977), heart rates (HR) observed at between $80-100 \%$ of an individual's maximum (Gledhill \& Jamnik, 1992), and energy requirements corresponding to $80 \%$ of a $\mathrm{FF} \dot{\mathrm{VO}}_{2} \max ($ Gledhill \& Jamnik, 1992). Interestingly, body composition among FF is known to impact performance in a number of ways. Excessive adipose tissue and exposure to high thermal environments simultaneously, inhibits a FF ability to dissipate 
heat through sweat aside from adding dead weight during tasks such as ladder and stair climbing (Williford, Duey, Olson, Howard, \& Wang, 1999). Therefore, given FF primarily perform in aerobic conditions and a large percent (70\%) of FF have been recorded as being overweight or obese (Wilkinson et al., 2014), a dietary intervention which promotes weight-loss without performance hindrance, potentially improving lowintensity aerobic performance, would benefit FF and tactical personnel alike.

A plethora of evidence is available examining the role of CRD on performance across a range of intensities. Although many of these interventions have used highly trained elite athletes (Burke et al., 2002; Burke et al., 2017; Lambert et al., 2001; Lambert, Speechly, Dennis, \& Noakes, 1994), there are a handful of recent studies which have looked at $\mathrm{CHO}$ restriction in healthy, moderately trained males that would closer mimic present day FF. Specifically, one study found that when eight middle-aged (40 \pm 10 years), recreational male runners $\left(\dot{\mathrm{V}}_{2}\right.$ peak $\left.49.2 \pm 4.2 \mathrm{~mL} \cdot \mathrm{kg}^{-1} \cdot \mathrm{min}^{-1}\right)$ were placed on a CRD for 3 weeks, fat oxidation rates significantly increased from pre-diet intervention to post-diet, and participants lost on average $2.5 \mathrm{~kg}$ of body mass without any decrements to running performance (Heatherly et al., 2017). This is consistent with other recent studies which placed healthy, non-elite but trained participants on CRD for 3- and 4 weeks (Klement et al., 2013; Zajac et al., 2014). The findings were conclusive: CRD for non-elite athletes will generally result in improved body composition, higher fat oxidation rates at rest and during exercise, and no apparent performance decrements (Klement et al., 2013; Zajac et al., 2014). These same findings have been shown in acute and chronic higher intensity exercise investigations where performance capacity might be hindered due to a reduction in glycogen stores while on a CRD. Arguably the most well 
controlled chronic CRD utilizing a resistance training program showed after eight weeks, participants produced similar strength values and skeletal adaptations to those following a higher CHO diet (J. M. Wilson et al., 2017). Further, this study not only showed that the CRD did not hinder anaerobic performance, but $\mathrm{CHO}$ restriction resulted in a more favorable testosterone range than those individuals following the WD.

With regard to performance, a common criticism of CRD are the short durations for which they are implemented. Although enzymatic and cellular changes can occur within 7 days of diet implementation (Carey et al., 2001; Goedecke et al., 1999), this short duration can lead to performance detriments given the individuals lack of accommodation time to the aforementioned adaptations. While 7 days does not seem to be an appropriate time period for observing a nutrition interventions effects on performance, Heathery et al. did find that positive performance responses to a low $\mathrm{CHO}$ diet can be found within a 21-day time period (Heatherly et al., 2017).

Given the current evidence, a CRD could potentially benefit FF performance by way of decreasing fat mass, but not affecting strength or aerobic performance negatively. Positive and negative responders to a CRD should be found within a 28-day time period as proposed by the present study. 


\section{CHAPTER III \\ MATERIALS AND METHODS}

\section{Participants}

Twenty-one apparently healthy, male professional FF were recruited from surrounding local fire departments for the proposed investigation. Sample size estimation was determined a priori, based on previous dietary interventions from our laboratory (Heatherly et al., 2017; Waldman et al., 2017), as well as unpublished FF investigations from our laboratory, and using G-Power software (Düsseldorf, Germany) which determined 15 participants would be sufficient to achieve a desired power of 0.8 , using a moderate-high effect size, and an alpha level set at 0.05 .

\section{Selection Criteria}

In brief, individuals were allowed to participate in the present study if they met inclusion and exclusion criteria previously set by our laboratory in both unpublished and published findings (Waldman et al., 2017). Inclusion criteria included: (1) participants must be an active duty, male FF, (2) meet the American College of Sports Medicine lowrisk guidelines (Medicine, 2013), (3) obtain at least 150 min of moderate-intensity aerobic activity or 60 min of vigorous intensity aerobic activity per week, (4) avoid consumption of all dietary supplements that are not acceptable by the National College Athletic Association for the duration of the study (steroids, multi-vitamins, thermogenics, etc.), (5) refrain from caffeine and alcohol consumption $24 \mathrm{~h}$ prior to the experimental 
testing sessions, (6) "cleared for duty" after a yearly physical examination which all FF must undergo, and (7) currently consuming ( $\geq 40 \% \mathrm{E}$ ) from $\mathrm{CHO}$ and have maintained stable body mass for the previous two weeks before beginning the present study. Subjects were excluded from the study if they were found to: (1) be currently taking anabolic hormones that are not medically administered, (2) not adhering to the CRD on multiple (3x) bouts when randomly selected for a dietary recall, and (3) be a current cigarette smoker or prescribed cardiometabolic prescription drugs by a medical professional. Three participants had to discontinue participation before beginning the CRD due to scheduling conflicts, one participant dropped on request due to personal obligations, and two participants were medically dropped due to serious injuries sustained from firefighting during the 28-day intervention. Therefore, a total of 15 participants completed the study $($ age $=33.5 \pm 9.7 \mathrm{yrs} ;$ height $=178.8 \pm 6.3 \mathrm{~cm} ;$ mass $=89.1 \pm 12.7 \mathrm{~kg} ;$ fire-service $=7.9$ $\pm 7.4 \mathrm{yrs})$.

\section{Experimental Design}

In order to examine the given hypotheses, the current study implemented a within-subject, repeated measures design with dependent variables analyzed at multiple time points across the intervention. To best observe shifts in blood markers, body composition, oxidation rates, and performance, participants reported to the laboratory on nine separate occasions, three initial sessions to washout any potential order and learning effect (Familiarization), three sessions 15-days later to establish a baseline (Baseline 1), and another three sessions following the 28-day CRD (Post-CRD). An overview of the study is shown in Figure 1. 


\section{Experimental Procedures}

The primary aim of the proposed study was to examine the effects of $\mathrm{CHO}$ restriction on cardiometabolic parameters in FF. Secondary purposes for the study included examining the effects of $\mathrm{CHO}$ restriction on body composition, oxidation rates, and performance variables in FF. Preliminary data were collected upon the initial visit. Participants completed an informed consent document approved by the University's Institutional Review Board, completed general health documents (i.e. health questionnaire, physical activity readiness-questionnaire (PAR-Q), medical history questionnaire), as well as provided a 3-day (e.g. Thursday, Friday, Saturday) dietary recall. After inclusion and exclusion criterion were met, each participant was informed of the purpose of the study and the following procedures required and expected of each participant for the duration of the study.

\section{Trials 1, 4, and 7}

Blood Sampling and Glucose Challenge Test. Trial 1 took place $48 \mathrm{~h}$ after preliminary data collection and occurred in the Joseph A. Chromiak Applied Physiology Laboratory located in McCarthy Gymnasium following at least a 10-12 h fast, between the hours of $0430-0900$. Given that some of the blood markers follow a diurnal pattern, participants arrived to all subsequent trials at the same time $( \pm 30 \mathrm{~min})$. All participants were asked to refrain from strenuous exercise, not related to their occupation, $48 \mathrm{~h}$ before reporting to the laboratory. Participants were also directed to come back to the laboratory the following day if exposed to smoke $24 \mathrm{~h}$ before trial 1, 4, or 7 took place. Upon arrival, participants had their body mass and height measured via a digital scale (Defender 5000, Ohaus Corporation, Parsippany, NJ, USA) and digital stadiometer 
(235D; QuickMedical, Issaquah, WA, USA), respectively. Body composition (shown as $\%$ fat) and resting metabolic rates (RMR) were analyzed via the BOD POD version 1.69 (Body Composition System; Life Measurement Instruments, Concord, CA).

Due to the lack of literature examining the loss of water and changes in lean body mass across a range of body composition assessments, differences in subcutaneous fat and lean muscle mass were further assessed using a seven-site skinfold technique as seen in past CRD literature (Heatherly et al., 2017) and in agreement with Jackson and Pollock ACSM skinfold measurement techniques (Medicine, 2013).

After skinfold measurements, individuals were asked to lie quietly in a supine position and relax for at least $5 \mathrm{~min}$ on a table, due to acute blood plasma shifts $(\sim 14 \%)$ that might have occurred when moving from a standing to lying position (Harrison, 1985). Following this time and after applying proper sterilization techniques to the blood draw site, a total of $12 \mathrm{~mL}$ of blood were drawn into two, $6 \mathrm{~mL}$ sodium heparin sealed vacutainers from the antecubital vein via a $21 \mathrm{G}$, Safety-Lok butterfly needle (REF\# 367287, Franklin Lakes, NJ). All sealed vacutainers were subsequently centrifuged at 4 ${ }^{\circ} \mathrm{C}$ for $10 \mathrm{~min}$ at $2500 \mathrm{rpm}$ and stored at $-80^{\circ} \mathrm{C}$ following plasma removal for later analysis.

After the initial antecubital blood draw, participants underwent a GCT and were asked to consume a $400 \mathrm{~mL}$ bolus of water containing $75 \mathrm{~g}$ of a glucose mixture within a 5 min time period (NOW Sports, Dextrose Powder). Participants had their finger pricked by a 26 gauge Dynarex $(1.8 \mathrm{~mm}$, Orangeburg, NY) self-withdrawing safety lancet, at which point 5 microliters $(\mu \mathrm{L})$ were analyzed for glucose (Precision Xtra, Abbott, Alameda, CA) levels at time points 0,30 , and 60 min to determine risk for impaired 
fasting glucose and glucose tolerance levels as defined by the World Health Organization (Alberti \& Zimmet, 1998) and previous literature (Ooshima, 1987; Stumvoll et al., 2000). During Trial 7, participants included the $75 \mathrm{~g}$ of $\mathrm{CHO}$ from the GCT towards their daily allotted $\mathrm{CHO}$ amount. Following the GCT, all subjects were then directed to a chair which provided back support and then asked to sit quietly for 20-25 min. The right arm was then elevated to heart level and BP recorded (V100 Monitor, Carescape ${ }^{\mathrm{TM}}$, Fairfield, CT) twice, with a 1-2 min time lapse between recordings. The two readings were then averaged unless the difference was greater than $5 \mathrm{~mm} \mathrm{Hg}$ at which point an additional reading was made.

Insulin. Insulin was analyzed in thawed plasma using a commercially available kit (Alpco, CAT\# 80-INSHUU-E01.1, Salem, NH, USA). Insulin is a polypeptide hormone secreted by the beta cells of the pancreatic islets and regulates the metabolism of $\mathrm{CHO}$, proteins, and fat. The ultrasensitive insulin ELISA utilizes a sandwich type immunoassay with a functional sensitivity of $0.135 \mu \mathrm{lU} / \mathrm{mL}$. Following reagent preparation, $25 \mu \mathrm{L}$ of samples, standards, and controls were added to their respective wells which are coated with a monoclonal antibody specific for insulin and then followed by adding $100 \mu \mathrm{L}$ of anti-human insulin specific detection antibody. The plate was then incubated for $60 \mathrm{~min}$ at room temperature $\left(18-25^{\circ} \mathrm{C}\right)$, followed by a wash $(6 \mathrm{x})$ with the prepared wash buffer. Tetramethylbenzidine (TMB) was then added followed by an additional 30-min incubation period. One $100 \mu \mathrm{L}$ of a stop solution was added to each well and then read at a wavelength of $450 \mathrm{~nm}$ according to the company's instructions. Following absorbance measurements, the mean data value for each set of duplicated 
samples was plotted on a standard curve and subsequently analyzed using a 4-parameter fit.

Cortisol. Cortisol was analyzed in duplicate samples from plasma using a competitive immunoassay via a commercially available kit (Alpco, CAT\# 11-CORHUE01, Salem, NH, USA). Cortisol is the major glucocorticoid secreted by the adrenal cortex and when excessively elevated, can negatively affect cardiometabolic markers (e.g. BP, blood glucose, cholesterol, etc.). After bringing all components of the ELISA kit to room temperature, all samples, reagents, and controls were then added to their respective wells where a competitive HRP-conjugate was added. The plate was then incubated at $37^{\circ} \mathrm{C}$ for $1 \mathrm{~h}$. A TMB substrate was then added which was catalyzed by HRP causing a blue coloration. The TMB reaction was terminated by a stop solution, then producing a yellow color and immediately read at an intensity of $450 \mathrm{~nm}$ with a sensitivity of $2.44 \mathrm{ng} / \mathrm{ml}$ and optical density read via 4-parameter curve per assay instructions.

C-Reactive Protein. Thawed plasma CRP levels were diluted 1:100 before assaying in duplicated samples according to the ELISA kit instructions (Alpco, CAT\# 309710s, Salem, NH, USA). Pilot data found that diluting plasma samples 1:100 resuled in absorbance values consistent with standard absorbances $(1.9-150 \mathrm{ng} / \mathrm{mL})$. CRP is an acute phase reactant and important marker of systemic and chronic low-grade inflammation. The current assay is a sandwich immune-assay ELISA and uses a polyclonal antibody to bind CRP during the first incubation step. Following the second incubation step, a second polyclonal-labeled antibody is added followed by the addition 
of a stopping solution (TMB). The stopping solution produces a yellowish color which absorbs light at $450 \mathrm{~nm}$. Absorbance corresponds to the concentration of CRP and a 4parameter algorithm was used to calculate the results.

Lipid Panel. Following proper sterile cleaning procedures of the blood draw site, participants had their finger pricked by a 26 gauge Dynarex (1.8 mm, Orangeburg, NY) self-withdrawing safety lancet, at which point $5 \mu \mathrm{L}$ were analyzed for a lipid panel (e.g. total cholesterol (TC), LDL-c, HDL-c, TAG, TC/HDL-c) using a Cholestech LDX System (Cholestech Corporation, Hayward, CA). The Cholestech LDX system utilizes a 'color reaction' step which allows for a reflectance reading to be collected for each lipid marker and subsequently its conversion into quantitative values, also known as reflectance photometry. The Cholestech LDX has been shown to be a valid tool for examining the aforementioned lipid markers and are within the acceptable guidelines of the National Cholesterol Education Program (Issa, Strunz, Giannini, Forti, \& Diament, 1996).

\section{Trials 2,5 , and 8}

Graded Exercise and Wingate Testing. Trial 2 took place $48 \mathrm{~h}$ later and consisted of a five stage, graded exercise test on a cycle ergometer using VelotronTM Wingate software (RacerMate, Inc., Seattle, WA, USA). Participants arrived to the laboratory and following at least a 10-12 h overnight fast, a HR H10, Polar Electro Inc., Lake Success, NY, USA) monitor was fixated across each participant's chest and cardiorespiratory measures collected using a MOXUS Modular VंO2 system (AEI technologies, Bastrop, TX, USA). The present graded exercise test was adopted from 
Achten and Jeukendrup (2003) as a valid protocol for measuring an individual's substrate oxidation rates and modified to start at a lighter intensity. Briefly, cycling began at $50 \mathrm{~W}$ and work rate increased $35 \mathrm{~W}$ every 3 min until five stages had been completed. Subjective measurements (i.e. rate of perceived exertion (RPE)) were obtained during the last 30-s of each stage using a 10 point modified Borg scale (Borg, 1982).

Following completion of the graded exercise test, participants were asked to continue cycling at 70 revolutions per min (RPM) and at a $100 \mathrm{~W}$ for a 4 min cool down period while the researchers removed the MOXUS headgear. At the end of the cool down period, participants were asked to complete a maximal, 30 -s Wingate sprint at $0.075 \mathrm{kp} \cdot \mathrm{kg}^{-1}$ body mass of resistance which was added magnetically by the Velotron. Prior to the sprint, participants were given a 7-s countdown to increase maximal cadence against a resistance of $100 \mathrm{~W}$.

Substrate Metabolism Calculations. All data collected from the MOXUS Modular $\dot{\mathrm{V} O} 2$ system was used to calculate substrate oxidation rates. $\dot{\mathrm{V} O} 2$, respiratory exchange ratio (RER), and carbon dioxide production ( $\mathrm{V} C \mathrm{CO} 2)$ were averaged from steady-state expired gases. With regard to substrate oxidation, the first $120 \mathrm{~s}$ of each stage were excluded and the remaining $60 \mathrm{~s}$ were recorded using breath by breath data and averaged in two, $30 \mathrm{~s}$ cycles. Rates of both fat and $\mathrm{CHO}$ oxidation (g•min-1) were calculated using Stoichiometric equations from the averaged $\dot{\mathrm{VO}} 2$ and $\dot{\mathrm{V} C O} 2$. The present Stoichiometric equation assumes the oxidation of protein contributes minimally to energy requirements $(\sim 5 \%)$ during the completion of the graded exercise test and therefore, will be ignored during calculations (Brouwer, 1957).

Fat oxidation $\left(\mathrm{g} \cdot \mathrm{min}^{-1}\right)=1.718 * \dot{\mathrm{V}} \mathrm{O}_{2}-1.718 * \dot{\mathrm{V} C O} \mathrm{C}_{2}$ 
CHO oxidation $\left(\mathrm{g} \bullet \mathrm{min}^{-1}\right)=4.170 * \dot{\mathrm{V}} \mathrm{CO}_{2}-2.965^{*} \dot{\mathrm{V}} \mathrm{O}_{2}$

\section{Trials 3, 6, and 9}

Firefighter Physical Performance Assessment. Following Trial 2, Trial 3

consisted of participants performing their bi-annual FF physical performance assessment (FPPA) which is a mandatory physical training test required by all active personnel $\mathrm{FF}$ in the surrounding region. The FPPA consists of a $2.41-\mathrm{km}$ timed run, immediately followed by completion of as many repetitions as possible within 2 min for each exercise: pull-ups, push-ups, and sit-ups, respectively. A 2.41-km loop outside the laboratory was marked off and the three remaining exercises took place inside the laboratory. Participants were asked to refrain from strenuous exercise, not related to their occupation, $24 \mathrm{~h}$ before arrival and to arrive in athletic attire. Upon arrival, participants performed a general warm up which consisted of cycling at a $100 \mathrm{~W}$ for 2 min followed by 10 repetitions of pull-ups, push-ups, sit-ups, and air squats. After participants had a HR monitor fixed across their chest, a timer was started followed by a "go" signal indicating to the participant the FPPA had started. Upon completion of the $2.41-\mathrm{km}$ run, the participant immediately entered the weight-room located in the laboratory to finish the three remaining exercises with no rest afforded between exercises. Completion of the FPPA and number of repetitions for all three exercises were used as data points for preand post-diet intervention.

Dietary Manipulation. After the completion of Trial 6, participants then began the diet intervention for a total of 28 days before reporting back to the laboratory for the last three sessions. The present study utilized a $\mathrm{CHO}$ restricted, but caloric ad-libitum diet 
protocol seen in recent research (Heatherly et al., 2017). The primary purpose for the adlib design was due to the occupation of the participants. Due to fluctuations in physical activity experienced by FF, implementation of a pre-determined caloric range undermines the decreased or increased energy expenditure that FF can experience on any day or during any time due to occupational demands. Moreover, given the role of adherence for the success of any dietary protocol (Gardner et al., 2018), an ad-libitum diet allows for flexibility into a participant's lifestyle and mimics real-life eating patterns. Therefore, during the first visit to the laboratory, participants were guided thoroughly on implementing a CRD into their current lifestyle. Participants were provided with $\mathrm{CHO}$ restricted sample daily menus, grocery lists with low $\mathrm{CHO}$ food items, and fast food choices relevant to the local surrounding fast food chains that included low $\mathrm{CHO}$ options. To further help with self-efficacy while on the diet, all participants were either met in person by the principal investigator (PI) or participated in a FaceTime phone session that took place at the local grocery store. During this session, participants were taught how to interpret a food label as well as calculate absolute net $\mathrm{CHO}(\mathrm{CHO}$ - fiber - sugar alcohol). The session ended with the participants and PI combining food items from the store to make actual low $\mathrm{CHO}$ meals and snacks each participant could implement into their 28-day intervention. After providing the PI with their initial 3-day food log, the participants average caloric intake was calculated and $25 \%$ of this number was then used as their allotted $\mathrm{CHO}$ amount per day. All other macronutrients (e.g. fat and protein) were allowed ad-libitum and participants were asked to track all foods and beverages daily in MyFitnessPal (MyFitnessPal, Calorie Counter, 2018, Baltimore, MD). In an attempt to maintain further adherence, participants were selected at random daily, using a random 
number generator, to retrieve and send a full day of food logs to the PI during the 28-day intervention. Furthermore, all participants were asked to send a complete 2-day food log consisting of a Friday and Saturday which was used to analyze and report weekly macronutrient and caloric changes. All dietary food logs were subsequently analyzed for caloric and macronutrient distribution using the food analysis software Nutrionist-Pro (version 7.4, 2018, Axxya Systems-Nutrionist Pro, Stafford, TX. USA). Each night messages were sent out by the PI to remind all participants to continue recording all foods as well as tracking macronutrient compositions and this allowed for a daily correspondence to be maintained between the participants and PI. Finally, the CRD intervention was overseen by a Registered Dietician maintained within the University's nutrition department.

Physical Fitness Regimen. In an effort to control for training volume during the diet intervention, both the fire-house station lieutenant and lead FF instructor collectively developed a four day per week traditional bodybuilding training protocol (e.g. chest, back, legs, arms and core). The training protocol manipulated repetitions, sets, and loads from week to week, but overall, maintained a relatively constant total training volume that did not differentiate more than $\sim 100 \mathrm{kgs}$ between each week. In addition, one aerobic conditioning day $(2.41-5.0 \mathrm{~km})$ was mandated to be completed by all participants and one field exercise (i.e. structure fire suppression, victim search and rescue, etc.) was performed bi-monthly. Training was overseen by the station lieutenant who verbally confirmed 13 participants met all training requirements, one participant completed $\sim 50 \%$ of the training requirements, and one participant (instructor) was unaccounted for given his current training regimen to prepare for a national FF competition which he competes 
in bi-yearly. Further, both the station lieutenant and battalion chief confirmed the aforementioned training regimen is regularly maintained among all $\mathrm{FF}$, regardless of the participants involvement with the present study.

\section{Statistical Methods}

Body composition (\% body fat, fat free mass, total mass, and fat mass, RMR, and seven-site skinfolds), blood concentrations of insulin, cortisol, CRP, TC, HDL-c, LDL-c, non-HDL-c, TAG, TAG/HDL-c, and TC/HDL-c ratios, as well as blood pressure (SBP

and DBP), Wingate variables (fatigue index, mean watts, peak watts, total work, finishing HR, relative mean watts, and relative peak watts), FPPA variables (2.41-km finishing time, 2.41-km finishing HR, pull-ups, push-ups, and sit-ups), and diet variables (protein, $\mathrm{CHO}$, and fat) measured by $\mathrm{g} / \mathrm{kg}$, were all analyzed using a dependent $t$-test. Time points 0,30 , and 60 min during the GCT were analyzed using a $2 \times 3$ (Treatment [Baseline vs. Post-CRD] $\times$ Time point) repeated measure analysis of variance (RMANOVA). Cardiorespiratory variables ( $\dot{\mathrm{V} E}$, $\mathrm{HR}, \mathrm{RER}, \dot{\mathrm{V}} \mathrm{O}_{2}, \dot{\mathrm{V}} \mathrm{CO}_{2}$, relative $\dot{\mathrm{V}} \mathrm{O}_{2}$, relative $\dot{\mathrm{V}} \mathrm{CO}_{2}$, and RPE) and substrate oxidation rates for both fat and $\mathrm{CHO}\left(\mathrm{g} \cdot \mathrm{min}^{-1}\right)$ were analyzed using a $2 \times 5($ Treatment [Baseline vs. Post-CRD] $\times$ Time point [Stages 1, 2, 3, 4, and 5]) RMANOVA. All other diet variables were analyzed using a one-way (Time point) ANOVA. If significant main effects or interaction effects were observed, Fisher's Least Significant Difference (LSD) post hoc tests were used to examine any further differences. Partial eta square $\left(\eta_{\mathrm{p}}{ }^{2}: 0.01=\right.$ small effect; $\eta_{\mathrm{p}}{ }^{2}: 0.09=$ moderate effect; $\eta_{\mathrm{p}}{ }^{2}: 0.25=$ large effect) and Cohen's $d(d: 0.2=$ small, $d: 0.5=$ moderate, and $d: 0.8=$ large effect) were calculated to provide effect sizes and are used to interpret meaningful differences (Cohen, 1988). Confidence intervals are reported as $95 \%$ CI [lower limit, upper limit] and used to 
interpret the value of the unknown population parameter. Statistical procedures were conducted using SAS 9.4 (SAS Institute, Inc. 2011, Cary, North Carolina, USA). 


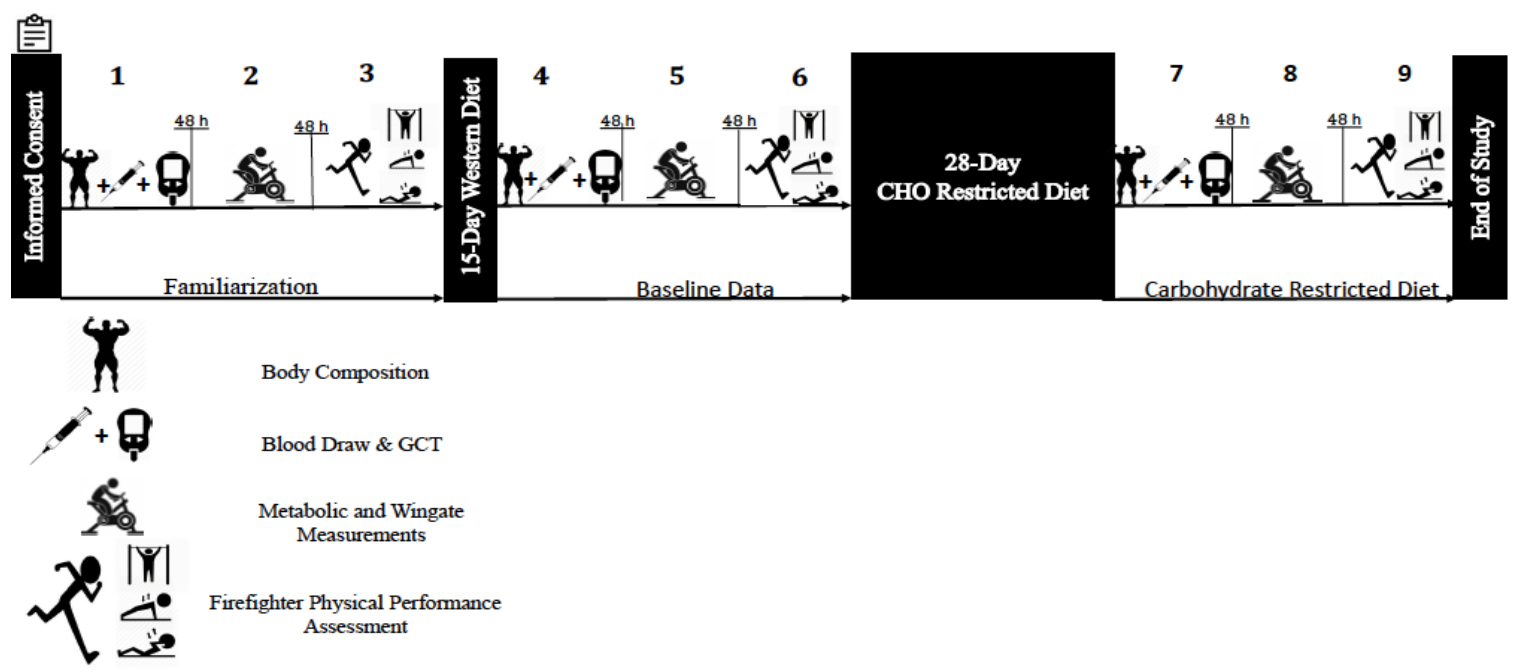

Figure 1. Schematic of experimental protocol.

The figure represents the overall timeline of the 28-day dietary intervention. $\mathrm{CHO}=$ Carbohydrate. 


\section{CHAPTER IV}

\section{RESULTS}

\section{Anthropometrics}

All data are reported as mean \pm standard deviation (SD). Body composition changes from pre to post diet are presented in Table 1. Body composition measurements collected from the BodPod demonstrated a significant difference found in mean body mass $(\mathrm{t}=5.99, p=0.001, d=0.22,95 \% \mathrm{CI}[1.76,3.71])$. Overall, body mass significantly decreased from $89.2 \pm 12.6$ to $86.5 \pm 12.5(\mathrm{~kg})$ following the diet. A significant decrease was found in fat mass $(\mathrm{t}=6.44, p=0.001, d=0.35,95 \%$ CI $[1.62$, 3.23]), but no significant differences were found for fat free mass $(\mathrm{t}=0.01, p=0.99, d=$ $0.00,95 \%$ CI $[-1.10,1.09])$. RMR significantly decreased following the $\operatorname{diet}(\mathrm{t}=2.25, p=$ $0.04, d=0.10,95 \% \mathrm{CI}[1.11,45.82])$ as did total $\%$ body fat $(\mathrm{t}=5.03, p=0.001, d=$ $0.34,95 \%$ CI $[1.26,3.14])$. With regard to the seven-site skinfold measurements, significant changes were found for the chest $(\mathrm{t}=4,70, p=0.001, d=0.70,95 \% \mathrm{CI}[1.52$, 4.08]), abdominals $(\mathrm{t}=2.34, p=0.03, d=0.40,95 \%$ CI $[0.22,5.11])$, and thigh $(\mathrm{t}=3.10$, $p=0.008, d=0.30,95 \%$ CI $[0.32,1.81])$. No significant differences were found for the axilla $(\mathrm{t}=1.80, p=0.09, d=0.16,95 \%$ CI $[-0.14,1.61])$, triceps $(\mathrm{t}=1.95, p=0.07, d=$ $0.16,95 \%$ CI $[-0.12,2.24])$, subscapular $(\mathrm{t}=0.63, p=0.54, d=0.09,95 \%$ CI $[-0.81$, 1.47]), and suprailiac $(\mathrm{t}=0.84, p=0.42, d=0.11,95 \%$ CI $[-0.84,1.90])$. Overall, a 
significant decrease was also found for $\%$ body fat as measured by skinfolds $(\mathrm{t}=3.25, p$ $=0.006, d=0.37,95 \% \mathrm{CI}[-0.42,2.05])$.

Finally, a significant decrease was found in both $\mathrm{SBP}(\mathrm{t}=3.07, p=0.008, d=$ $0.87,95 \% \mathrm{CI}[1.81,10.19])$ and $\mathrm{DBP}(\mathrm{t}=3.11, p=0.007, d=0.76,95 \% \mathrm{CI}[1.53,8.33])$ following the diet intervention.

\section{Blood Concentrations}

Changes in blood levels as measured by ELISA can be viewed in Figures 2, 3, and 4, and changes in blood levels as measured by the Cholestech LDX can be viewed in Table 1. In terms of plasma insulin, no significant differences were found from pre to post-intervention ( $\mathrm{t}=1.54, p=0.15, d=0.44,95 \% \mathrm{CI}[-0.76,4.67])$ nor were significant differences found for plasma cortisol ( $\mathrm{t}=0.63, p=0.54, d=0.16,95 \%$ CI $[-1.80,3.28])$. However, a significant decrease was found for plasma CRP from pre to post diet $(\mathrm{t}=$ $2.16, p=0.05, d=0.30,95 \%$ CI $[0.00,0.41])$.

A significant increase was found for HDL-c $(\mathrm{t}=2.50, p=0.02, d=0.34,95 \% \mathrm{CI}$ $[-8.06,-0.61])$. No further significant differences were found for TC $(\mathrm{t}=1.04, p=0.32, d$ $=0.25,95 \% \mathrm{CI}[-28.83,10.03]), \mathrm{LDL}-\mathrm{c}(\mathrm{t}=1.72, p=0.11, d=0.19,95 \% \mathrm{CI}[-27.23$, 3.08]), non-HDL ( $\mathrm{t}=0.70, p=0.50, d=0.18,95 \% \mathrm{CI}[-26.58,13.52])$, or TC/HDL-c $(\mathrm{t}=$ $0.74, p=0.47, d=0.11,95 \% \mathrm{CI}[-0.25,0.52])$. However, significance was approached for decreases in both TAG $(\mathrm{t}=1.83, p=0.08, d=0.64,95 \% \mathrm{CI}[-3.81,47.41])$ and TAG/HDL-c $(\mathrm{t}=1.99, p=0.06, d=0.59,95 \%$ CI $[-0.06,1.52])$. 


\section{Wingate Testing}

\section{Mean Power Output}

Following the diet intervention, absolute mean power output did not significantly change $(\mathrm{t}=1.07, p=0.30, d=0.10,95 \%$ CI $[-13.35,40.15])$. Regarding relative mean power output, significant differences were not found pre- to post-treatment $(\mathrm{t}=0.39, p=$ $0.70, d=0.03,95 \%$ CI $[-0.36,0.25])$.

\section{Peak Power Output}

There were no significant differences following the diet for absolute peak power $(\mathrm{t}=0.43, p=0.67, d=0.06,95 \%$ CI $[-71.57,107.60])$. Moreover, relative peak power output was not significantly different pre-to post-intervention $(\mathrm{t}=0.62, p=0.55, d=$ $0.08,95 \%$ CI $[-1.46,0.80])$.

\section{Fatigue Index}

Significant differences were not found for fatigue index following the diet intervention $(\mathrm{t}=0.44, p=0.67, d=0.09,95 \%$ CI $[-2.99,4.53])$.

\section{Total Work}

Total work completed pre- and post-diet were not significantly different from one another $(\mathrm{t}=0.08, p=0.94, d=0.01,95 \% \mathrm{CI}[-913.50,982.60])$.

\section{Wingate Heart Rate}

Significant differences were not found for $\operatorname{HR}(\mathrm{t}=0.46, p=0.66, d=0.09,95 \%$ CI [-2.97, 4.57]). Overall, finishing HR were similarly matched pre- and post-diet, $179 \pm$ 9 bpm vs. $178 \pm 12$ bpm, respectively. All Wingate testing variables can be viewed in Table 2 . 


\section{Firefighter Physical Performance Assessment}

All FPPA variables pre- and post-diet intervention can be viewed in Figure 5. A significant difference was observed from pre- to post-diet for the $2.41-\mathrm{km}$ finishing run time $(\mathrm{t}=3.09, p=0.008, d=0.01,95 \%$ CI $[0.13,0.70])$. However, 2.41-km finishing HR were not significantly different from one another $(\mathrm{t}=0.00, p=1.00, d=0.00,95 \% \mathrm{CI}[-$ $3.06,3.06])$, thus suggesting that physical exertion was not significantly different across both trials. Participants performed significantly more pull-ups post-CRD than at baseline $(\mathrm{t}=3.27, p=0.005, d=0.34,95 \%$ CI $[-4.09,-0.85])$. However, no further significant changes were found for either push-ups $(\mathrm{t}=1.42, p=0.18, d=0.46,95 \%$ CI $[-16.25$, $3.32])$ or sit-ups $(\mathrm{t}=0.83, p=0.42, d=0.20,95 \% \mathrm{CI}[-7.17,3.17])$.

\section{Glucose Challenge Test}

Blood glucose responses to the GCT pre and post diet intervention can be viewed in Figure 6. With respect to the GCT, there was not a significant treatment $\times$ time point interaction $\left(\mathrm{F}=2.21, p=0.12, \eta_{\mathrm{p}}{ }^{2}=0.06,95 \% \mathrm{CI}[0.00,0.15]\right)$. Further, there were no significant treatment effects found pre or post-CRD $\left(\mathrm{F}=0.01, p=0.93, \eta_{\mathrm{p}}{ }^{2}=0.00,95 \%\right.$ CI $[0.00,0.21])$. There was a significant difference found for time point $(\mathrm{F}=97.26, p=$ $0.001, \eta_{\mathrm{p}}^{2}=0.74,95 \%$ CI $\left.[0.57,0.76]\right)$. Overall, blood glucose responses were highest at $30 \mathrm{~min}$. The $60 \mathrm{~min}$ time point remained significantly higher than minute 0 , but significantly lower than the $30 \mathrm{~min}$ period due to a fall in blood glucose levels following the 30 min time point. 


\section{Graded Exercise Testing}

\section{Substrate Oxidation Rates}

Substrate oxidation rates for both fat and $\mathrm{CHO}\left(\mathrm{g} \cdot \mathrm{min}^{-1}\right)$ can be viewed in Figure 7 . With respect to fat oxidation, there was no treatment $\times$ time point interaction $(F=$ $0.99, p=0.42, \eta_{\mathrm{p}}{ }^{2}=0.03,95 \%$ CI $\left.[0.00,0.07]\right)$. However, significant main effects were found for treatment $\left(\mathrm{F}=7.22, p=0.008, \eta_{\mathrm{p}}{ }^{2}=0.05,95 \% \mathrm{CI}[0.00,0.13]\right)$ and for time point $\left(\mathrm{F}=25.39, p=0.001, \eta_{\mathrm{p}}^{2}=0.45,95 \% \mathrm{CI}[0.28,0.50]\right)$. Overall, fat oxidation rates significantly increased from baseline to post-CRD, $0.18 \pm 0.19$ vs. $0.24 \pm 0.25\left(\mathrm{~g} \bullet \mathrm{min}^{-1}\right)$, respectively. Further, time points 1-5 were all significantly different from each other, with fat oxidation rates decreasing during each stage $(p<0.05)$.

With regards to $\mathrm{CHO}$ oxidation rates, there was no treatment $\times$ time point interaction $\left(\mathrm{F}=1.00, p=0.41, \eta_{\mathrm{p}}{ }^{2}=0.03,95 \% \mathrm{CI}[0.00,0.07]\right)$. However, significant main effects were found for treatment $\left(\mathrm{F}=11.76, p=0.008, \eta_{\mathrm{p}}{ }^{2}=0.09,95 \%\right.$ CI $[0.01$, $0.16])$ and for time point $\left(\mathrm{F}=241.07, p=0.001, \eta_{\mathrm{p}}{ }^{2}=0.88,95 \% \mathrm{CI}[0.83,0.89]\right)$. Overall, there was a significant decrease in $\mathrm{CHO}$ oxidation rates from baseline to the post-CRD intervention, $2.15 \pm 1.24$ vs. $1.91 \pm 1.19\left(\mathrm{~g} \bullet \mathrm{min}^{-1}\right)$, respectively. Further, time points 1-5 were all significantly different from each other, with $\mathrm{CHO}$ oxidation rates increasing during each stage $(p<0.05)$.

\section{Cardiorespiratory Responses}

With respect to $\mathrm{HR}$, there was no treatment $\times$ time point interaction $(\mathrm{F}=0.34, p=$ $0.89, \eta_{\mathrm{p}}{ }^{2}=0.01,95 \%$ CI $\left.[0.00,0.02]\right)$. There were however, significant main effects found for both treatment $\left(\mathrm{F}=4.60, p=0.03, \eta_{\mathrm{p}}{ }^{2}=0.03,95 \% \mathrm{CI}[0.00,0.09]\right)$ and time points $\left(\mathrm{F}=396.45, p=0.001, \eta_{\mathrm{p}}^{2}=0.93,95 \% \mathrm{CI}[0.89,0.93]\right)$. Overall, HR was found to 
be significantly higher $(+2 \mathrm{bpm})$ during the graded exercise test following the diet.

Further, time points 1-5 were all significantly different from each other, with HR increasing during each stage $(p<0.01)$.

There was no treatment $\times$ time point interaction found for $\mathrm{RPE}(\mathrm{F}=1.00, p=0.42$, $\left.\eta_{\mathrm{p}}{ }^{2}=0.03,95 \% \mathrm{CI}[0.00,0.06]\right)$. There were however, significant main effects found for both treatment $\left(\mathrm{F}=5.47, p=0.02, \eta_{\mathrm{p}}{ }^{2}=0.03,95 \% \mathrm{CI}[0.00,0.09]\right)$ and time points $(\mathrm{F}=$ $\left.210.86, p=0.001, \eta_{\mathrm{p}}{ }^{2}=0.87,95 \% \mathrm{CI}[0.81,0.88]\right)$. In brief, the differences found for RPE regarding treatment showed that RPE was lower following the intervention than at baseline $(p<0.05)$. Further, RPE increased across 1-5 time points and were all significantly different from each other $(p<0.01)$.

With respect to relative $\dot{\mathrm{V}} \mathrm{CO}_{2}$, there was no treatment $\times$ time point interaction $(\mathrm{F}=$ $\left.0.38, p=0.82, \eta_{\mathrm{p}}{ }^{2}=0.01,95 \% \mathrm{CI}[0.00,0.03]\right)$. Moreover, significant differences were not found for main effect treatment $\left(\mathrm{F}=0.38, p=0.54, \eta_{\mathrm{p}}{ }^{2}=0.00,95 \%\right.$ CI $\left.[0.00,0.04]\right)$, but significant differences were found for main effect time point $(\mathrm{F}=452.42, p=0.001$, $\eta_{\mathrm{p}}{ }^{2}=0.93,95 \%$ CI $\left.[0.09,0.93]\right)$. Overall, relative $\dot{\mathrm{V}}_{2}$ increased across 1-5 time points and were all significantly different from each other $(p<0.01)$. Regarding absolute $\dot{\mathrm{V}} \mathrm{CO}_{2}$, no treatment $\times$ time point interaction $\left(\mathrm{F}=0.41, p=0.80, \eta_{\mathrm{p}}{ }^{2}=0.01,95 \% \mathrm{CI}[0.00,0.04]\right)$ was found. However, significant main effects were found for treatment $(\mathrm{F}=11.38, p=$ $\left.0.001, \eta_{\mathrm{p}}{ }^{2}=0.08,95 \% \mathrm{CI}[0.01,0.16]\right)$ and time point $\left(\mathrm{F}=739.72, p=0.001, \eta_{\mathrm{p}}{ }^{2}=0.96\right.$, $95 \% \mathrm{CI}[0.94,0.96])$. Overall, baseline values of $\mathrm{V} \mathrm{CO}_{2}$ were significantly higher than after the diet intervention, $1.96 \pm 0.67$ vs. $1.88 \pm 0.67 \mathrm{~L} / \mathrm{min}$, respectively. Further, $\dot{\mathrm{V}} \mathrm{CO}_{2}$ increased across 1-5 time points and were all significantly different from each other $(p<$ $0.01)$. 
With respect to relative $\dot{\mathrm{V}} \mathrm{O}_{2}$, there was no treatment $\times$ time point interaction $(\mathrm{F}=$ $2.01, p=0.10, \eta_{\mathrm{p}}{ }^{2}=0.06,95 \%$ CI $\left.[0.00,0.11]\right)$. Moreover, significant differences were not found for main effect treatment $\left(\mathrm{F}=0.84, p=0.35, \eta_{\mathrm{p}}^{2}=0.01,95 \% \mathrm{CI}[0.00,0.05]\right)$, but significant differences were found for main effect time point $(\mathrm{F}=557.78, p=0.001$, $\eta_{\mathrm{p}}{ }^{2}=0.95,95 \%$ CI $\left.[0.92,0.95]\right)$. Overall, relative $\dot{\mathrm{V}} \mathrm{O}_{2}$ increased across $1-5$ time points and were all significantly different from each other $(p<0.01)$. Regarding absolute $\dot{\mathrm{V}} \mathrm{O}_{2}$, there was no treatment $\times$ time point interaction $\left(\mathrm{F}=1.86, p=0.12, \eta_{\mathrm{p}}{ }^{2}=0.06,95 \% \mathrm{CI}\right.$ $[0.00,0.10])$. Moreover, significant differences were not found for main effect treatment $\left(\mathrm{F}=2.62, p=0.11, \eta_{\mathrm{p}}{ }^{2}=0.02,95 \% \mathrm{CI}[0.00,0.08]\right)$, but significant differences were found for main effect time point $\left(\mathrm{F}=784.90, p=0.001, \eta_{\mathrm{p}}{ }^{2}=0.96,95 \% \mathrm{CI}[0.94,0.96]\right)$. Overall, absolute $\dot{\mathrm{V}}_{2}$ increased across 1-5 time points and were all significantly different from each other $(p<0.01)$.

With respect to relative $\dot{\mathrm{VE}}$, there was no treatment $\times$ time point interaction $(\mathrm{F}=$ $0.41, p=0.80, \eta_{\mathrm{p}}{ }^{2}=0.01,95 \%$ CI $\left.[0.00,0.03]\right)$. Moreover, significant differences were not found for main effect treatment $\left(\mathrm{F}=0.14, p=0.71, \eta_{\mathrm{p}}{ }^{2}=0.00,95 \% \mathrm{CI}[0.00,0.03]\right)$, but significant differences were found for main effect time point $(\mathrm{F}=297.06, p=0.001$, $\eta_{\mathrm{p}}{ }^{2}=0.90,95 \%$ CI $\left.[0.85,0.91]\right)$. Overall, $\dot{\mathrm{V} E}$ increased across $1-5$ time points and were all significantly different from each other $(p<0.01)$.

With respect to relative RER, there was no treatment $\times$ time point interaction $(\mathrm{F}=$ $0.13, p=0.97, \eta_{\mathrm{p}}^{2}=0.00,95 \%$ CI $\left.[0.00,0.00]\right)$. However, significant differences were found for main effect treatment $\left(\mathrm{F}=24.11, p=0.001, \eta_{\mathrm{p}}{ }^{2}=0.16,95 \% \mathrm{CI}[0.05,0.24]\right)$ and time point $\left(\mathrm{F}=102.18, p=0.001, \eta_{\mathrm{p}}{ }^{2}=0.76,95 \% \mathrm{CI}[0.66,0.78]\right)$. Overall, RER values were significantly lower for post-CRD compared to baseline, $0.91 \pm 0.09$ vs. 0.95 
\pm 0.09 , respectively. Further, RER increased across $1-5$ time points and were all significantly different from each other $(p<0.01)$.

\section{Macronutrient Diet Breakdown}

\section{Kilocalories and Nutrients}

All macronutrient changes during the study can be viewed in Table 3. With regard to caloric intake, a significant main effect was not found for time point $(\mathrm{F}=1.75, p=$ $0.15, \eta_{\mathrm{p}}{ }^{2}=0.11,95 \%$ CI $\left.[0.00,0.19]\right)$. Overall, kcals remained similarly matched across the diet intervention. Regarding total consumption of sugar, a significant decrease was found following the start of the $\operatorname{diet}\left(\mathrm{F}=10.00, p=0.001, \eta_{\mathrm{p}}{ }^{2}=0.42,95 \% \mathrm{CI}[0.15\right.$, $0.48])$. Overall, consumption of sugar at baseline was significantly higher $(p<0.01)$ than at all other time points during the diet. With respect to fiber intake, a significant difference was not found during the intervention $\left(\mathrm{F}=1.17, p=0.34, \eta_{\mathrm{p}}{ }^{2}=0.08,95 \% \mathrm{CI}\right.$ $[0.00,0.15])$. Overall, fiber intake remained fairly constant from baseline to post-CRD. Regarding cholesterol intake, a significant main effect for time point was not found $(\mathrm{F}=$ $\left.1.59, p=0.19, \eta_{\mathrm{p}}^{2}=0.10,95 \% \mathrm{CI}[0.00,0.18]\right)$. Overall, participants daily intake of cholesterol was not significantly different from baseline to post-diet intervention. Finally, a significant difference for saturated fat ingestion was not found across the diet intervention $\left(\mathrm{F}=0.47, p=0.75, \eta_{\mathrm{p}}{ }^{2}=0.03,95 \%\right.$ CI $\left.[0.00,0.07]\right)$.

\section{Dietary Carbohydrate Intake}

With regards to $\mathrm{CHO}$ intake, a significant main effect was found for both absolute CHO intake $\left(\mathrm{F}=50.55, p=0.001, \eta_{\mathrm{p}}^{2}=0.78,95 \% \mathrm{CI}[0.61,0.80]\right)$ as well as percentage 
of CHO intake $\left(\mathrm{F}=45.11, p=0.001, \eta_{\mathrm{p}}^{2}=0.76,95 \% \mathrm{CI}[0.58,0.78]\right)$. Further, relative $(\mathrm{g} / \mathrm{kg}) \mathrm{CHO}$ intake significantly decreased following the diet $(\mathrm{t}=8.20, p=0.001, d=$ $2.11,95 \%$ CI $[1.32,2.25])$.

\section{Dietary Protein Intake}

A significant main effect was found for both absolute protein intake $(\mathrm{F}=7.51, p=$ $\left.0.001, \eta_{\mathrm{p}}{ }^{2}=0.35,95 \% \mathrm{CI}[0.10,0.42]\right)$ as well as percentage of protein intake $(\mathrm{F}=18.41$, $\left.p=0.001, \eta_{\mathrm{p}}{ }^{2}=0.57,95 \% \mathrm{CI}[0.31,0.61]\right)$. However, relative $(\mathrm{g} / \mathrm{kg})$ protein intake was not significantly different following the diet $(\mathrm{t}=1.92, p=0.07, d=0.65,95 \%$ CI $[-0.67$, $0.04])$.

\section{Dietary Fat Intake}

A significant main effect was not found for absolute fat intake $(\mathrm{F}=0.67, p=0.61$, $\eta_{\mathrm{p}}{ }^{2}=0.05,95 \%$ CI $\left.[0.00,0.10]\right)$, however, the percentage of fat intake did significantly increase post-CRD $\left(\mathrm{F}=8.46, p=0.001, \eta_{\mathrm{p}}{ }^{2}=0.38,95 \% \mathrm{CI}[0.12,0.45]\right)$. Further, relative $(\mathrm{g} / \mathrm{kg})$ fat intake was not significantly different following the $\operatorname{diet}(\mathrm{t}=0.60, p=$ $0.56, d=0.20,95 \%$ CI $[-0.57,0.32])$. 


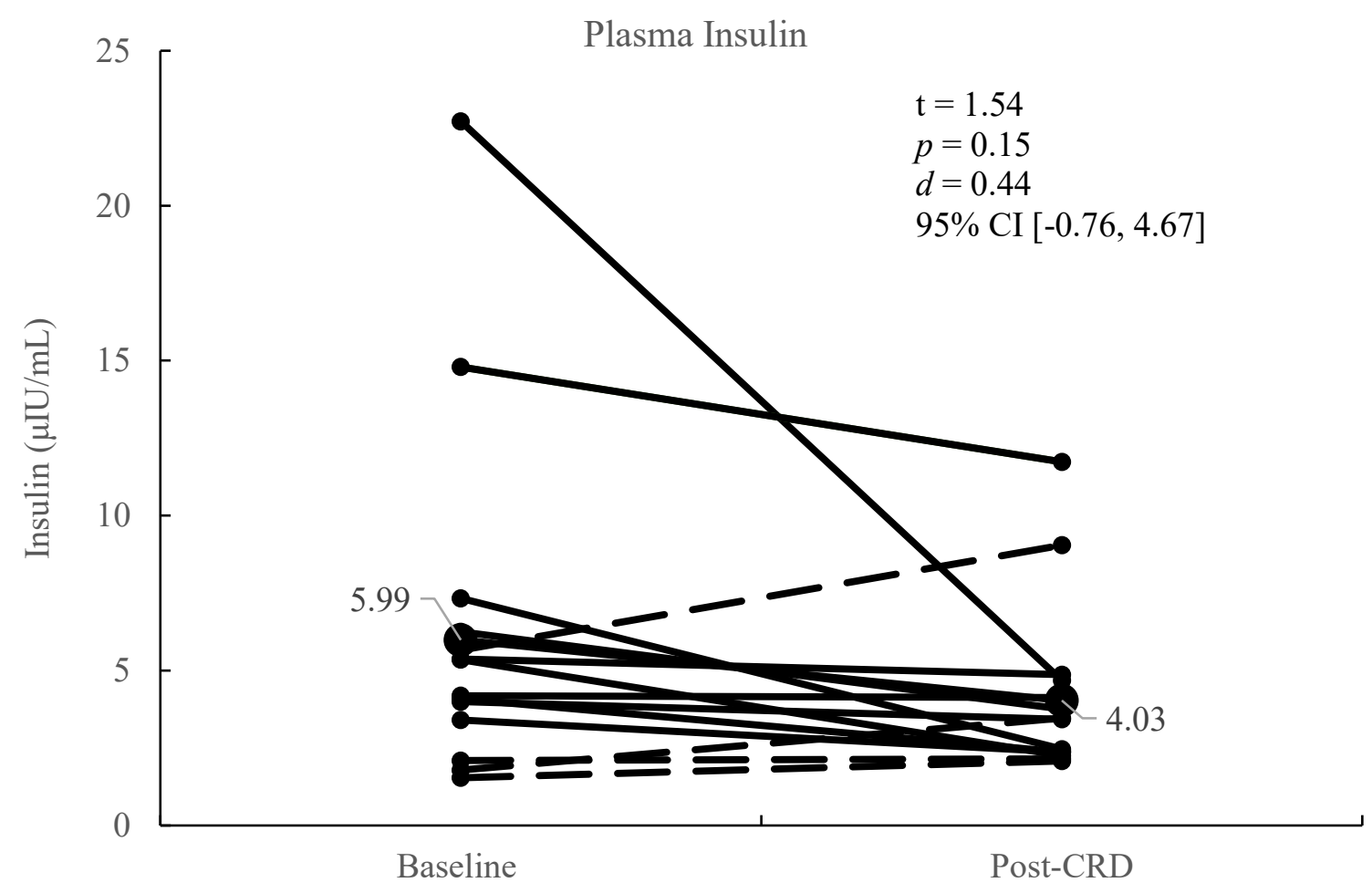

Figure 2. Insulin.

Individual plasma insulin responses for the 28-day CRD. The bold lines represent individual improvements in resting insulin measurements. The dashed lines represent individuals that failed to match or improve resting insulin measurements following the diet intervention. The bold line with the larger marker ends represents mean values. 


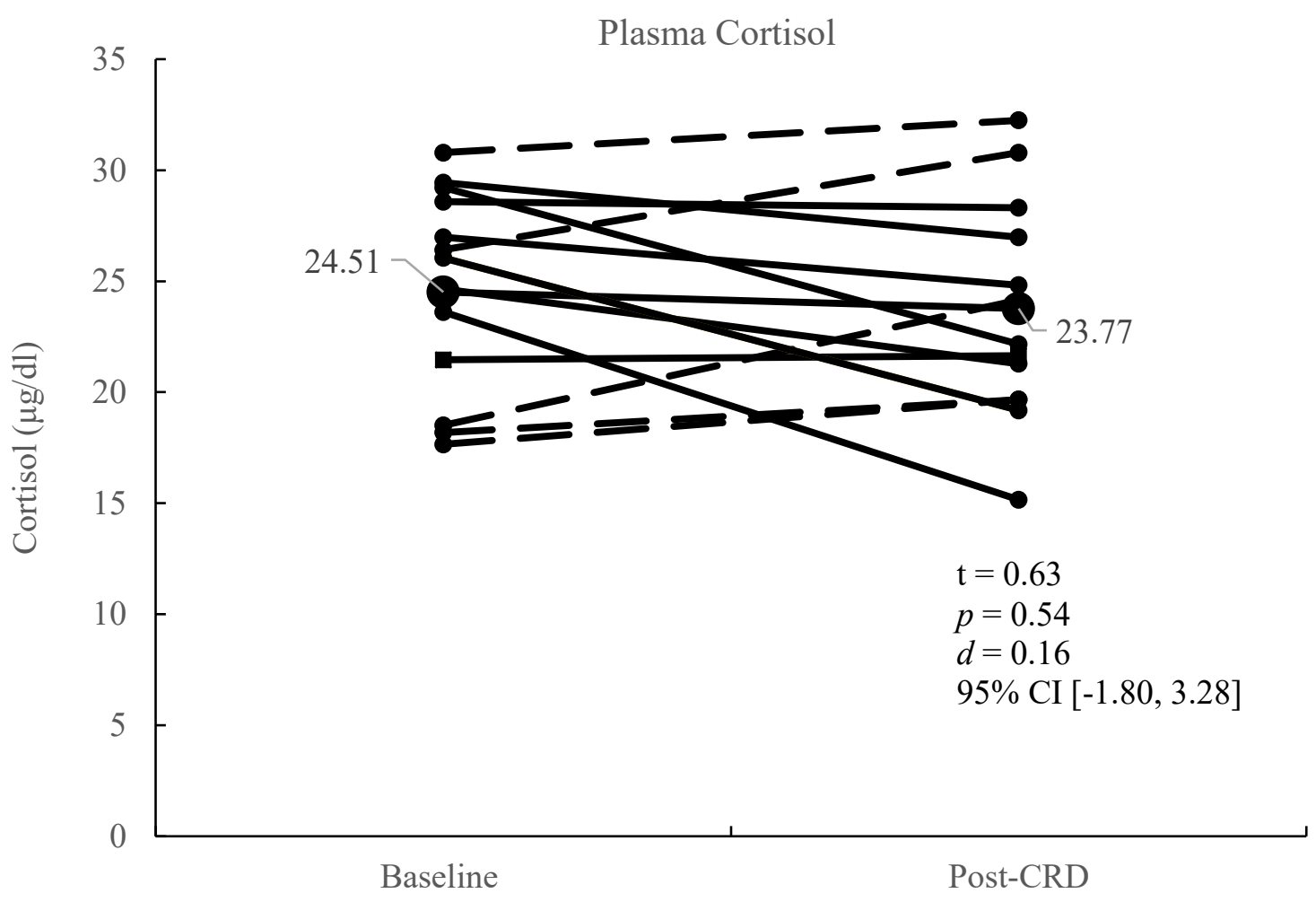

Figure 3. Cortisol.

Individual plasma cortisol responses for the 28-day CRD. The bold lines represent individual improvements in resting cortisol measurements. The dashed lines represent individuals that failed to match or improve resting cortisol measurements following the diet intervention. The bold line with the larger marker ends represents mean values. 


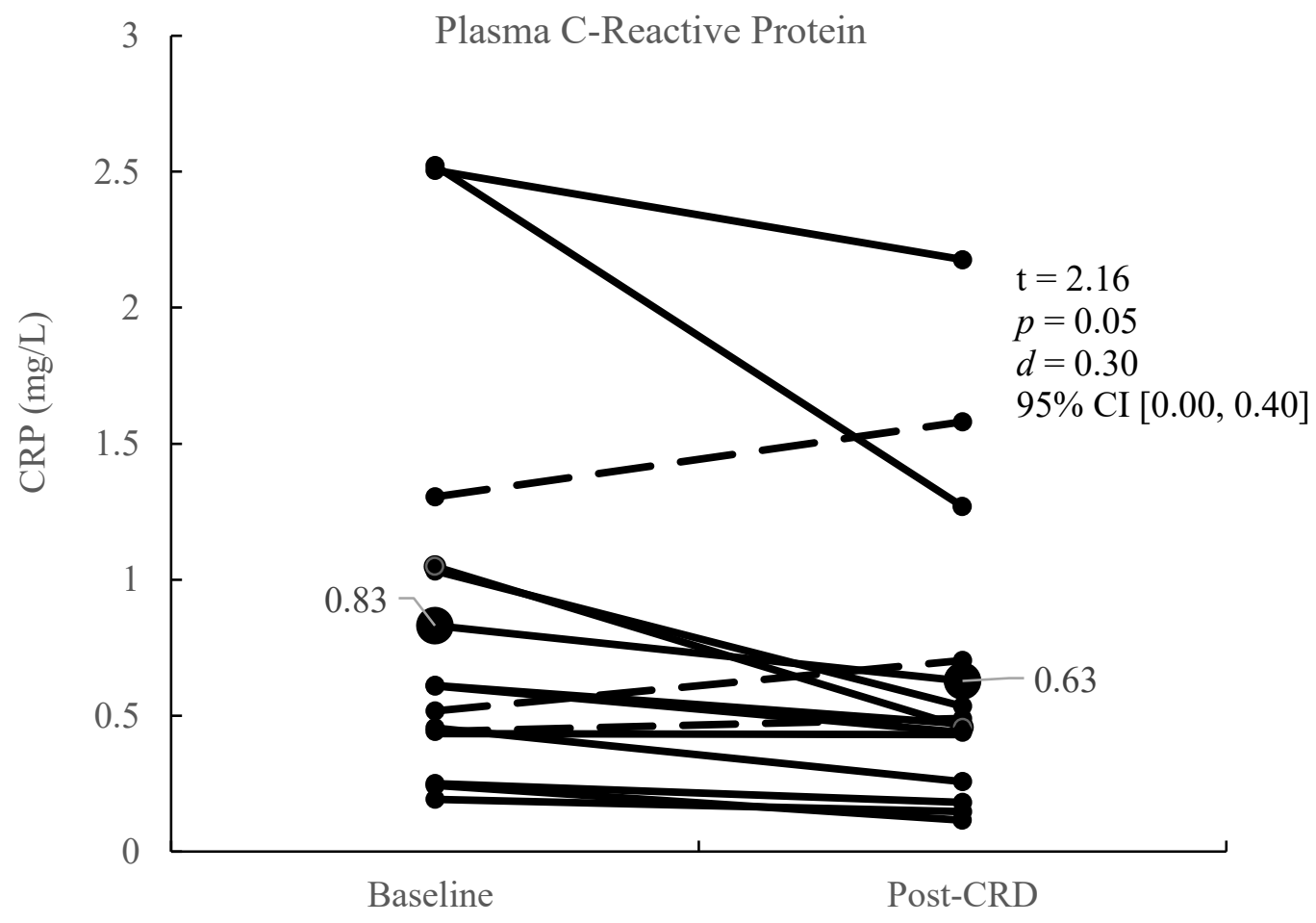

Figure 4. C-Reactive protein.

Individual plasma CRP responses for the 28-day CRD. The bold lines represent individual improvements in resting CRP measurements. The dashed lines represent individuals that failed to match or improve resting CRP measurements following the diet intervention. The bold line with the larger marker ends represents mean values. 

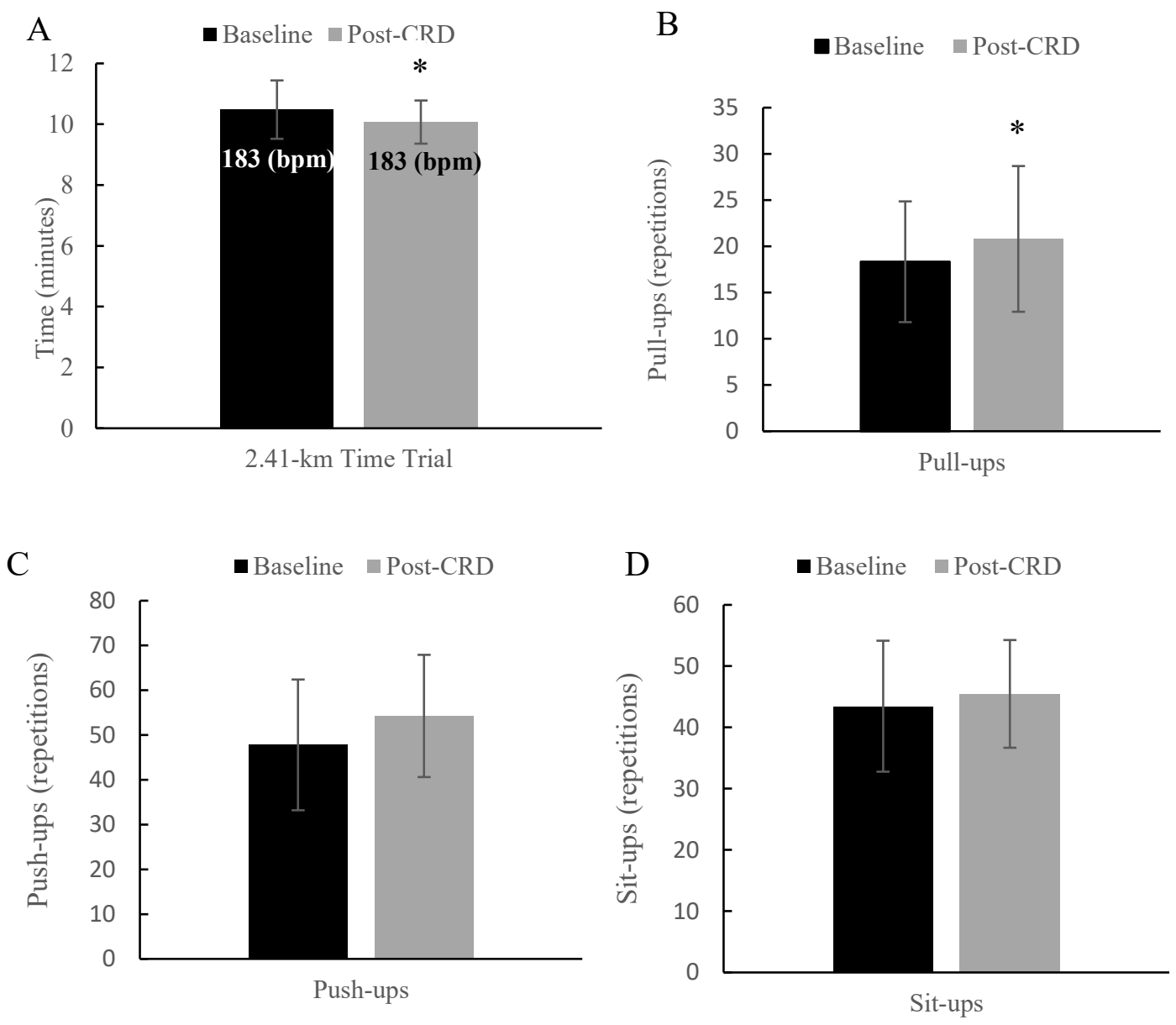

Figure 5. Firefighter physical performance assessment.

Results show changes (mean \pm SD) for FPPA performance variables in the order they were completed, pre- and post-CRD. (A). Each bar represents mean time (min) to completion ( $\pm \mathrm{SD}$ ) during the 2.41-km time trial run; Average HR for each trial is shown in its respective bar. (B). Completed number of pull-ups. (C). Completed number of push-ups. (D). Completed number of sit-ups. *Significant change found pre- to post-CRD $(p<0.05)$. 


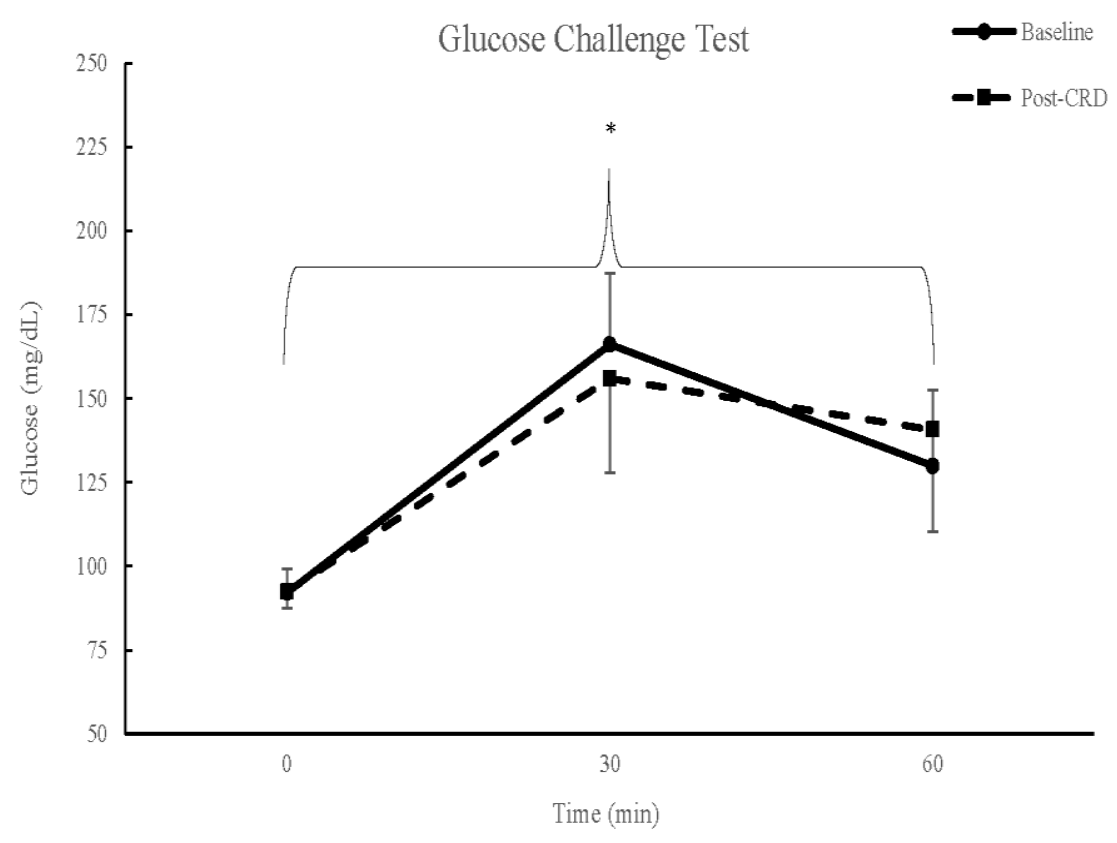

Figure 6. Glucose challenge test.

Responses show blood glucose responses (mean \pm SD) at time points 0,30 , and $60 \mathrm{~min}$ following ingestion of a $75 \mathrm{~g}$ glucose. *Indicates significance $(p<0.05)$ between time points, but not treatments. 

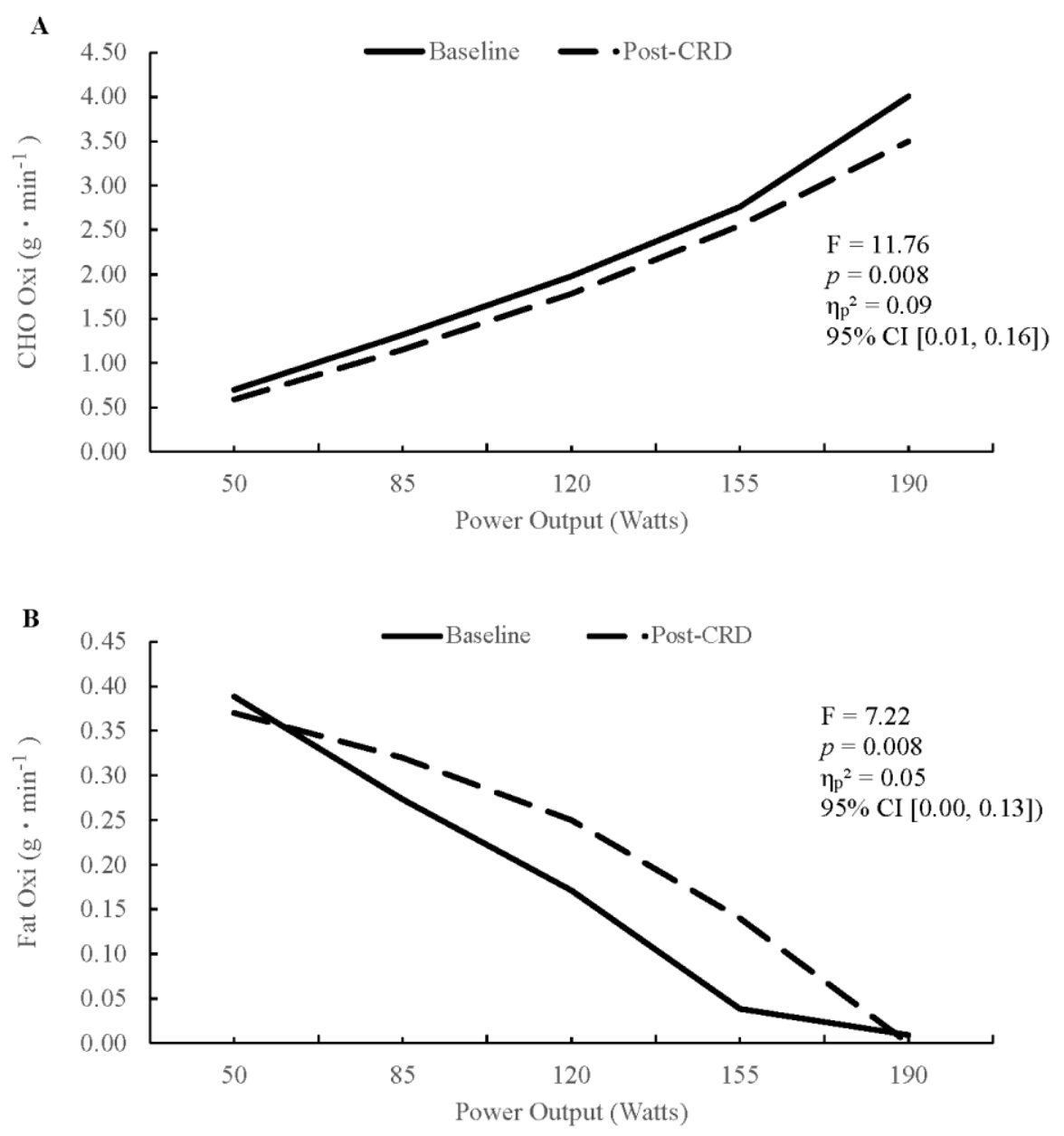

Figure 7. Substrate oxidation rates.

Results show relationships (mean $\pm \mathrm{SD}$ ) between substrate utilization (A: CHO oxidation rates; B: Fat oxidation rates) and exercise power output in FF across a 28 day CRD intervention. 
Table 1

Body Composition and Lipid Responses

\begin{tabular}{|c|c|c|}
\hline & Baseline & Post-CRD \\
\hline Body mass (kg) & $89.2 \pm 12.8$ & $86.5 \pm 12.5 \ddagger$ \\
\hline BodPod Fat (\%) & $19.6 \pm 6.3$ & $17.4 \pm 6.5 t$ \\
\hline BodPod Fat (kg) & $17.8 \pm 7.0$ & $15.3 \pm 6.8 \ddagger$ \\
\hline BodPod Lean Mass (kg) & $71.6 \pm 9.3$ & $71.6 \pm 9.2$ \\
\hline Resting Metabolic Rate & $1916.1 \pm 248.5$ & $1892.7 \pm 236.9$ \\
\hline \multicolumn{3}{|l|}{ Skinfold thickness (mm) } \\
\hline Chest & $12.6 \pm 3.7$ & $8.9 \pm 3.6 t$ \\
\hline Midaxillary & $10.9 \pm 4.3$ & $10.2 \pm 4.8^{*}$ \\
\hline Tricep & $9.6 \pm 3.4$ & $8.5 \pm 3.0^{*}$ \\
\hline Subscapularis & $13.3 \pm 2.9$ & $12.9 \pm 4.4$ \\
\hline Abdominal & $19.7 \pm 6.5$ & $17.1 \pm 7.0 \dagger$ \\
\hline Suprailliac & $10.6 \pm 3.9$ & $10.1 \pm 4.9$ \\
\hline Thigh & $12.1 \pm 3.6$ & $11.1 \pm 3.5 \div$ \\
\hline Sum & $87.7 \pm 24.8$ & $78.8 \pm 26.9 \dagger$ \\
\hline Skinfold BF (\%) & $13.4 \pm 3.2$ & $12.2 \pm 3.5 t$ \\
\hline Systolic BP (mm Hg) & $124.0 \pm 8.0$ & $118.0 \pm 6.0 \ddagger$ \\
\hline Diastolic BP (mm Hg) & $76.0 \pm 6.0$ & $70.0 \pm 6.0$ \\
\hline Total Cholesterol (mg/dL) & $167.0 \pm 27.3$ & $176.0 \pm 44.9$ \\
\hline HDL-c (mg/dL) & $46.0 \pm 12.7$ & $51.0 \pm 15.5 \dagger$ \\
\hline Non-HDL-c (mg/dL) & $119.0 \pm 30.0$ & $126.0 \pm 40.4$ \\
\hline LDL-c (mg/dL) & $99.0 \pm 29.0$ & $108.0 \pm 40.1$ \\
\hline Triacylglycerols (mg/dL) & $92.0 \pm 45.5$ & $70.0 \pm 15.2 *$ \\
\hline Triacylglycerols/HDL-c (mg/dL) & $2.3 \pm 1.6$ & $1.6 \pm 0.7^{*}$ \\
\hline Total Cholesterol/HDL-c & $3.9 \pm 1.3$ & $3.7 \pm 1.1$ \\
\hline
\end{tabular}

Responses shown are following 4 weeks of carbohydrate-restricted diet (CRD) versus habitual baseline diet $(\mathrm{n}=15$; mean \pm SD).

$\dagger=\mathrm{p}<0.05$

$\ddagger=\mathrm{p}<0.01$

$*=$ approached significance $(\mathrm{p}<0.10)$. 
Table 2

Wingate Testing

\begin{tabular}{ccc}
\hline Variable & Baseline & Post-CRD \\
\hline Peak Power (watts) & $1264.5 \pm 301.9$ & $1246.4 \pm 333.0$ \\
Mean Power (watts) & $719.3 \pm 127.9$ & $705.9 \pm 149.9$ \\
Total Work (joules) & $21579.3 \pm 384.8$ & $21545.4 \pm 4620.3$ \\
Fatigue Index (watts/second) & $27.6 \pm 7.9$ & $26.9 \pm 8.2$ \\
Relative Mean Power (watts/kg) & $8.1 \pm 1.3$ & $8.1 \pm 1.4$ \\
Relative Peak Power (watts/kg) & $14.2 \pm 2.9$ & $14.5 \pm 4.0$ \\
Max Heart Rate (bpm) & $179.0 \pm 9.0$ & $178.0 \pm 12.0$ \\
\hline
\end{tabular}

Data are presented as mean \pm SD. Wingate testing results are reported for pre-and postdiet intervention. 
Table 3

Macronutrient Composition Breakdown

\begin{tabular}{|c|c|c|c|c|c|}
\hline \multirow[b]{2}{*}{ Diet Variable } & \multicolumn{5}{|c|}{ 28-days Carbohydrate Restricted Diet } \\
\hline & Baseline & Day-7 & Day-14 & Day-21 & Post-CRD \\
\hline $\mathrm{K} /$ cals & $2090 \pm 770$ & $1696 \pm 677$ & $1877 \pm 766$ & $1813 \pm 877$ & $1650 \pm 911$ \\
\hline Protein $(\mathrm{E} \%)$ & $18 \pm 7 \dagger$ & $32 \pm 6$ & $31 \pm 6$ & $30 \pm 8$ & $29 \pm 7$ \\
\hline Protein $(\mathrm{g})$ & $88 \pm 34 \dagger$ & $133 \pm 48$ & $144 \pm 59$ & $130 \pm 52$ & $114 \pm 52$ \\
\hline Protein $(\mathrm{g} / \mathrm{kg})$ & $\begin{array}{l}0.9 \pm \\
0.4^{* * *}\end{array}$ & & & & $1.3 \pm 0.5$ \\
\hline $\mathrm{CHO}(\mathrm{E} \%)$ & $47 \pm 8^{*}$ & $20 \pm 8$ & $18 \pm 11$ & $23 \pm 10$ & $23 \pm 11$ \\
\hline $\mathrm{CHO}(\mathrm{g})$ & $244 \pm 98^{*}$ & $76 \pm 31$ & $77 \pm 32$ & $95 \pm 36$ & $84 \pm 34$ \\
\hline $\mathrm{CHO}(\mathrm{g} / \mathrm{kg})$ & $2.7 \pm 1.1 * *$ & & & & $0.9 \pm 0.3$ \\
\hline Fat (E\%) & $35 \pm 7 \dagger$ & $48 \pm 10$ & $51 \pm 9$ & $47 \pm 11$ & $48 \pm 11$ \\
\hline Fat $(\mathrm{g})$ & $85 \pm 40$ & $96 \pm 53$ & $110 \pm 56$ & $102 \pm 74$ & $95 \pm 75$ \\
\hline Fat $(\mathrm{g} / \mathrm{kg})$ & $0.9 \pm 0.4 \ddagger$ & & & & $1.0 \pm 0.7$ \\
\hline Saturated Fat (g) & $30 \pm 10$ & $32 \pm 21$ & $38 \pm 23$ & $35 \pm 27$ & $33 \pm 27$ \\
\hline Cholesterol (mg) & $323 \pm 233$ & $294 \pm 232$ & $229 \pm 222$ & $182 \pm 169$ & $180 \pm 127$ \\
\hline Sugar (g) & $87 \pm 70^{*}$ & $29 \pm 23$ & $30 \pm 28$ & $32 \pm 19$ & $29 \pm 16$ \\
\hline Fiber $(\mathrm{g})$ & $14 \pm 7$ & $17 \pm 11$ & $18 \pm 18$ & $14 \pm 10$ & $12 \pm 8$ \\
\hline $\begin{array}{l}\text { Results shown are } \\
\text { *Indicates signific } \\
\text { **Indicates signif } \\
\text { ***Approached si } \\
\text { Indicates signific } \\
\text { †Indicates signific }\end{array}$ & $\begin{array}{l}\text { diet variables } \\
\text { ntly greater th } \\
\text { antly greater } \\
\text { nificance }(p< \\
\text { ntly lower tha } \\
\text { ntly lower tha }\end{array}$ & $\begin{array}{l}\text { cross the ent } \\
\text { an days 7-28 } \\
\text { han Post-CR } \\
0.10) \text {. } \\
\text { Post-CRD } \\
\text { days 7-28 }\end{array}$ & $\begin{array}{l}\text { ntervention. } \\
<0.05) \text {. } \\
<0.05) \text {. } \\
0.05) \text {. } \\
0.05) \text {. }\end{array}$ & $=15 ;$ mean \pm & \\
\hline
\end{tabular}




\section{CHAPTER V}

\section{DISCUSSION}

The purpose of this investigation was to examine the metabolic and performance effects of a 28-day CRD in male FF. Overall, the results from this study suggest 4 weeks of a CRD can mitigate markers of CVD as evidenced by significant improvements to HDL-c, body composition, blood pressure, and reductions in CRP. Further, these metabolic improvements were accompanied by significantly faster $2.41-\mathrm{km}$ run times and an increase in pull-up repetitions although no changes were found in push-ups, sit-ups, or Wingate variables. Current data are mixed with regards to the performance effects of $\mathrm{CHO}$ restriction with some studies demonstrating improvements to performance (Goedecke et al., 1999; Heatherly et al., 2017; Klement et al., 2013; Lambert et al., 1994; Paoli et al., 2012; Wilson et al., 2017), no changes at all (Pitsiladis \& Maughan, 1999), and other studies showing performance detriments (Burke et al., 2017). However, this study demonstrates that when following a CRD for 4 weeks, performance either improved (e.g. 2.41-km time trial and pull-ups) or had no negative effects other than a slight but significant increase in HR $(+2 \mathrm{bpm})$ during the graded exercise test. Other positive adaptations found during the investigation include significant reductions in RER, RPE, CHO oxidation, and increases in fat oxidation.

The primary aim of the present study was to examine the cardiometabolic effects of a CRD using the AHA guidelines for heart disease risk stratification (Go et al., 2014). 
To date, it is now accepted that LDL-c can no longer be considered a sole indicator of heart disease risk nor even be considered a strong indicator for the development of heart disease without also the consideration of cholesterol particle size, density, and count (Holmes et al., 2018; St-Pierre et al., 2001). Evidence has emerged in the past 10 years with studies demonstrating markers of CRP (Rudolf \& Lewandrowski, 2014), HDL-c (Briel et al., 2009), TC/HDL-c (Arsenault et al., 2009), and/or TAG/HDL-c (Luz, Favarato, Faria-Neto Junior, Lemos, \& Chagas, 2008) as being stronger indicators for developing CVD. Moreover, the AHA has declared reductions to CRP and increases in HDL-c can be considered the two strongest predictors of the development of heart disease when examined collectively (Pearson et al., 2003; Ridker, 2003). In achieving the aforementioned cardiometabolic improvements, leading organizations such as the AHA and National Heart, Lung, and Blood Institute have made nutrition recommendations with emphasis on reducing dietary fat and cholesterol (DeSalvo et al., 2016; Larosa et al., 1990). However, this study is unique in that it used the same heart disease risk guidelines put forth by the AHA, but an opposite approach with regards to nutrition instead emphasizing a reduction in total $\mathrm{CHO}$ intake. Collectively, our findings show that a $\mathrm{CRD}$ with high intakes of dietary fats can improve markers for heart disease as evidenced by significant increases in HDL-c $(+4.4 \mathrm{mg} / \mathrm{dL} ; p=0.02)$ and significant decreases in CRP levels $(-0.2 \mathrm{mg} / \mathrm{L} ; p=0.05)$. Although significant differences were not found with respect to TC/HDL-c, TAG/HDL-c, non-HDL-c, or TAG, our CVD markers that were different were strengthened by the significant reductions observed in both SBP $(-6.0 \mathrm{~mm} \mathrm{Hg} ; p=$ $0.008)$ and DBP $(-5.0 \mathrm{~mm} \mathrm{Hg} ; p=0.007)$. These changes in BP are in agreement with previous studies which found weight reductions of 2-4 $\mathrm{kg}$ also resulted in decreases of 
almost $5 \mathrm{~mm} \mathrm{Hg}$ in both SBP and DBP (Semlitsch et al., 2016; Siebenhofer et al., 2016). Data from observational studies show increases of $10 \mathrm{~mm} \mathrm{Hg}$ in SBP or $5 \mathrm{~mm} \mathrm{Hg}$ in DBP can result in an increase of 20-25\% higher rate of death stemming from CHD within a 10 year span (MacMahon et al., 1990). As a group, the FF in this study were able to change their BP category from elevated to normal (124.0 vs. $118.0 \mathrm{~mm} \mathrm{Hg}$ ) according to the updated guidelines published in 2017 by the AHA (Whelton et al., 2018).

FF are documented as being one of the most overweight male occupations in America with higher mortality rates from CVD than from firefighting (Kales \& Smith, 2014; Walker SC Poston et al., 2011). Also well documented is the increased risk for onthe-job injuries in the fire service when an individual has an elevated BMI ( $\left.>25 \mathrm{~kg} / \mathrm{m}^{2}\right)$ (Jahnke, Poston, Haddock, \& Jitnarin, 2013; Walker SC Poston et al., 2011; Schmidt \& Mckune, 2012). A high BMI is also associated with higher BP and presents an even greater risk when the accumulation of adipose tissue is around the abdominal region known as android fat (Britton et al., 2013). Our data demonstrated that a 28-day CRD significantly reduced fat mass $(\sim 2.4 \mathrm{~kg})$, specifically around the abdominal region $(\sim 2.7$ $\mathrm{mm}$ ), while also maintaining lean mass. This is an interesting finding given that total caloric intake (2091 \pm 770 vs. $1759 \pm 808$ kcals) was not significantly different during the study and all nutrients were ad-libitum within the allotted $\mathrm{CHO}$ amount. Previous research has shown that FF over consume a majority of their calories from high-sugar, low-nutrient sources (Haddock et al., 2015). This study's participants significantly reduced sugar consumption $(\sim 39 \% ; 82$ vs. $32 \mathrm{~g} ; p=0.001)$ and arguably reduced their daily intake of low nutrient dense foods and beverages. This data currently point towards $\mathrm{CHO}$ restriction as an effective nutrition intervention optimizing body composition 
without requiring a significant caloric deficit. The maintenance of lean mass was attributed to the increase in absolute protein intake during the diet intervention (88 vs. $130 \mathrm{~g})$. Although relative protein $(\mathrm{g} / \mathrm{kg})$ did not reach statistical significance $(p=0.07)$, the increase from 0.9 to $1.3 \mathrm{~g} / \mathrm{kg}$ put our participants in the lower range of dietary recommendations for maintaining lean mass while losing fat (Demling \& DeSanti, 2000; Layman, 2004). Additionally, a thorough review demonstrated there exists an inverse relationship between protein intake and BP (Elliott, 2003).

Another unique finding following this study was the lack of increase in either TC or LDL-c. Although few studies have examined the biochemical changes that occur when following a CRD, those which have generally show a slight-to-moderate rise in both LDL-c and TC (Klement et al., 2013; Zajac et al., 2014). It is possible however, the rise in different cholesterols associated with $\mathrm{CRD}$ are in regard to a $\mathrm{KD}$, which requires lower intakes of protein and $\mathrm{CHO}$ as well as higher intakes of fat. Although the current study utilized a CRD, the parameters were not so extreme as to be considered a KD as such stringent parameters on macronutrients are not applicable or realistic for high-stress occupations such as FF. Regardless, this study suggests that individuals who suffer with components of metabolic syndrome can achieve favorable cardiometabolic adaptations with slight decreases in $\mathrm{CHO}$ intake, as illustrated in Tables 1 and 3. These data are further strengthened by a previous study which showed that modest reductions in $\mathrm{CHO}$ $(\sim 10 \%)$ across a 3-day period can alter nearly 400 FFA transcriptional genes, including SREBP-1c and reduce overall TAG circulation (Sparks et al., 2006). This study's participants reduced overall $\mathrm{CHO}$ intake by an average of $(21 \%)$ and reduced TAG appearance which approached significance $(p=0.08)$. Recent evidence has demonstrated 
TAG levels are generally a stronger predictor for the development of CVD than are levels of LDL-c due to the relationship TAG levels share with low-grade inflammation, low levels of HDL-c, and elevated CRP values (Singh \& Singh, 2016). While molecular data were not collected during the present study, based on our findings which show significant decreases in CRP, significant increases in HDL-c, and near significant reductions in circulating levels of TAG (Figure 4; Table 1); it is appropriate to speculate a 28-day CRD had similar effects on SREBP-1c as Sparks et al. found (Sparks et al., 2006)

Further hypotheses made by the research team such as improvements in insulin, cortisol, and glucose tolerance were not supported (Figures 2, 3, and 6). However, the sample of FF studied were already deemed normal according to these three resting markers and did not accurately reflect what the FEMA study suggested about FF as a population (i.e. insulin resistant) (Superko et al., 2011). However, previous research has shown even healthy males following a CRD can show modest reductions in already normal levels of resting insulin values (3.8 to $1.7 \mathrm{ng} / \mathrm{mL}$ ) within a 5-day period (Waldman et al., 2017). The population tested in this study also had healthy levels of insulin and therefore, findings would most likely be different for FF who are overweight or with impaired glucose tolerance. It is also possible the lack of changes specifically to insulin were not observed due to the duration of the current study which examined changes after 28-days rather than every 5-days for 15-days as observed in (Waldman et al., 2017). Although only speculation, insulin might have decreased early during the diet $(<10$-days) and risen again to normal, baseline levels by day 28 .

We further hypothesized that following a CRD would improve metabolic flexibility in our participants as measured by oxidation rates and cardiorespiratory 
markers via graded exercise test on a cycle ergometer. Dr. San-Millán and Dr. Brooks recently proposed and conducted an innovative research strategy for the indirect assessment of metabolic flexibility in individuals by measuring lactate and oxidations rates during a similar cycling exercise test. (San-Millán \& Brooks, 2017). Briefly, metabolic flexibility is a term used to describe a healthy individual's capacity to adapt to fuel oxidation in response to nutrient availability (Storlien, Oakes, \& Kelley, 2004). Being in a state of metabolic inflexibility has been linked to insulin resistance (J. E. Galgani, Moro, \& Ravussin, 2008), heart disease (Taegtmeyer, Golfman, Sharma, Razeghi, \& Van Arsdall, 2004), and obesity (Battaglia, Zheng, Hickner, \& Houmard, 2012). Variables which demonstrate metabolic inflexibility are high resting $\mathrm{CHO}$ oxidation rates $\left(\sim 1.5 \mathrm{~g} \bullet \mathrm{min}^{-1}\right)$, high resting blood lactate levels $\left(\sim 2 \mathrm{mmol} \bullet \mathrm{L}^{-1}\right)$, and low resting fat oxidation rates $\left(\sim 0.2 \mathrm{~g} \bullet \mathrm{min}^{-1}\right)$ (San-Millán \& Brooks, 2017). Exercise is known to improve the cell's capability to utilize different substrates, as endurance athletes are well regarded for having increased lactate clearance (Bergman et al., 1999) and lipid oxidation rates (Bergman, Butterfield, Wolfel, Casazza, et al., 1999), decreased reliance on $\mathrm{CHO}$ as a fuel source (Bergman, Butterfield, Wolfel, Lopaschuk, et al., 1999), and much more robust mitochondrial reticulums (Jacobs \& Lundby, 2012; Maruszak et al., 2014; Nogales-Gadea et al., 2011). CHO restriction and caloric deficit diets have also been shown to improve some of the mentioned markers in endurance trained males (Heatherly et al., 2017), resistance trained males (Waldman et al., 2017), and obese individuals (J. Galgani \& Ravussin, 2009).

This study demonstrated that following a 28-day CRD can improve symptoms of metabolic inflexibility as seen in significant reductions in post-intervention $\mathrm{CHO}$ 
oxidation rates $\left(\sim 0.24 \mathrm{~g} \bullet \mathrm{min}^{-1} ; p=0.008\right)$, RER values $(\sim 0.04 ; p=0.001)$ and significant increases in post-intervention fat oxidation rates $\left(\sim 0.07 \mathrm{~g} \bullet \mathrm{min}^{-1} ; p=0.008\right)$. Although baseline lactate levels were not collected as performed by San-Millán and Brooks, these data collectively demonstrated these participants were able to effectively shift fuel selection from primarily a glucose dependent system at rest (resting $\mathrm{CHO}$ oxidation rates pre to post-diet; $0.7 \mathrm{vs} 0.6 \mathrm{~g} \cdot \mathrm{min}^{-1}$ ) to greater reliance on FFA after following the diet. Lactate has been shown to decrease fat oxidation rates by inhibition of lipolysis through the GPR81 receptor (San-Millán \& Brooks, 2017). While lactate was not addressed in the present study, an inverse relationship exists between fat oxidation and lactate levels (Liu et al., 2009) and thus, it is reasonable to assume lactate levels would also have been handled more efficiently as a mitochondrial substrate and equated to lower resting values post-intervention. Lower blood lactate values as well as greater dependence on fat for energy both at rest and during exercise would then explain the significant decrease in resting $\dot{\mathrm{V} C O} 2$ values $\left(\sim 0.12 \mathrm{~L} / \mathrm{min}^{-1} ; p=0.03\right)$, as well as overall significant reductions in exercising $\dot{\mathrm{VCO}_{2}}\left(1.96\right.$ vs. $\left.1.88 \mathrm{~L} / \mathrm{min}^{-1} ; p=0.001\right)$ values during the graded cycling test following the diet intervention. These data are backed by studies which have demonstrated lower $\dot{\mathrm{V} C O} 2$ when lipids are the primary oxidized fuel source as opposed to glucose (Efthimiou et al., 1992; Kuo, Shiao, \& Lee, 1993; Talpers, Romberger, Bunce, \& Pingleton, 1992). A unique finding to this study is the absent rise related to either absolute or relative $\dot{\mathrm{VO}}_{2}(p>0.05)$ commonly used as a criticism for the reduced exercise economy when following a CRD (Burke et al., 2017). Research shows that per molecule, glucose produces a higher oxidative phosphorylation yield than does a FFA due to the greater ratio of reducing equivalents $\mathrm{NADH} / \mathrm{FADH}_{2}$ during $\mathrm{CHO}$ metabolism 
as opposed to $\beta$-oxidation and overall, a higher ATP yield per $\mathrm{O}_{2}$ molecule consumed (Leverve, Batandier, \& Fontaine, 2007). Subsequently, when individuals become fat adapted, oxygen consumption and total work output generally increase. Although from a biochemistry viewpoint these claims are correct (Krogh \& Lindhard, 1920), these statements have also led to criticism, as the only time being fat adapted has negatively impacted performance or shown indifferences has been in elite endurance trained athletes (Burke et al., 2000; Burke et al., 2017; Carey et al., 2001; Goedecke et al., 1999; Vogt et al., 2003). For athletes nearing maximal capacity of arterial oxygen extraction, a shift from $\mathrm{CHO}$ towards fat oxidation may in fact limit performance and impair exercise economy. Similar to the argument Heatherly et al., the participants in this study were non-elite, middle-age male FF with arguably a higher relative ceiling for oxygen extraction and any potential increases in $\mathrm{V}_{2}$ during exercise would most likely be offset by significant decreases in body mass (Heatherly et al., 2017). Even so, the graded exercise test took place on a cycle ergometer which negated any changes in body mass and still, absolute $\dot{\mathrm{VO}}_{2}$ values remained unchanged. While only speculation, it is possible the changes in absolute $\dot{\mathrm{VO}}_{2}$ and much higher fat oxidation rates observed in previous studies are due to the incorporation of a KD such as in the FASTER study (Volek et al., 2016), when compared to fat oxidation rates observed in the current investigation (1.2 vs. $0.2 \mathrm{~g} \cdot \mathrm{min}^{-1}$, respectively). The present study was intent on implementing a non-KD CRD and merely restricting $\mathrm{CHO}$ to only $\sim 25 \%$. KD generally require intakes of $\mathrm{CHO}$ under $\sim 10 \%$ and this would not have been realistic for our participants. Therefore, it's plausible the $\mathrm{CHO}$ intake of our participants was low enough to contribute to a significant shift in fat oxidation rates, but not so severe $\mathrm{CHO}$ oxidation was impaired; additionally oxygen 
consumption subsequently increased to compensate as $\dot{V} E$ was not significantly different between treatments.

A small but significant $(+2 \mathrm{bpm} ; p=0.03)$ increase was found during the graded exercise test post-CRD for HR. Research is clear that the sympathetic nervous system is influenced by CHO availability (Helge, Richter, \& Kiens, 1996; Lima-Silva et al., 2010; McAllister et al., 2016; Penev, Spiegel, Marcinkowski, \& Van Cauter, 2005; Sasaki, Hotta, \& Ishiko, 1991) and a past study has shown similar increases in HR during an exercise cycling bout due to elevated plasma catecholamine levels following an isocaloric, 7 week CRD (Helge et al., 1996). Therefore, it is reasonable to speculate the increased HR in the present study was also due to higher plasma catecholamine levels following our cycling exercise test, though these were not directly measured. While critics of low $\mathrm{CHO}$ diets might find an elevated HR a negative outcome, it is important to point out a small, but also significant decrease (2.2 vs. $2.0 ; p=0.02)$ was found in overall RPE following the diet, suggesting a reduced perceived effort while cycling. Although both variables reached statistical significance, their implications for cardiometabolic and performance benefits are small and should not be weighed heavily in interpreting the benefits of a 28-day CRD.

Secondary aims of the present investigation were to examine the performance effects of a CRD in male FF. FF are often tasked with duties that require high levels of strength and cardiorespiratory fitness, such as victim carries, ladder climbs, floor crawls (20-40 m), long and short distance sprints or runs, and all while wearing heavy $(\sim 20-35$ $\mathrm{kg}$ ) PPE (Gavhed \& Holmér, 1989). High temperatures $\left(+100^{\circ} \mathrm{C}\right)$ further intensify the cardiometabolic demands required of FF and increase the rate of glycogen depletion as 
observed by Cheuvront et al. (2010). Previous low CHO diet investigations have shown significant reductions in glycolytic enzymes (e.g. pyruvate dehydrogenase) and $\mathrm{CHO}$ metabolism during high-intensity cycling bouts (Stellingwerff et al., 2006). It is reasonable to assume a $\mathrm{CRD}$ which impairs $\mathrm{CHO}$ metabolism could potentially be detrimental to FF performance. However, it should be re-stated that impairments to performance are usually seen in studies utilizing either a KD or elite endurance trained athletes. The present FF were following a resistance training program $(\sim 4 \mathrm{x} w \mathrm{w})$ over the course of the intervention and $90 \%$ of the FF adhered to the training protocol. Further, FF are required both by the National Firefighter Protection Association (N. F. P. Association, 2017) and their training officer to accumulate 60 min of training each day with strength and aerobic work. Given the FF average of number of years $(7.9 \pm 7.4 \mathrm{yrs})$ spent in the fire-service, then in agreement with National Strength and Conditioning Association standards, these FF meet the intermediate resistance trained classification (Haff \& Triplett, 2015). With regard to resistance training and performance, the data favors a low $\mathrm{CHO}$ diet as being more advantageous for a resistance-trained population, compared to an endurance trained group (Gregory, Hamdan, Torisky, \& Akers, 2017; Kephart et al., 2018; Paoli et al., 2012; Waldman et al., 2017; J. M. Wilson et al., 2017). The results from this study suggest 4 weeks of a CRD did not significantly impact measurements (e.g. fatigue index, mean power, peak power, relative mean and peak power, HR, and total work; $p>0.05$ ) of a 30 -s high-intensity cycling bout. There were however, significant improvements observed during the FPPA. Specifically, FF improved both 2.41-km run time and pull-up repetitions (see Figure 5). There were no further differences observed in either push-ups or sit-ups and no performance decrements found 
during the FPPA. While the investigators are aware that the FPPA might not exactly replicate the physical requirements a FF can experience during a field training or on-duty call, it is currently the standard used bi-yearly across the nation to determine if a FF is fit for duty. It was for this reason the FPPA was chosen as a pre- and post-intervention testing variable and deemed appropriate to utilize in examining how a CRD might impact the physical readiness of a FF. Given these participants maintained their normal training routine, performance was not hypothesized to improve since this study was merely a diet intervention. Although this hypothesis was supported by the results of all Wingate variables, the FPPA was significantly impacted, most likely due to the relative bodyweight requirements of each task (i.e. running and calisthenics). Examining the data would suggest loss of fat mass $(\sim 2.4 \mathrm{~kg})$ while maintaining muscle mass had the greatest impact on our performance variables and can be attributed to the higher protein intake occurring when following a CRD. As seen in past studies (Waldman et al., 2017), when $\mathrm{CHO}$ are restricted, protein naturally increases to make up for the caloric deficit and is arguably the most important macronutrient for creating an optimal body composition (Campbell et al., 2007).

Some limitations were present during the investigation that should be addressed. As with all dietary interventions relying on self-reported data, each meal that our participants consumed could not be monitored. The data we received were assumed to be valid as participants were asked to record everything consumed in MyFitnessPal. However, as is the case with high-stress, on-call and $24 \mathrm{~h}$ shift occupations, it is possible forced impromptu meals, snacks, or drinks went unreported. An attempt to limit any possible discrepancies as much as possible by requesting food logs at random throughout 
the week. Further, our team asked for weekly food logs from all participants including both a weekday and weekend daywere requested. A second limitation could be if the FF participated in additional training regimens outside of what was required of them. While all participants verbally agreed they had followed the training program provided by the training officer and no further exercise had occurred, additional training sessions would have skewed body composition and performance variables. However, attempts to control and limit this were made by designing a within, crossover study which should have washed out any influencers or outliers if this did occur. On-duty calls could not be controlled. While the battalion chief voiced the 28 -days during the intervention was a similar month with regards to on-duty calls as previous months, this still remains a limitation. In an effort to minimize this, participants were asked before training sessions if they had performed rigorous exercise in the past $48 \mathrm{~h}$ or if they had been exposed to smoke in the past $24 \mathrm{~h}$ and if so, participants were asked to come back the following day for testing.

While this study reflects limitations found in other dietary interventions, a strength to this investigation is both its duration (28-days) and number of participants ( $\mathrm{n}$ $=15$ ). A common criticism to CRD is the short duration (<21-days) for which they are conducted. Although metabolic changes can be found in as short as five days (Goedecke et al., 1999), it is also understood these same adaptations impair performance acutely. Heatherly et al. found responders to a CRD can be identified within 21-days (Heatherly et al., 2017) and Aragon et al. suggested diets less than 28-days would most likely not provide adequate time for performance adaptions to occur to any specific diet (Aragon et al., 2017). Our participants followed the diet for 28 -days before reporting back to the 
laboratory for the final three sessions. Moreover, studies investigating diet interventions generally only finish with 5-11 participants (Heatherly et al., 2017; Langfort, Zarzeczny, Pilis, Nazar, \& Kaciuba-Uścitko, 1997; Phinney, Bistrian, Evans, Gervino, \& Blackburn, 1983; Phinney et al., 1983; Waldman et al., 2017). This study started with 21 and finished with 15 participants. Finally, to date this is only the second investigation to implement a diet intervention with FF and the first to use a CRD. 


\section{CHAPTER VI}

\section{CONCLUSION}

The primary purpose of the current investigation was to examine changes in cardiometabolic markers and perform a risk assessment in a high-stress occupation when following a CRD for 28-days. The secondary study purpose was related to performance responses when following a low $\mathrm{CHO}$ diet. Collectively, our results suggest that a 28 -day CRD (1) significantly decreases markers of CVD and improves HDL-c, 2) significantly improves favorable body composition changes (specifically fat mass), and 3) significantly improves FF performance on their bi-annual FPPA.

Overall, current nutrition guidelines provided by organizations such as the AHA encourage individuals struggling with weight and heart disease to reduce cholesterol and fat intake and place emphasis on more $\mathrm{CHO}$ sources (i.e. fruit, vegetables, whole grains, wheat, etc.). Our data suggests markers of heart disease can be significantly reduced and performance maintained in high-stress occupations such as FF when following a CRD. Researchers can use our intervention as a model for future nutrition studies aimed at implementing dietary changes in similar populations. Futures studies should examine the importance of personalized nutrition and other dietary protocols (i.e. intermittent fasting, time-restricted eating, cyclic ketogenic dieting) for mitigating metabolic disease, inflammation, and oxidative stress in high-stress occupations. 


\section{REFERENCES}

Aarsland, A., \& Wolfe, R. R. (1998). Hepatic secretion of VLDL fatty acids during stimulated lipogenesis in men. Journal of Lipid Research, 39(6), 1280-1286.

Abel, M. G., Mortara, A. J., \& Pettitt, R. W. (2011). Evaluation of circuit-training intensity for firefighters. The Journal of Strength \& Conditioning Research, 25(10), 2895-2901.

Achten, J., Gleeson, M., \& Jeukendrup, A. E. (2002). Determination of the exercise intensity that elicits maximal fat oxidation. Medicine and Science in Sports and Exercise, 34(1), 92-97.

Achten, J., \& Jeukendrup, A. (2003). Maximal fat oxidation during exercise in trained men. International Journal of Sports Medicine, 24(08), 603-608.

Alberti, K. G. M. M., \& Zimmet, P. f. (1998). Definition, diagnosis and classification of diabetes mellitus and its complications. Part 1: diagnosis and classification of diabetes mellitus. Provisional report of a WHO consultation. Diabetic Medicine, 15(7), 539-553.

Ali, A. H., Koutsari, C., Mundi, M., Stegall, M. D., Heimbach, J. K., Taler, S. J., ... \& Turcotte, L. P. (2011). Free fatty acid storage in human visceral and subcutaneous adipose tissue: role of adipocyte proteins. Diabetes, 60(9), 2300-2307

American College of Sports Medicine (2013). ACSM's guidelines for exercise testing and prescription, Baltimore, MD: Lippincott Williams \& Wilkins. 
American Diabetes Association, A. D. (2002). Evidence-based nutrition principles and recommendations for the treatment and prevention of diabetes and related complications. Diabetes Care, 25(1), 202-212.

Appelhans, B. M. (2009). Neurobehavioral inhibition of reward-driven feeding: implications for dieting and obesity. Obesity, 17(4), 640-647.

Aragon, A. A., Schoenfeld, B. J., Wildman, R., Kleiner, S., VanDusseldorp, T., Taylor, L., .. \& Kalman, D. S. (2017). International society of sports nutrition position stand: diets and body composition. Journal of the International Society of Sports Nutrition, 14(1), 16.

Arsenault, B. J., Rana, J. S., Stroes, E. S., Després, J.-P., Shah, P. K., Kastelein, J. J., ... \& Khaw, K.-T. (2009). Beyond low-density lipoprotein cholesterol: respective contributions of non-high-density lipoprotein cholesterol levels, triglycerides, and the total cholesterol/high-density lipoprotein cholesterol ratio to coronary heart disease risk in apparently healthy men and women. Journal of the American College of Cardiology, 55(1), 35-41.

Arya, S., Isharwal, S., Misra, A., Pandey, R. M., Rastogi, K., Vikram, N. K., .. \& \& Luthra, K. (2006). C-reactive protein and dietary nutrients in urban Asian Indian adolescents and young adults. Nutrition, 22(9), 865-871.

Astrup, A., Larsen, T. M., \& Harper, A. (2004). Atkins and other low-carbohydrate diets: hoax or an effective tool for weight loss? The Lancet, 364(9437), 897-899.

Avena, N. M., Rada, P., \& Hoebel, B. G. (2008). Evidence for sugar addiction: behavioral and neurochemical effects of intermittent, excessive sugar intake. Neuroscience \& Biobehavioral Reviews, 32(1), 20-39. 
Azadbakht, L., \& Esmaillzadeh, A. (2008). Red meat intake is associated with metabolic syndrome and the plasma C-reactive protein concentration in women. The Journal of Nutrition, 139(2), 335-339.

Barker, A. R., Gracia-Marco, L., Ruiz, J. R., Castillo, M. J., Aparicio-Ugarriza, R., González-Gross, ... \& Molnar, D. (2017). Physical activity, sedentary time, TV viewing, physical fitness and cardiovascular disease risk in adolescents: The HELENA study. International Journal of Cardiology, 254(1), 303-309.

Battaglia, G. M., Zheng, D., Hickner, R. C., \& Houmard, J. A. (2012). Effect of exercise training on metabolic flexibility in response to a high-fat diet in obese individuals. American Journal of Physiology-Endocrinology And Metabolism, 303(12), E1440-E1445.

Beck, B., Stricker-Krongrad, A., Burlet, A., Nicolas, J., \& Burlet, C. (1990). Influence of diet composition on food intake and hypothalamic neuropeptide Y (NPY) in the rat. Neuropeptides, 17(4), 197-203.

Benoit, F. L., Martin, R. L., \& Watten, R. H. (1965). Changes in body composition during weight reduction in obesity: Balance studies comparing effects of fasting and a ketogenic diet. Annals of Internal Medicine, 63(4), 604-612.

Bergman, B., Butterfield, G., Wolfel, E., Casazza, G., Lopaschuk, G., \& Brooks, G. (1999). Evaluation of exercise and training on muscle lipid metabolism. American Journal of Physiology-Endocrinology And Metabolism, 276(1), E106-E117. 
Bergman, B., Butterfield, G., Wolfel, E., Lopaschuk, G., Casazza, G., Horning, M., \& Brooks, G. (1999). Muscle net glucose uptake and glucose kinetics after endurance training in men. American Journal of Physiology-Endocrinology and Metabolism, 277(1), E81-E92.

Bergman, B. C., Wolfel, E. E., Butterfield, G. E., Lopaschuk, G. D., Casazza, G. A., Horning, M. A., \& Brooks, G. A. (1999). Active muscle and whole body lactate kinetics after endurance training in men. Journal of Applied Physiology, 87(5), 1684-1696.

Berthoud, H.-R., Münzberg, H., \& Morrison, C. D. (2017). Blaming the brain for obesity: Integration of hedonic and homeostatic mechanisms. Gastroenterology, 152(7), 1728-1738.

Bisschop, P., Arias, A. P., Ackermans, M., Endert, E., Pijl, H., Kuipers, F., ... \& Romijn, J. (2000). The effects of carbohydrate variation in isocaloric diets on glycogenolysis and gluconeogenesis in healthy men. The Journal of Clinical Endocrinology \& Metabolism, 85(5), 1963-1967.

Borg, G. A. (1982). Psychophysical bases of perceived exertion. Medicine and Science in Sports and Exercise, 14(5), 377-381.

Bowry, V. W., Ingold, K. U., \& Stocker, R. (1992). Vitamin E in human low-density lipoprotein. When and how this antioxidant becomes a pro-oxidant. Biochemical Journal, $288(2), 341-344$. 
Bratanova-Tochkova, T. K., Cheng, H., Daniel, S., Gunawardana, S., Liu, Y.-J., Mulvaney-Musa, J., Schermerhorn, T., Straub, S. G., Yajima, H., \& Sharp, G. W. (2002). Triggering and augmentation mechanisms, granule pools, and biphasic insulin secretion. Diabetes, 51(suppl 1), S83-S90.

Bravata, D. M., Sanders, L., Huang, J., Krumholz, H. M., Olkin, I., Gardner, C. D., \& Bravata, D. M. (2003). Efficacy and safety of low-carbohydrate diets: a systematic review. The Journal of the American Medical Association, 289(14), 1837-1850.

Brehm, B. J., Seeley, R. J., Daniels, S. R., \& D’alessio, D. A. (2003). A randomized trial comparing a very low carbohydrate diet and a calorie-restricted low fat diet on body weight and cardiovascular risk factors in healthy women. The Journal of Clinical Endocrinology \& Metabolism, 88(4), 1617-1623.

Briel, M., Ferreira-Gonzalez, I., You, J. J., Karanicolas, P. J., Akl, E. A., Wu, P., ... \& Sharman, A. (2009). Association between change in high density lipoprotein cholesterol and cardiovascular disease morbidity and mortality: systematic review and meta-regression analysis. British Medicine Journal, 338, b92.

Brinkworth, G. D., Buckley, J. D., Noakes, M., Clifton, P. M., \& Wilson, C. J. (2009). Long-term effects of a very low-carbohydrate diet and a low-fat diet on mood and cognitive function. Archives of Internal Medicine, 169(20), 1873-1880.

doi:https://doi.org/10.1001/archinternmed.2009.329

Britton, K. A., Massaro, J. M., Murabito, J. M., Kreger, B. E., Hoffmann, U., \& Fox, C. S. (2013). Body fat distribution, incident cardiovascular disease, cancer, and allcause mortality. Journal of the American College of Cardiology, 62(10), 921-925. 
Brouwer, E. (1957). On simple formulae for calculating the heat expenditure and the quantities of carbohydrate and fat oxidized in metabolism of men and animals, from gaseous exchange (Oxygen intake and carbonic acid output) and urine-N. Acta Physiologica et Pharmacologica Neerlandica, 6, 795.

Buchholz, A. C., \& Schoeller, D. A. (2004). Is a calorie a calorie? The American Journal of Clinical Nutrition, 79(5), 899S-906S.

Burke, L. M., Angus, D. J., Cox, G. R., Cummings, N. K., Febbraio, M. A., Gawthorn, K., .. \& Hargreaves, M. (2000). Effect of fat adaptation and carbohydrate restoration on metabolism and performance during prolonged cycling. Journal of Applied Physiology, 89(6), 2413-2421.

Burke, L. M., Hawley, J. A., Angus, D. J., Cox, G. R., Clark, S. A., Cummings, N. K., ... \& Hargreaves, M. (2002). Adaptations to short-term high-fat diet persist during exercise despite high carbohydrate availability. Medicine and Science in Sports and Exercise, 34(1), 83-91.

Burke, L. M., Ross, M. L., Garvican-Lewis, L. A., Welvaert, M., Heikura, I. A., Forbes, S. G., .. \& Sharma, A. P. (2017). Low carbohydrate, high fat diet impairs exercise economy and negates the performance benefit from intensified training in elite race walkers. The Journal of Physiology, 595(9), 2785-2807.

Caban, A. J., Lee, D. J., Fleming, L. E., Gómez-Marín, O., LeBlanc, W., \& Pitman, T. (2005). Obesity in US workers: The national health interview survey, 1986 to 2002. American Journal of Public Health, 95(9), 1614-1622. 
Cai, T.-Q., Ren, N., Jin, L., Cheng, K., Kash, S., Chen, R., .. \& Waters, M. G. (2008). Role of GPR81 in lactate-mediated reduction of adipose lipolysis. Biochemical and Biophysical Research Communications, 377(3), 987-991.

Campbell, B., Kreider, R. B., Ziegenfuss, T., La Bounty, P., Roberts, M., Burke, D., ... \& Antonio, J. (2007). International Society of Sports Nutrition position stand: protein and exercise. Journal of the International Society of Sports Nutrition, 4(1), 8.

Cannon, B., \& Nedergaard, J. (2004). Brown adipose tissue: function and physiological significance. Physiological Reviews, 84(1), 277-359.

Carey, A. L., Staudacher, H. M., Cummings, N. K., Stepto, N. K., Nikolopoulos, V., Burke, L. M., \& Hawley, J. A. (2001). Effects of fat adaptation and carbohydrate restoration on prolonged endurance exercise. Journal of Applied Physiology, 91(1), 115-122.

Castelli, W. (1984). Epidemiology of coronary heart disease: The Framingham study. The American Journal of Medicine, 76(2), 4-12.

Castelli, W. P. (1986). The triglyceride issue: A view from Framingham. American Heart Journal, 112(2), 432-437.

Cefalu, W. T. (2001). Insulin resistance: Cellular and clinical concepts. Experimental Biology and Medicine, 226(1), 13-26.

Chan, M. (2017). Obesity and diabetes: The slow-motion disaster. The Milbank Quarterly, 95(1), 11-14. 
Cheuvront, S. N., Kenefick, R. W., Montain, S. J., \& Sawka, M. N. (2010). Mechanisms of aerobic performance impairment with heat stress and dehydration. Journal of Applied Physiology, 109(6), 1989-1995.

Chiu, S., Bergeron, N., Williams, P. T., Bray, G. A., Sutherland, B., \& Krauss, R. M. (2015). Comparison of the DASH (Dietary Approaches to Stop Hypertension) diet and a higher-fat DASH diet on blood pressure and lipids and lipoproteins: a randomized controlled trial-3. The American Journal of Clinical Nutrition, 103(2), 341-347.

Chiu, S., Williams, P. T., \& Krauss, R. M. (2017). Effects of a very high saturated fat diet on LDL particles in adults with atherogenic dyslipidemia: A randomized controlled trial. PloS One, 12(2), e0170664.

Cohen, J. (1988). Statistical power analysis for the behavioral sciences. Hilsdale. NJ: Lawrence Earlbaum Associates, 2.

Coyle, E. F. (1995). Substrate utilization during exercise in active people. The American Journal of Clinical Nutrition, 61(4), 968S-979S.

Danesh, J., Wheeler, J. G., Hirschfield, G. M., Eda, S., Eiriksdottir, G., Rumley, A., ... \& Gudnason, V. (2004). C-reactive protein and other circulating markers of inflammation in the prediction of coronary heart disease. New England Journal of Medicine, 350(14), 1387-1397.

Demling, R. H., \& DeSanti, L. (2000). Effect of a hypocaloric diet, increased protein intake and resistance training on lean mass gains and fat mass loss in overweight police officers. Annals of Nutrition and Metabolism, 44(1), 21-29. doi:https://doi.org/10.1159/000012817 
Dennison, K. J., Mullineaux, D. R., Yates, J. W., \& Abel, M. G. (2012). The effect of fatigue and training status on firefighter performance. The Journal of Strength \& Conditioning Research, 26(4), 1101-1109.

DeSalvo, K. B., Olson, R., \& Casavale, K. O. (2016). Dietary guidelines for Americans. The Journal of the American Medical Association, 315(5), 457-458.

Diabetes Prevention Program Research Group (2002). Reduction in the incidence of type 2 diabetes with lifestyle intervention or metformin. New England Journal of Medicine, 346(6), 393-403.

Dimri, G., Malhotra, M., Gupta, J. S., Kumar, T. S., \& Arora, B. (1980). Alterations in aerobic-anaerobic proportions of metabolism during work in heat. European Journal of Applied Physiology and Occupational Physiology, 45(1), 43-50.

Dobson, M., Choi, B., Schnall, P. L., Wigger, E., Garcia-Rivas, J., Israel, L., \& Baker, D. B. (2013). Exploring occupational and health behavioral causes of firefighter obesity: a qualitative study. American Journal of Industrial Medicine, 56(7), 776790.

Donovan, R., Nelson, T., Peel, J., Lipsey, T., Voyles, W., \& Israel, R. G. (2009). Cardiorespiratory fitness and the metabolic syndrome in firefighters. Occupational Medicine, 59(7), 487-492.

Draznin, B., Wang, C., Adochio, R., Leitner, J., \& Cornier, M.-A. (2012). Effect of dietary macronutrient composition on AMPK and SIRT1 expression and activity in human skeletal muscle. Hormone and Metabolic Research, 44(09), 650-655. 
Dreon, D., Fernstrom, H., Miller, B., \& Krauss, R. (1994). Low-density lipoprotein subclass patterns and lipoprotein response to a reduced-fat diet in men. The FASEB Journal, 8(1), 121-126.

Dreon, D. M., Fernstrom, H. A., Williams, P. T., \& Krauss, R. M. (1999). A very-low-fat diet is not associated with improved lipoprotein profiles in men with a predominance of large, low-density lipoproteins-. The American Journal of Clinical Nutrition, 69(3), 411-418.

Eckel, R. H., Jakicic, J. M., Ard, J. D., De Jesus, J. M., Miller, N. H., Hubbard, V. S., ... \& Millen, B. E. (2014). 2013 AHA/ACC guideline on lifestyle management to reduce cardiovascular risk: a report of the American College of Cardiology/American Heart Association Task Force on Practice Guidelines. Journal of the American College of Cardiology, 63(25 Part B), 2960-2984.

Eckel, R. H., \& Krauss, R. M. (1998). American Heart Association call to action: Obesity as a major risk factor for coronary heart disease. Circulation, 97(21), 2099-2100.

Efthimiou, J., Mounsey, P., Benson, D., Madgwick, R., Coles, S., \& Benson, M. (1992). Effect of carbohydrate rich versus fat rich loads on gas exchange and walking performance in patients with chronic obstructive lung disease. Thorax, 47(6), 451456.

Elliott, P. (2003). Protein intake and blood pressure in cardiovascular disease. Proceedings of the Nutrition Society, 62(2), 495-504.

Ervin, R. B., \& Ogden, C. L. (2013). Consumption of added sugars among US adults, 2005-2010. NCHS Data Brief 122, 1-8. 
Esposito, K., Nappo, F., Marfella, R., Giugliano, G., Giugliano, F., Ciotola, M., ... \& Giugliano, D. (2002). Inflammatory cytokine concentrations are acutely increased by hyperglycemia in humans: role of oxidative stress. Circulation, 106(16), 20672072.

Feinman, R. D., Pogozelski, W. K., Astrup, A., Bernstein, R. K., Fine, E. J., Westman, E. C., ... \& McFarlane, S. I. (2015). Dietary carbohydrate restriction as the first approach in diabetes management: Critical review and evidence base. Nutrition, $31,1-13$.

Ferrannini, E., \& Camastra, S. (1998). Relationship between impaired glucose tolerance, non-insulin-dependent diabetes mellitus and obesity. European Journal of Clinical Investigations, 28 Suppl 2, 3-6; discussion 6-7.

Ferris, H. A., \& Kahn, C. R. (2012). New mechanisms of glucocorticoid-induced insulin resistance: make no bones about it. The Journal of Clinical Investigation, 122(11), 3854 .

Ford, E. S., Giles, W. H., \& Dietz, W. H. (2002). Prevalence of the metabolic syndrome among US adults: findings from the third National Health and Nutrition Examination Survey. The Journal of the American Medical Association, 287(3), 356-359.

Franklin, T. B., Saab, B. J., \& Mansuy, I. M. (2012). Neural mechanisms of stress resilience and vulnerability. Neuron, 75(5), 747-761. 
Franz, M. J., Bantle, J. P., Beebe, C. A., Brunzell, J. D., Chiasson, J. L., Garg, A., ... \& Wheeler, M. (2002). Evidence-based nutrition principles and recommendations for the treatment and prevention of diabetes and related complications. Diabetes Care, 25(1), 148-198.

Froehlich, F., Gonvers, J., \& Fried, M. (1995). Role of nutrient fat and cholecystokinin in regulation of gallbladder emptying in man. Digestive Diseases and Sciences, 40(3), 529-533.

Galgani, J., \& Ravussin, E. (2009). Energy metabolism, fuel selection and body weight regulation. International Journal of Obesity, 32(S7), S109.

Galgani, J. E., Moro, C., \& Ravussin, E. (2008). Metabolic flexibility and insulin resistance. American Journal of Physiology-Endocrinology and Metabolism, 295(5), E1009-E1017.

Gannon, M. C., \& Nuttall, F. Q. (2004). Effect of a high-protein, low-carbohydrate diet on blood glucose control in people with type 2 diabetes. Diabetes, 53(9), 23752382.

Gardner, C. D., Trepanowski, J. F., Del Gobbo, L. C., Hauser, M. E., Rigdon, J., Ioannidis, J. P., ... \& King, A. C. (2018). Effect of low-fat vs low-carbohydrate diet on 12-month weight loss in overweight adults and the association with genotype pattern or insulin secretion: the DIETFITS randomized clinical trial. The Journal of the American Medical Association, 319(7), 667-679.

Gavhed, D. C., \& Holmér, I. (1989). Thermoregulatory responses of firemen to exercise in the heat. European Journal of Applied Physiology and Occupational Physiology, 59(1-2), 115-122. 
Ginsberg, H. N. (2000). Insulin resistance and cardiovascular disease. Journal of Clinical Investigation, 106(4), 453.

Gledhill, N., \& Jamnik, V. (1992). Characterization of the physical demands of firefighting. Canadian Journal of Sport Sciences= Journal Canadien des Sciences du Sport, 17(3), 207-213.

Gleeson, M., \& Bishop, N. C. (2000). Modification of immune responses to exercise by carbohydrate, glutamine and anti-oxidant supplements. Immunology \& Cell Biology, 78(5), 554-561.

Go, A. S., Mozaffarian, D., Roger, V. L., Benjamin, E. J., Berry, J. D., Blaha, M. J., .. \& Fox, C. S. (2014). Heart disease and stroke statistics—2014 update: a report from the American Heart Association. Circulation, 129(3), e28.

Goedecke, J. H., Christie, C., Wilson, G., Dennis, S. C., Noakes, T. D., Hopkins, W. G., \& Lambert, E. V. (1999). Metabolic adaptations to a high-fat diet in endurance cyclists. Metabolism, 48(12), 1509-1517.

Golay, A., Allaz, A. F., Morel, Y., de Tonnac, N., Tankova, S., \& Reaven, G. (1996). Similar weight loss with low-or high-carbohydrate diets. The American Journal of Clinical Nutrition, 63(2), 174-178.

Gordon, H., \& Larivière, M. (2014). Physical and psychological determinants of injury in Ontario forest firefighters. Occupational Medicine, 64(8), 583-588.

Gould, R. G. (1951). Lipid metabolism and atherosclerosis. American Journal of Medicine, 11(2), 209-227. 
Green, G. M., Taguchi, S., Friestman, J., Chey, W. Y., \& Liddle, R. A. (1989). Plasma secretin, CCK, and pancreatic secretion in response to dietary fat in the rat. American Journal of Physiology-Gastrointestinal and Liver Physiology, 256(6), G1016-G1021.

Gregory, R. M., Hamdan, H., Torisky, D., \& Akers, J. (2017). A low-carbohydrate ketogenic diet combined with 6-weeks of crossfit training improves body composition and performance. International Journal of Sports and Exercise Medicine, 3, 1-10.

Grieb, P., Kłapcińska, B., Smol, E., Pilis, T., Pilis, W., Sadowska-Krępa, E., ... \& Stańczak, K. (2008). Long-term consumption of a carbohydrate-restricted diet does not induce deleterious metabolic effects. Nutrition Research, 28(12), 825833.

Gropper, S. S., \& Smith, J. L. (2012). Advanced nutrition and human metabolism, Belmont, CA: Wadsworth Cengage Learning.

Haddock, C. K., Day, R. S., Poston, W. S., Jahnke, S. A., \& Jitnarin, N. (2015). Alcohol use and caloric intake from alcohol in a national cohort of U.S. career firefighters. Journal of Studies on Alcohol and Drugs, 76(3), 360-366.

Haff, G. G., \& Triplett, N. T. (2015). Essentials of Strength Training and Conditioning 4th Edition, Champaign IL: Human kinetics.

Hall, K. D., \& Guo, J. (2017). Obesity energetics: body weight regulation and the effects of diet composition. Gastroenterology, 152(7), 1718-1727. 
Harcombe, Z., Baker, J. S., DiNicolantonio, J. J., Grace, F., \& Davies, B. (2016).

Evidence from randomised controlled trials does not support current dietary fat guidelines: a systematic review and meta-analysis. Open Heart, 3(2), e000409.

Harrison, M. (1985). Effects of thermal stress and exercise on blood volume in humans. Physiological Reviews, 65(1), 149-209.

Hartmann-Boyce, J., Johns, D., Jebb, S., \& Aveyard, P. (2014). Effect of behavioural techniques and delivery mode on effectiveness of weight management: systematic review, meta-analysis and meta-regression. Obesity Reviews, 15(7), 598-609.

Heatherly, A. J., Killen, L. G., Smith, A. F., Waldman, H. S., Hollingsworth, A., Seltmann, C. L., \& O'Neal, E. K. (2017). Effects of ad libitum low carbohydrate high-fat dieting in middle-age male runners. Medicine and Science in Sports and Exercise, 50(3), 570-579.

Helge, J. W., Richter, E. A., \& Kiens, B. (1996). Interaction of training and diet on metabolism and endurance during exercise in man. The Journal of Physiology, 492(1), 293-306.

Hespel, P., \& Richter, E. A. (1990). Glucose uptake and transport in contracting, perfused rat muscle with different pre-contraction glycogen concentrations. The Journal of Physiology, 427, 347-359.

Holmes, M. V., Millwood, I. Y., Kartsonaki, C., Hill, M. R., Bennett, D. A., Boxall, R., ... \& Hu, R. (2018). Lipids, lipoproteins, and metabolites and risk of myocardial infarction and stroke. Journal of the American College of Cardiology, 71(6), 620632. 
Horwich, T. B., Hamilton, M. A., MacLellan, W. R., \& Fonarow, G. C. (2002). Low serum total cholesterol is associated with marked increase in mortality in advanced heart failure. Journal of Cardiac Failure, 8(4), 216-224.

Hu, T., Yao, L., Reynolds, K., Niu, T., Li, S., Whelton, P., He, J., \& Bazzano, L. (2016). The effects of a low-carbohydrate diet on appetite: A randomized controlled trial. Nutrition, Metabolism and Cardiovascular Diseases, 26(6), 476-488.

Hu, T., Yao, L., Reynolds, K., Niu, T., Li, S., Whelton, P. K., ... \& Bazzano, L. A. (2016). Adherence to low-carbohydrate and low-fat diets in relation to weight loss and cardiovascular risk factors. Obesity Science and Practice, 2(1), 24-31. doi:https://doi.org/10.1002/osp4.23

Huang, C.-J., Webb, H. E., Zourdos, M. C., \& Acevedo, E. O. (2013). Cardiovascular reactivity, stress, and physical activity. Frontiers in Physiology, 4, 314.

Ignatowski, A. (1908). Influence of animal food on the organsim of rabbits. Izvest Imper Voennomed Akad St Petersburg, 16, 154-173.

Ishii, S., IIzuka, K., Miller, B. C., \& Uyeda, K. (2004). Carbohydrate response element binding protein directly promotes lipogenic enzyme gene transcription. Proceedings of the National Academy of Sciences of the United States of America, 101(44), 15597-15602.

Issa, J. S., Strunz, C., Giannini, S. D., Forti, N., \& Diament, J. (1996). Precision and accuracy of blood lipid analyses by a portable device (Cholestech-LDX). Arquivos Brasileiros de Cardiologia, 66(6), 339-342. 
Jacobs, R. A., \& Lundby, C. (2012). Mitochondria express enhanced quality as well as quantity in association with aerobic fitness across recreationally active individuals up to elite athletes. Journal of Applied Physiology, 114(3), 344-350.

Jahnke, S., Poston, W., Haddock, C., \& Jitnarin, N. (2013). Obesity and incident injury among career firefighters in the central United States. Obesity, 21(8), 1505-1508.

Jansen, A. S., Van Nguyen, X., Karpitskiy, V., Mettenleiter, T. C., \& Loewy, A. D. (1995). Central command neurons of the sympathetic nervous system: Basis of the fight-or-flight response. Science, 270(5236), 644.

Kales, S. N., \& Smith, D. L. (2014). Sudden cardiac death in the fire service. Occupational Medicine, 64(4), 228-230.

Kapadia, R., Yi, J.-H., \& Vemuganti, R. (2008). Mechanisms of anti-inflammatory and neuroprotective actions of PPAR-gamma agonists. Frontiers in Bioscience: A Journal and Virtual Library, 13, 1813.

Kelley, D. E., Goodpaster, B., Wing, R. R., \& Simoneau, J.-A. (1999). Skeletal muscle fatty acid metabolism in association with insulin resistance, obesity, and weight loss. American Journal of Physiology-Endocrinology and Metabolism, 277(6), E1130-E1141.

Kelley, D. E., Mokan, M., Simoneau, J.-A., \& Mandarino, L. J. (1993). Interaction between glucose and free fatty acid metabolism in human skeletal muscle. Journal of Clinical Investigation, 92(1), 91.

Kelley, D. E., \& Simoneau, J.-A. (1994). Impaired free fatty acid utilization by skeletal muscle in non-insulin-dependent diabetes mellitus. Journal of Clinical Investigation, 94(6), 2349. 
Kephart, W. C., Pledge, C. D., Roberson, P. A., Mumford, P. W., Romero, M. A., Mobley, C. B., ... \& Wilson, J. M. (2018). The three-month effects of a ketogenic diet on body composition, blood parameters, and performance metrics in crossFit trainees: A pilot study. Sports, 6(1), 1.

Kessler, D. A. (2010). The end of overeating: Taking control of the insatiable American appetite, New York, NY: Rodale.

Keys, A. (1953). Atherosclerosis: A problem in newer public health. Atherosclerosis, 1, 19.

Keys, A., Menotti, A., Aravanis, C., Blackburn, H., Djordevič, B. S., Buzina, R., ... \& Kimura, N. (1984). The seven countries study: 2,289 deaths in 15 years. Preventive Medicine, 13(2), 141-154.

Keys, A., Mienotti, A., Karvonen, M. J., Aravanis, C., Blackburn, H., Buzina, R., ... \& Keys, M. H. (1986). The diet and 15-year death rate in the seven countries study. American Journal of Epidemiology, 124(6), 903-915.

Klement, R. J., Frobel, T., Albers, T., Fikenzer, S., Prinzhausen, J., \& Kämmerer, U. (2013). A pilot case study on the impact of a self-prescribed ketogenic diet on biochemical parameters and running performance in healthy and physically active individuals. Nutrition and Medicine, 1(1), 10.

Kose, E., Guzel, O., Demir, K., \& Arslan, N. (2017). Changes of thyroid hormonal status in patients receiving ketogenic diet due to intractable epilepsy. Journal of Pedriatic Endocrinology and Metabolism, 30(4), 411-416. doi:https://doi.org/10.1515/jpem-2016-0281 
Krauss, R. M. (2005). Dietary and genetic probes of atherogenic dyslipidemia. Arteriosclerosis, Thrombosis, and Vascular Biology, 25(11), 2265-2272.

Krebs, N. F., Gao, D., Gralla, J., Collins, J. S., \& Johnson, S. L. (2010). Efficacy and safety of a high protein, low carbohydrate diet for weight loss in severely obese adolescents. The Journal of Pediatrics, 157(2), 252-258.

Kresge, N., Simoni, R. D., \& Hill, R. L. (2005). The biosynthetic pathway for cholesterol: Konrad Bloch. Journal of Biological Chemistry, 280(10), 135-137.

Krogh, A., \& Lindhard, J. (1920). The relative value of fat and carbohydrate as sources of muscular energy: With appendices on the correlation between standard metabolism and the respiratory quotient during rest and work. Biochemical Journal, 14(3-4), 290-363.

Kuo, C. D., Shiao, G. M., \& Lee, J. D. (1993). The effects of high-fat and highcarbohydrate diet loads on gas exchange and ventilation in COPD patients and normal subjects. Chest, 104(1), 189-196.

Lakka, H.-M., Laaksonen, D. E., Lakka, T. A., Niskanen, L. K., Kumpusalo, E., Tuomilehto, J., \& Salonen, J. T. (2002). The metabolic syndrome and total and cardiovascular disease mortality in middle-aged men. The Journal of the American Medical Association, 288(21), 2709-2716.

Lambert, E. V., Goedecke, J. H., van Zyl, C., Murphy, K., Hawley, J. A., Dennis, S. C., \& Noakes, T. D. (2001). High-fat diet versus habitual diet prior to carbohydrate loading: effects on exercise metabolism and cycling performance. International Journal of Sport Nutrition and Exercise Metabolism, 11(2), 209-225. 
Lambert, E. V., Speechly, D. P., Dennis, S. C., \& Noakes, T. D. (1994). Enhanced endurance in trained cyclists during moderate intensity exercise following 2 weeks adaptation to a high fat diet. European Journal of Applied Physiology and Occupational Physiology, 69(4), 287-293.

Langfort, J., Zarzeczny, R., Pilis, W., Nazar, K., \& Kaciuba-Uścitko, H. (1997). The effect of a low-carbohydrate diet on performance, hormonal and metabolic responses to a 30-s bout of supramaximal exercise. European Journal of Applied Physiology and Occupational Physiology, 76(2), 128-133.

Larosa, J. C., Fry, A. G., Muesing, R., \& Rosing, D. R. (1980). Effects of high-protein, low-carbohydrate dieting on plasma lipoproteins and body weight. Journal of the American Dietetic Association, 77(3), 264-270.

Larosa, J. C., Hunninghake, D., Bush, D., Criqui, M. H., Getz, G. S., Gotto, A. M., ... \& Weisfeldt, M. L. (1990). The cholesterol facts. A summary of the evidence relating dietary fats, serum cholesterol, and coronary heart disease. A joint statement by the American Heart Association and the National Heart, Lung, and Blood Institute. The Task Force on Cholesterol Issues, American Heart Association. Circulation, 81(5), 1721-1733.

Layman, D. K. (2004). Protein quantity and quality at levels above the RDA improves adult weight loss. Journal of the American College of Nutrition, 23(6 Suppl), 631s-636s. 
Lee, M. C., Schiffman, S. S., \& Pappas, T. N. (1994). Role of neuropeptides in the regulation of feeding behavior: a review of cholecystokinin, bombesin, neuropeptide Y, and galanin. Neuroscience \& Biobehavioral Reviews, 18(3), 313323.

Lemon, P., \& Hermiston, R. T. (1977). The human energy cost of fire fighting. Journal of Occupational and Environmental Medicine, 19(8), 558-562.

Leverve, X., Batandier, C., \& Fontaine, E. (2007). Choosing the right substrate. Novartis Foundation Symposium, 280, 108-121; discussion 121-107, 160-104.

Liao, T. H., Hamosh, P., \& Hamosh, M. (1984). Fat digestion by lingual lipase: mechanism of lipolysis in the stomach and upper small intestine. Pediatric Research, 18(5), 402-409.

Liebman, M. (2014). When and why carbohydrate restriction can be a viable option. Nutrition, 30(7), 748-754.

Lima-Silva, A. E., Bertuzzi, R., Dalquano, E., Nogueira, M., Casarini, D., Kiss, M. A., ... \& Pires, F. (2010). Influence of high-and low-carbohydrate diet following glycogen-depleting exercise on heart rate variability and plasma catecholamines. Applied Physiology, Nutrition, and Metabolism, 35(4), 541-547.

Lin, J., Yang, R., Tarr, P. T., Wu, P.-H., Handschin, C., Li, S., ... \& Tontonoz, P. (2005). Hyperlipidemic effects of dietary saturated fats mediated through PGC-1 $\beta$ coactivation of SREBP. Cell, 120(2), 261-273.

Liu, C., Wu, J., Zhu, J., Kuei, C., Yu, J., Shelton, J., .. \& Mirzadegan, T. (2009). Lactate inhibits lipolysis in fat cells through activation of an orphan G-protein-coupled receptor, GPR81. Journal of Biological Chemistry, 284(5), 2811-2822. 
Lopez-Garcia, E., Schulze, M. B., Meigs, J. B., Manson, J. E., Rifai, N., Stampfer, M. J., $\ldots \& \mathrm{Hu}, \mathrm{F} . \mathrm{B} .(2005)$. Consumption of trans fatty acids is related to plasma biomarkers of inflammation and endothelial dysfunction. The Journal of Nutrition, 135(3), 562-566.

Lowe, M. R., \& Butryn, M. L. (2007). Hedonic hunger: A new dimension of appetite? Physiology \& Behavior, 91(4), 432-439.

Luz, P. L. d., Favarato, D., Faria-Neto Junior, J. R., Lemos, P., \& Chagas, A. C. P. (2008). High ratio of triglycerides to HDL-cholesterol predicts extensive coronary disease. Clinics, 63(4), 427-432.

MacMahon, S., Peto, R., Collins, R., Godwin, J., Cutler, J., Sorlie, P., .. \& Stamler, J. (1990). Blood pressure, stroke, and coronary heart disease: part 1, prolonged differences in blood pressure: prospective observational studies corrected for the regression dilution bias. The Lancet, 335(8692), 765-774.

Maruszak, A., Adamczyk, J., Siewierski, M., Sozański, H., Gajewski, A., \& Żekanowski, C. (2014). Mitochondrial DNA variation is associated with elite athletic status in the P olish population. Scandinavian journal of medicine \& science in sports, 24(2), 311-318.

Mathers, C. D., \& Loncar, D. (2006). Projections of global mortality and burden of disease from 2002 to 2030. PLoS Medicine, 3(11), e442.

McAllister, M. J., Webb, H. E., Tidwell, D. K., Smith, J. W., Fountain, B. J., ... \& Williams, R. D., Jr. (2016). Exogenous Carbohydrate Reduces Cortisol Response from Combined Mental and Physical Stress. International Journal of Sports Medicine, 37(14), 1159-1165 doi:https://doi.org/10.1055/s-0042-113467 
McClernon, F. J., Yancy, W. S., Jr., Eberstein, J. A., Atkins, R. C., \& Westman, E. C. (2007). The effects of a low-carbohydrate ketogenic diet and a low-fat diet on mood, hunger, and other self-reported symptoms. Obesity (Silver Spring), 15(1), 182-187. doi:https://doi.org/10.1038/oby.2007.516

McKeown, N. M., Meigs, J. B., Liu, S., Saltzman, E., Wilson, P. W., \& Jacques, P. F. (2004). Carbohydrate nutrition, insulin resistance, and the prevalence of the metabolic syndrome in the Framingham Offspring Cohort. Diabetes Care, 27(2), $538-546$.

McMahon, M., Gerich, J., \& Rizza, R. (1988). Effects of glucocorticoids on carbohydrate metabolism. Diabetes/Metabolism Research and Reviews, 4(1), 17-30.

Mead, J. F. (1986). Lipids: chemistry, biochemistry, and nutrition, New York, NY: Plenum Press.

Mohanty, P., Hamouda, W., Garg, R., Aljada, A., Ghanim, H., \& Dandona, P. (2000). Glucose challenge stimulates reactive oxygen species (ROS) generation by leucocytes. The Journal of Clinical Endocrinology \& Metabolism, 85(8), 29702973.

Montonen, J., Boeing, H., Fritsche, A., Schleicher, E., Joost, H.-G., Schulze, M. B., ... \& Pischon, T. (2013). Consumption of red meat and whole-grain bread in relation to biomarkers of obesity, inflammation, glucose metabolism and oxidative stress. European Journal of Nutrition, 52(1), 337-345.

Moore, K. J., Sheedy, F. J., \& Fisher, E. A. (2013). Macrophages in atherosclerosis: a dynamic balance. Nature Reviews Immunology, 13(10), 709.

Mougios, V. (2006). Exercise biochemistry, Champaign, IL: Human Kinetics. 
Moustaid, N., Beyer, R. S., \& Sul, H. S. (1994). Identification of an insulin response element in the fatty acid synthase promoter. Journal of Biological Chemistry, $269(8), 5629-5634$.

National Fire Protection Association (2017). NFPA 1582, Standard on comprehensive occupational medical program for fire departments. Quincy, MA: National Fire Protection Association.

Newbold, H. (1988). Reducing the serum cholesterol level with a diet high in animal fat. Southern Medical Journal, 81(1), 61-63.

Nickols-Richardson, S. M., Coleman, M. D., Volpe, J. J., \& Hosig, K. W. (2005). Perceived hunger is lower and weight loss is greater in overweight premenopausal women consuming a low-carbohydrate/high-protein vs high-carbohydrate/low-fat diet. Journal of the American Dietetic Association, 105(9), 1433-1437.

Noakes, M., Foster, P. R., Keogh, J. B., James, A. P., Mamo, J. C., \& Clifton, P. M. (2006). Comparison of isocaloric very low carbohydrate/high saturated fat and high carbohydrate/low saturated fat diets on body composition and cardiovascular risk. Nutrition \& Metabolism, 3(1), 7.

Noakes, T. D., \& Windt, J. (2017). Evidence that supports the prescription of lowcarbohydrate high-fat diets: a narrative review. British Journal of Sports Medicine, 51(2), 133-139.

Nogales-Gadea, G., Pinós, T., Ruiz, J. R., Marzo, P. F., Fiuza-Luces, C., López-Gallardo, E., ... \& Morán, M. (2011). Are mitochondrial haplogroups associated with elite athletic status? A study on a Spanish cohort. Mitochondrion, 11(6), 905-908. 
Norouzy, A., Leeds, A., Emery, P., \& Bayat, I. (2009). Effect of single high vs low glycemic index (GI) meal on gut hormones. Poster session presented at the Soceity for Endocrinology, Harrogate, UK.

Ooshima, T. (1987). Studies on glucose challenge test (GCT) as a screening procedure for gestational diabetes mellitus. Nihon Sanka Fujinka Gakkai Zasshi, 39(10), $1737-1744$.

Opie, L. H. (2009). Caloric restriction models reverse metabolic syndrome. Journal of the American College of Cardiology, 53(10), 899-900.

Oram, J. F., \& Lawn, R. M. (2001). ABCA1: The gatekeeper for eliminating excess tissue cholesterol. Journal of Lipid Research, 42(8), 1173-1179.

Palsdottir, H., \& Hunte, C. (2004). Lipids in membrane protein structures. Biochimica et Biophysica Acta (BBA)-Biomembranes, 1666(1), 2-18.

Paoli, A., Grimaldi, K., D’Agostino, D., Cenci, L., Moro, T., Bianco, A., \& Palma, A. (2012). Ketogenic diet does not affect strength performance in elite artistic gymnasts. Journal of the International Society of Sports Nutrition, 9(1), 34.

Parks, E. J. (2002). Changes in fat synthesis influenced by dietary macronutrient content. Proceedings of the Nutrition Society, 61(2), 281-286.

Parthasarathy, S., Raghavamenon, A., Garelnabi, M. O., \& Santanam, N. (2010). Oxidized low-density lipoprotein. Free Radicals and Antioxidant Protocols, 610(1), 403-417. 
Pearson, T. A., Mensah, G. A., Alexander, R. W., Anderson, J. L., Cannon, R. O., 3rd, Criqui, M., ... \& Vinicor, F. (2003). Markers of inflammation and cardiovascular disease: application to clinical and public health practice: A statement for healthcare professionals from the Centers for Disease Control and Prevention and the American Heart Association. Circulation, 107(3), 499-511.

Penev, P., Spiegel, K., Marcinkowski, T., \& Van Cauter, E. (2005). Impact of carbohydrate-rich meals on plasma epinephrine levels: dysregulation with aging. The Journal of Clinical Endocrinology \& Metabolism, 90(11), 6198-6206.

Pepys, M. B., \& Hirschfield, G. M. (2003). C-reactive protein: A critical update. The Journal of Clinical Investigation, 111(12), 1805-1812.

Perroni, F., Tessitore, A., Cortis, C., Lupo, C., D'artibale, E., Cignitti, L., \& Capranica, L. (2010). Energy cost and energy sources during a simulated firefighting activity. The Journal of Strength \& Conditioning Research, 24(12), 3457-3463.

Phinney, S. D., Bistrian, B. R., Evans, W., Gervino, E., \& Blackburn, G. (1983). The human metabolic response to chronic ketosis without caloric restriction: preservation of submaximal exercise capability with reduced carbohydrate oxidation. Metabolism, 32(8), 769-776.

Phinney, S. D., Bistrian, B. R., Wolfe, R. R., \& Blackburn, G. L. (1983). The human metabolic response to chronic ketosis without caloric restriction: Physical and biochemical adaptation. Metabolism, 32(8), 757-768.

doi:https://doi.org/10.1016/0026-0495(83)90105-1 
Phinney, S. D., Horton, E. S., Sims, E. A., Hanson, J. S., Danforth, E., \& Lagrange, B. M. (1980). Capacity for moderate exercise in obese subjects after adaptation to a hypocaloric, ketogenic diet. The Journal of Clinical Investigation, 66(5), 11521161.

Pitsiladis, Y., \& Maughan, R. (1999). The effects of alterations in dietary carbohydrate intake on the performance of high-intensity exercise in trained individuals. European Journal of Applied Physiology and Occupational Physiology, 79(5), $433-442$.

Poston, W. S., Haddock, C. K., Jahnke, S. A., Jitnarin, N., \& Day, R. S. (2013). An examination of the benefits of health promotion programs for the national fire service. BMC Public Health, 13, 805. doi:10.1186/1471-2458-13-805

Poston, W. S., Haddock, C. K., Jahnke, S. A., Jitnarin, N., Tuley, B. C., \& Kales, S. N. (2011). The prevalence of overweight, obesity, and substandard fitness in a population-based firefighter cohort. Journal of Occupational and Environmental Medicine, 53(3), 266.

Prasad, K. (2003). C-reactive protein and cardiovascular diseases. International Journal of Angiology, 12(1), 1-12.

Reaven, G. (2004). The metabolic syndrome or the insulin resistance syndrome? Different names, different concepts, and different goals. Endocrinology and Metabolism Clinics of North America, 33(2), 283.

Reaven, G. M. (1993). Role of insulin resistance in human disease (syndrome X): An expanded definition. Annual review of medicine, 44(1), 121-131. 
Redman, L. M., \& Ravussin, E. (2011). Caloric restriction in humans: impact on physiological, psychological, and behavioral outcomes. Antioxidants \& Redox Signaling, 14(2), 275-287.

Ridker, P. M. (2003). Clinical application of C-reactive protein for cardiovascular disease detection and prevention. Circulation, 107(3), 363-369.

Ridker, P. M., Hennekens, C. H., Buring, J. E., \& Rifai, N. (2000). C-reactive protein and other markers of inflammation in the prediction of cardiovascular disease in women. New England Journal of Medicine, 342(12), 836-843.

Rudolf, J., \& Lewandrowski, K. B. (2014). Cholesterol, lipoproteins, high-sensitivity creactive protein, and other risk factors for atherosclerosis. Clinics in Laboratory Medicine, 34(1), 113-127.

Salans, L. B., Cushman, S. W., \& Weismann, R. E. (1973). Studies of human adipose tissue Adipose cell size and number in nonobese and obese patients. The Journal of Clinical Investigation, 52(4), 929-941.

Salmeron, J., Manson, J. E., Stampfer, M. J., Colditz, G. A., Wing, A. L., \& Willett, W. C. (1997). Dietary fiber, glycemic load, and risk of non-insulin-dependent diabetes mellitus in women. The Journal of the American Medical Association, 277(6), 472-477.

Saltiel, A. R., \& Kahn, C. R. (2001). Insulin signalling and the regulation of glucose and lipid metabolism. Nature, 414(6865), 799-806.

San-Millán, I., \& Brooks, G. A. (2017). Assessment of metabolic flexibility by means of measuring blood lactate, fat, and carbohydrate oxidation responses to exercise in professional endurance athletes and less-fit individuals. Sports Medicine, 1-13. 
Sankhla, M., Sharma, T. K., Mathur, K., Rathor, J. S., Butolia, V., Gadhok, A. K., Vardey, S. K., Sinha, M., \& Kaushik, G. G. (2012). Relationship of oxidative stress with obesity and its role in obesity induced metabolic syndrome. Clinical Laboratory, 58(5-6), 385-392.

Sasaki, H., Hotta, N., \& Ishiko, T. (1991). Comparison of sympatho-adrenal activity during endurance exercise performed under high-and low-carbohydrate diet conditions. The Journal of Sports Medicine and Physical Fitness, 31(3), 407-412.

Sato, J., Kanazawa, A., Makita, S., Hatae, C., Komiya, K., Shimizu, T., Ikeda, F., Tamura, Y., Ogihara, T., \& Mita, T. (2017). A randomized controlled trial of 130 g/day low-carbohydrate diet in type 2 diabetes with poor glycemic control. Clinical Nutrition, 36(4), 992-1000.

Schaeffer, M. A., \& Baum, A. (1984). Adrenal cortical response to stress at Three Mile Island. Psychosomatic Medicine, 46(3), 227-237.

Schmidt, C., \& Mckune, A. (2012). Association between physical fitness and job performance in fire-fighters. Ergonomics SA: Journal of the Ergonomics Society of South Africa, 24(2), 44-57.

Schoeller, D. A., \& Buchholz, A. C. (2005). Energetics of obesity and weight control: does diet composition matter? Journal of the American Dietetic Association, 105(5), 24-28.

Schwarz, J.-M., Linfoot, P., Dare, D., \& Aghajanian, K. (2003). Hepatic de novo lipogenesis in normoinsulinemic and hyperinsulinemic subjects consuming highfat, low-carbohydrate and low-fat, high-carbohydrate isoenergetic diets. The American Journal of Clinical Nutrition, 77(1), 43-50. 
Selye, H. (1955). Stress and disease. The Laryngoscope, 65(7), 500-514.

Semlitsch, T., Jeitler, K., Berghold, A., Horvath, K., Posch, N., Poggenburg, S., \& Siebenhofer, A. (2016). Long-term effects of weight-reducing diets in people with hypertension. The Cochrane Library, 3, Cd008274. doi:https://doi.org/10.1002/14651858.CD008274.pub3

Shai, I., Schwarzfuchs, D., Henkin, Y., Shahar, D. R., Witkow, S., Greenberg, I., Golan, R., Fraser, D., Bolotin, A., \& Vardi, H. (2008). Weight loss with a lowcarbohydrate, Mediterranean, or low-fat diet. New England Journal of Medicine, $359(3), 229-241$.

Sharman, M. J., Kraemer, W. J., Love, D. M., Avery, N. G., Gómez, A. L., Scheett, T. P., \& Volek, J. S. (2002). A ketogenic diet favorably affects serum biomarkers for cardiovascular disease in normal-weight men. The Journal of Nutrition, 132(7), 1879-1885.

Siebenhofer, A., Jeitler, K., Horvath, K., Berghold, A., Posch, N., Meschik, J., \& Semlitsch, T. (2016). Long-term effects of weight-reducing drugs in people with hypertension. The Cochrane Library, 3, Cd007654. doi:https://doi.org/10.1002/14651858.CD007654.pub4

Singh, A. K., \& Singh, R. (2016). Triglyceride and cardiovascular risk: A critical appraisal. Indian Journal of Endocrinology and Metabolism, 20(4), 418.

Siri-Tarino, P. W., Chiu, S., Bergeron, N., \& Krauss, R. M. (2015). Saturated fats versus polyunsaturated fats versus carbohydrates for cardiovascular disease prevention and treatment. Annual Review of Nutrition, 35, 517-543. 
Slawik, M., \& Vidal-Puig, A. J. (2007). Adipose tissue expandability and the metabolic syndrome. Genes \& Nutrition, 2(1), 41-45.

Smith, D. L. (2011). Firefighter fitness: improving performance and preventing injuries and fatalities. Current Sports Medicine Reports, 10(3), 167-172.

Soteriades, E. S., Smith, D. L., Tsismenakis, A. J., Baur, D. M., \& Kales, S. N. (2011). Cardiovascular disease in US firefighters: a systematic review. Cardiology in Review, 19(4), 202-215.

Sparks, L. M., Xie, H., Koza, R. A., Mynatt, R., Bray, G. A., \& Smith, S. R. (2006). High-fat/low-carbohydrate diets regulate glucose metabolism via a long-term transcriptional loop. Metabolism, 55(11), 1457-1463.

Spaulding, S. W., Chopra, I. J., Sherwin, R. S., \& Lyall, S. S. (1976). Effect of caloric restriction and dietary composition of serum T3 and reverse T3 in man. The Journal of Clinical Endocrinology \& Metabolism, 42(1), 197-200. doi:https://doi.org/10.1210/jcem-42-1-197

St-Pierre, A., Ruel, I., Cantin, B., Dagenais, G., Bernard, P.-M., Després, J.-P., \& Lamarche, B. (2001). Comparison of various electrophoretic characteristics of LDL particles and their relationship to the risk of ischemic heart disease. Circulation, 104(19), 2295-2299.

Stellingwerff, T., Spriet, L. L., Watt, M. J., Kimber, N. E., Hargreaves, M., Hawley, J. A., \& Burke, L. M. (2006). Decreased PDH activation and glycogenolysis during exercise following fat adaptation with carbohydrate restoration. American Journal of Physiology-Endocrinology And Metabolism, 290(2), E380-E388. 
Stephens, F. B., Constantin-Teodosiu, D., \& Greenhaff, P. L. (2007). New insights concerning the role of carnitine in the regulation of fuel metabolism in skeletal muscle. The Journal of Physiology, 581(2), 431-444.

Stolk, R., Lamberts, S., De Jong, F., Pols, H., \& Grobbee, D. (1996). Gender differences in the associations between cortisol and insulin in healthy subjects. Journal of Endocrinology, 149(2), 313-318.

Storlien, L., Oakes, N. D., \& Kelley, D. E. (2004). Metabolic flexibility. Proceedings of the Nutrition Society, 63(2), 363-368.

Strålfors, P., Björgell, P., \& Belfrage, P. (1984). Hormonal regulation of hormonesensitive lipase in intact adipocytes: identification of phosphorylated sites and effects on the phosphorylation by lipolytic hormones and insulin. Proceedings of the National Academy of Sciences, 81(11), 3317-3321.

Stroebe, W., Papies, E. K., \& Aarts, H. (2008). From homeostatic to hedonic theories of eating: self-regulatory failure in food-rich environments. Applied Psychology, 57(s1), 172-193.

Stumvoll, M., Mitrakou, A., Pimenta, W., Jenssen, T., Yki-Järvinen, H., Van Haeften, T., Renn, W., \& Gerich, J. (2000). Use of the oral glucose tolerance test to assess insulin release and insulin sensitivity. Diabetes Care, 23(3), 295-301.

Sumithran, P., \& Proietto, J. (2013). The defence of body weight: a physiological basis for weight regain after weight loss. Clinical Science, 124(4), 231-241. 
Superko, H. R., Momary, K. M., Pendyala, L. K., Williams, P. T., Frohwein, S., Garrett, B. C., ... \& Rolader, S. (2011). Firefighters, heart disease, and aspects of insulin resistance: The FEMA firefighter heart disease prevention study. Journal of Occupational and Environmental Medicine, 53(7), 758-764.

Taegtmeyer, H., Golfman, L., Sharma, S., Razeghi, P., \& Van Arsdall, M. (2004). Linking gene expression to function: metabolic flexibility in the normal and diseased heart. Annals of the New York Academy of Sciences, 1015(1), 202-213.

Talpers, S. S., Romberger, D. J., Bunce, S. B., \& Pingleton, S. K. (1992). Nutritionally associated increased carbon dioxide production: excess total calories vs high proportion of carbohydrate calories. Chest, 102(2), 551-555.

Tay, J., Brinkworth, G. D., Noakes, M., Keogh, J., \& Clifton, P. M. (2008). Metabolic effects of weight loss on a very-low-carbohydrate diet compared with an isocaloric high-carbohydrate diet in abdominally obese subjects. Journal of the American College of Cardiology, 51(1), 59-67.

Tomiyama, A. J., Mann, T., Vinas, D., Hunger, J. M., DeJager, J., \& Taylor, S. E. (2010). Low calorie dieting increases cortisol. Psychosomatic Medicine, 72(4), 357.

van Loon, L. J., Greenhaff, P. L., Constantin-Teodosiu, D., Saris, W. H., \& Wagenmakers, A. J. (2001). The effects of increasing exercise intensity on muscle fuel utilisation in humans. The Journal of Physiology, 536(Pt 1), 295.

Vance, J. E., \& Vance, D. E. (2008). Biochemistry of lipids, lipoproteins and membranes, Oxford, UK: Elsevier. 
Varga, T., Czimmerer, Z., \& Nagy, L. (2011). PPARs are a unique set of fatty acid regulated transcription factors controlling both lipid metabolism and inflammation. Biochimica et Biophysica Acta (BBA)-Molecular Basis of Disease, $1812(8), 1007-1022$.

Verschuren, W. M., Jacobs, D. R., Bloemberg, B. P., Kromhout, D., Menotti, A., Aravanis, C., ... \& Fidanza, F. (1995). Serum total cholesterol and long-term coronary heart disease mortality in different cultures: Twenty-five-year followup of the seven countries study. The Journal of the American Medical Association, 274(2), 131-136.

Vogt, M., Puntschart, A., Howald, H., Mueller, B., Mannhart, C., Gfeller-tuescher, L., Mullis, P., \& Hoppeler, H. (2003). Effects of dietary fat on muscle substrates, metabolism, and performance in athletes. Medicine \& Science in Sports \& Exercise, 35(6), 952-960.

Volek, J. S., Ballard, K. D., Silvestre, R., Judelson, D. A., Quann, E. E., Forsythe, C. E., Fernandez, M. L., \& Kraemer, W. J. (2009). Effects of dietary carbohydrate restriction versus low-fat diet on flow-mediated dilation. Metabolism, 58(12), 1769-1777.

Volek, J. S., \& Feinman, R. D. (2005). Carbohydrate restriction improves the features of Metabolic Syndrome. Metabolic Syndrome may be defined by the response to carbohydrate restriction. Nutrition \& Metabolism, 2(1), 31 . 
Volek, J. S., Fernandez, M. L., Feinman, R. D., \& Phinney, S. D. (2008). Dietary carbohydrate restriction induces a unique metabolic state positively affecting atherogenic dyslipidemia, fatty acid partitioning, and metabolic syndrome. Progress in Lipid Research, 47(5), 307-318.

Volek, J. S., Freidenreich, D. J., Saenz, C., Kunces, L. J., Creighton, B. C., Bartley, J. M., ... \& Maresh, C. M. (2016). Metabolic characteristics of keto-adapted ultraendurance runners. Metabolism, 65(3), 100-110.

Volek, J. S., Gómez, A. L., \& Kraemer, W. J. (2000). Fasting lipoprotein and postprandial triacylglycerol responses to a low-carbohydrate diet supplemented with n-3 fatty acids. Journal of the American College of Nutrition, 19(3), 383391.

Volek, J. S., Phinney, S. D., Forsythe, C. E., Quann, E. E., Wood, R. J., Puglisi, M. J., ... \& Feinman, R. D. (2009). Carbohydrate restriction has a more favorable impact on the metabolic syndrome than a low fat diet. Lipids, 44(4), 297-309.

Volek, J. S., \& Sharman, M. J. (2004). Cardiovascular and hormonal aspects of very-lowcarbohydrate ketogenic diets. Obesity, 12(S11), 115S-123S.

Volek, J. S., Sharman, M. J., Love, D. M., Avery, N. G., Scheett, T. P., \& Kraemer, W. J. (2002). Body composition and hormonal responses to a carbohydrate-restricted diet. Metabolism, 51(7), 864-870.

Volk, B. M., Kunces, L. J., Freidenreich, D. J., Kupchak, B. R., Saenz, C., Artistizabal, J. C., ... \& Kraemer, W. J. (2014). Effects of step-wise increases in dietary carbohydrate on circulating saturated fatty acids and palmitoleic acid in adults with metabolic syndrome. PloS One, 9(11), e113605. 
Waldman, H. S., Krings, B. M., Basham, S. A., Smith, J., Fountain, B. J., \& McAllister, M. J. (2017). Effects of a 15-Day low carbohydrate, high-fat diet in resistancetrained men. Journal of Strength and Conditioning Research. Advance online publication. doi:https://doi.org/10.1519/JSC.0000000000002282

Waldman, H. S., Krings, B. M., Smith, J. W., \& McAllister, M. J. (2018). A shift toward a high-fat diet in the current metabolic paradigm: A new perspective. Nutrition, $46,33-35$.

Walker, B. R. (2007). Glucocorticoids and cardiovascular disease. European Journal of Endocrinology, 157(5), 545-559.

Walker, B. R., Best, R., Shackleton, C. H., Padfield, P. L., \& Edwards, C. R. (1996). Increased vasoconstrictor sensitivity to glucocorticoids in essential hypertension. Hypertension, 27(2), 190-196.

Walker, B. R., Phillips, D. I., Noon, J. P., Panarelli, M., Andrew, R., Edwards, H. V., ... \& Watt, G. C. (1998). Increased glucocorticoid activity in men with cardiovascular risk factors. Hypertension, 31(4), 891-895.

Walter, K. N., Corwin, E. J., Ulbrecht, J., Demers, L. M., Bennett, J. M., Whetzel, C. A., \& Klein, L. C. (2012). Elevated thyroid stimulating hormone is associated with elevated cortisol in healthy young men and women. Thyroid Research, 5(1), 13.

Wasserman, D. H. (2009). Four grams of glucose. American Journal of PhysiologyEndocrinology And Metabolism, 296(1), E11-E21.

Westman, E. C., \& Vernon, M. C. (2008). Has carbohydrate-restriction been forgotten as a treatment for diabetes mellitus? A perspective on the ACCORD study design. Nutrition \& Metabolism, 5(1), 10. 
Whelton, P. K., Carey, R. M., Aronow, W. S., Casey, D. E., Jr., Collins, K. J., Dennison Himmelfarb, C., ... \& Wright, J. T., Jr. (2018). 2017

ACC/AHA/AAPA/ABC/ACPM/AGS/APhA/ASH/ASPC/NMA/PCNA Guideline for the prevention, detection, evaluation, and management of high blood pressure in adults: Executive summary: A report of the American College of Cardiology/American Heart Association Task Force on Clinical Practice Guidelines. Hypertension, 71(6), 1269-1324. doi:https://doi.org/10.1161/hyp.0000000000000066

Wilcox, G. (2005). Insulin and insulin resistance. Clinical Biochemist Reviews, 26(2), 19. Wilkinson, M. L., Brown, A. L., Poston, W. S. C., Haddock, C. K., Jahnke, S. A., \& Day, R. S. (2014). Peer reviewed: Physician weight recommendations for overweight and obese firefighters, United States, 2011-2012. Preventing chronic disease, 11.

Williford, H. N., Duey, W. J., Olson, M. S., Howard, R., \& Wang, N. (1999). Relationship between fire fighting suppression tasks and physical fitness. Ergonomics, 42(9), 1179-1186.

Wilson, J. M., Lowery, R. P., Roberts, M. D., Sharp, M. H., Joy, J. M., Shields, K. A., ... \& D'Agostino, D. (2017). The effects of ketogenic dieting on body composition, strength, power, and hormonal profiles in resistance training males. Journal of Strength and Conditioning Research. Advance online publication. doi:https://doi.org/10.1519/JSC.0000000000001935

Wilson, P. W. (1994). Established risk factors and coronary artery disease: the Framingham Study. American Journal of Hypertension, 7(2), 7S-12S. 
Wing, R. R., \& Hill, J. O. (2001). Successful weight loss maintenance. Annual Review of Nutrition, 21(1), 323-341.

Wing, R. R., \& Phelan, S. (2005). Long-term weight loss maintenance. The American Journal of Clinical Nutrition, 82(1), 222S-225S.

Wisse, B. E., Kim, F., \& Schwartz, M. W. (2007). An integrative view of obesity. Science, 318(5852), 928-929.

Witters, L., \& Kemp, B. (1992). Insulin activation of acetyl-CoA carboxylase accompanied by inhibition of the 5'-AMP-activated protein kinase. Journal of Biological Chemistry, 267(5), 2864-2867.

Wu, A. H. (2014). Biomarkers for cholesterol absorption and synthesis in hyperlipidemic patients: role for therapeutic selection. Clinics in Laboratory Medicine, 34(1), $157-166$.

Wymann, M. P., \& Schneiter, R. (2008). Lipid signalling in disease. Nature Reviews Molecular Cell Biology, 9(2), 162.

Yang, J., Farioli, A., Korre, M., \& Kales, S. N. (2015). Dietary preferences and nutritional information needs among career firefighters in the United States. Global Advances in Health and Medicine, 4(4), 16-23.

Young, C. M., Scanlan, S. S., Im, H. S., \& Lutwak, L. (1971). Effect of body composition and other parameters in obese young men of carbohydrate level of reduction diet. American Journal of Clinical Nutrition, 24(3), 290-296.

Young, R. A. (1976). Fat, energy and mammalian survival. American Zoologist, 16(4), 699-710. 
Yudkin, J., \& Carey, M. (1960). The treatment of obesity by the "high-fat" diet: The inevitability of calories. The Lancet, 276(7157), 939-941. doi:https://doi.org/10.1016/S0140-6736(60)92019-5

Zajac, A., Poprzecki, S., Maszczyk, A., Czuba, M., Michalczyk, M., \& Zydek, G. (2014). The effects of a ketogenic diet on exercise metabolism and physical performance in off-road cyclists. Nutrients, 6(7), 2493-2508.

Zhang, C., Rexrode, K. M., Van Dam, R. M., Li, T. Y., \& Hu, F. B. (2008). Abdominal obesity and the risk of all-cause, cardiovascular, and cancer mortality: sixteen years of follow-up in US women. Circulation, 117(13), 1658-1667.

Ziauddeen, H., Alonso-Alonso, M., Hill, J. O., Kelley, M., \& Khan, N. A. (2015).

Obesity and the neurocognitive basis of food reward and the control of intake. Advances in Nutrition: An International Review Journal, 6(4), 474-486. 
APPENDIX A

IRB APPROVAL 


\section{NOTICE OF APPROVAL FOR HUMAN RESEARCH}

DATE:

TO:

PROTOCOL TITLE:

PROTOCOL NUMBER: APPROVAL PERIOD:
June 25, 2018

JohnEric Smith, Department of Kinesiology

Effects of a thirty-day carbohydrate restricted diet on metabolic and performance markers in professional firefighters.

IRB-18-226

Approval Date: June 25, 2018
Expiration Date: May 15, 2019

Your amendment request for the protocol listed above have been approved. The proposed change(s), as described in the amendment, have been approved. You are approved to proceed with your research as modified. If necessary a stamped copy has been uploaded in the Attachment section. Please use this letter and the stamped copy as verification of the approval.

This approval is issued under Mississippi State University's Federal Wide Assurance 00000647 with the Office for Human Research Protections (OHRP).

Please direct any questions about the actions on this project to the HRPP at 325.3994 or irb@research.msstate.edu.

Kari Reeves 
APPENDIX B

INFORMED CONSENT 


\section{Mississippi State University \\ Informed Consent Form for Participation in Research}

Title of Research Study: Effects of a thirty-day carbohydrate restricted diet on metabolic and performance markers in professional firefighters.

Study Site: Ballew 201B \& McCarthy Gymnasium, J.A. Chromiak Exercise Physiology Lab Room 131

Lead Researcher: Dr. JohnEric Smith, PhD

Co-Lead Researchers: Dr. Matthew McAllister, PhD, Dr. John Lamberth, PhD, and Dr. Brent Fountain, PhD, RD.

Student Researcher: Hunter Waldman, MS, CSCS

\section{Purpose}

The purpose of this research is to examine a carbohydrate restricted diet (CRD) in firefighters (FF). The research question is if a CRD can reduce heart disease risk in FF.

\section{$\underline{\text { Target Recruitment }}$}

Recruiting methods are aimed toward individuals who meet the inclusion/exclusion criteria. Given that FF suffer more deaths from heart disease (CVD) than from fires, this study will examine if FF on a CRD can decrease their risk for CVD.

\section{Procedures}

Research Overview:

This study will consist of 51 days of recording and monitoring your daily food intake. You will report to the lab on nine separate days. Before starting the study, you will complete an informed consent document approved by the University's Institutional Review Board. You will also fill out some health documents (i.e. health questionnaire, physical activity readinessquestionnaire (PAR-Q)). You will then provide a 3-day diet recall with a Thursday, Friday, and Saturday included. If inclusion and exclusion criterion are met, you will be informed of the purpose of the study and the following procedures. 


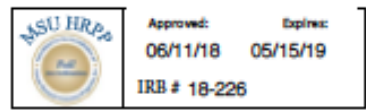

After paperwork is complete, you will perform trials 1-3 while eating your normal diet. At the end of the first 3 trials, you will record your current diet in a food log over the course of 21 days. Following day 21 , you will report to the lab to repeat trials 4-6. These will serve as the baseline data before beginning the actual diet. Following trial 6 , you will start the CRD. This will take place for 30 days unless you quit the diet at an earlier time. All food will still be recorded over this time period and at the end of day 30 , you will finish trials 7-9.

\section{Trials 1, 4, and 7}

Trial 1 will take place $48 \mathrm{~h}$ after paperwork data collection. Testing will take place in the lab following at least a 10-12 $\mathrm{h}$ fast. You will be asked to refrain from exercise that is not related to your job $48 \mathrm{~h}$ before coming to the lab. You will also be directed to come back to the lab for trial 1 if exposed to smoke $24 \mathrm{~h}$ before trial 1 takes place. Upon arrival, you will have your body mass and height measured by a scale and stadiometer. Body composition and metabolic rates will be collected by the BOD POD. Differences in fat and lean muscle mass will be assessed using a seven-site skinfold technique and bioelectrical impedance analysis (BIA). After body composition, you will be asked to sit quietly for at least 5 min on a chair. Then a total of $12 \mathrm{~mL}$ of blood will be drawn into two $6 \mathrm{~mL}$ sealed tubes from the appropriate vein, pending visibility on the left arm. These two samples will then be analyzed at a later date. After the blood draw, you will then undergo a glucose challenge test (GCT) and consume a $300 \mathrm{ml}$ bolus of water containing $75 \mathrm{~g}$ of dextrose. You will then have your finger or earlobe pricked by a 26-gauge self-withdrawing safety lancet. Five microliters will be collected for glucose and lipid levels at time points 0,30 , and $60 \mathrm{~min}$. You will then be directed to a chair which provides back support and sit for $20 \mathrm{~min}$. The right arm will then have BP recorded, twice, with a 1-2 min time between recordings. The two readings will then be averaged unless the difference is greater than 5 at which point, an additional reading will be made.

\section{Trials 2, 5, and 8}

Trial 2 will take place $48 \mathrm{~h}$ later and consist of an exercise protocol on a cycle ergometer. After you arrive to the lab and following at least a 10-12 h overnight fast, a HR monitor will be placed across your chest. Data will be collected using a MOXUS system. Cycling will begin at $95 \mathrm{~W}$ and work rate will increase $35 \mathrm{~W}$ every $3 \mathrm{~min}$ until four stages have been completed. Perceived exertion will be obtained during the last $30 \mathrm{~s}$ of each stage using a Borg scale. Following the end of the test, you will be asked to continue cycling for a 4 min cool down period. During this time, the researchers will remove your headgear. At the end of the $4 \mathrm{~min}$, you will then complete a maximal, 30-s Wingate sprint. Prior to the sprint, you will be given a 7-s countdown to increase your pedaling. You will be familiarized with the exercise test during the preliminary trial.

\section{Hydration and Sodium Measurements}




\begin{tabular}{|c|c|c|}
\hline SU HRp, & Aoproved: & $\begin{array}{r}\text { Lapims } \\
05 / 15 / 19\end{array}$ \\
\hline$\sqrt{3}$ & $\operatorname{IRB}=18-22$ & \\
\hline
\end{tabular}

To assess hydration and sodium, you will be provided two, $500 \mathrm{~mL}$ bottles of water to drink the night before the blood draw session and exercise test.

During these sessions, you will drink one bottle of water during your last meal of the day and consume your second bottle of water the hour before you go to bed. No fluids or food will be allowed until the next morning.

During the blood draw sessions, you will drink your last bottle of water upon arriving to the lab. Blood will then be drawn as detailed elsewhere.

During the exercise sessions, you will consume a bottle of water upon arrival. You will then be asked to provide a urine sample of $50 \mathrm{~mL}$ to the researcher. You will then be weighed on a digital and BIA scale in briefs only, after toweling off any sweat before and after the exercise test. You will then have a small patch placed on your forearm to measure sweat while you exercise. The place where the patch will be applied will be cleaned before the patch is placed on your arm. At the end of the exercise test, patches will then be removed and analyzed for sweat loss.

\section{Trials 3,6 , and 9}

Following Trial 2, Trial 3 will consist of you performing your bi-annual firefighter physical performance assessment (FPPA). The FPPA consists of a 1.5-mile timed run, immediately followed by max repetitions within $2 \mathrm{~min}$ for each exercise: pushups, sit-ups, and pullups. Rest is not built into this performance test; however, you are welcome to rest as needed. A 1.5-mile loop outside the lab will be marked off and the three remaining exercises will take place inside the lab. You will be asked to refrain from exercise, not related to your occupation, $24 \mathrm{~h}$ before arrival. You will be asked to arrive in athletic attire. After a 5 min warm-up, a timer will start followed by a "go" signal indicating the test has started. You will complete the 1.5-mile run and then enter the weight-room located in the lab to finish the three remaining exercises.

Dietary Manipulation

After the end of trial 6, you will then begin the diet for 30-days. The present study will use a $\mathrm{CHO}$ restricted, but caloric ad-libitum diet seen in previous research conducted here at Mississippi State University, IRB \#16-645. The purpose for this is due to your occupation. Due to changes in physical activity with FF, setting a pre-determined caloric range does not account for the decreased or increased energy expenditure that you can experience on any day. Therefore, during the first visit to the lab, you will be guided on implementing a CRD into your lifestyle. You will be provided with $\mathrm{CHO}$ restricted sample menus, grocery lists, and fast food choices with low $\mathrm{CHO}$ options. 


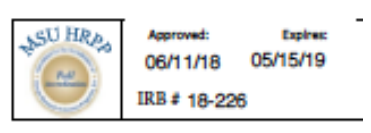

During the study, you will track all food intake and stay below the $\mathrm{CHO}$ number given to you. After providing the principal investigator (PI) with your 3 -day food log, $25 \%$ of your $\mathrm{CHO}$ intake will be calculated and used as your $\mathrm{CHO}$ amount per day. All other macronutrients (e.g. fat and protein) will be allowed as much as you want. In an attempt to maintain adherence, you will be selected at random during the study, to send a full day of your food logs to the PI. You will also be asked to send a 2-day food log with a Sunday and Monday at the end of each week. Nightly reminders will be sent out by the PI to remind you to continue recording all foods. Finally, the diet will be overseen by Dr. Brent Fountain, a registered dietician maintained within the University's Department of Nutrition and co-investigator for the current study.

\section{Blood Sampling}

As detailed above, you will have a total of 3 blood draws across the duration of this study. Further, you will have your finger or earlobe pricked by a self-withdrawing lancet a total of 9 times.

\section{Time Commitment}

Sessions 1, 4, and 7 are expected to require 90 min each. Sessions 2, 5, and 8 are expected to require 45 min each. Sessions 3,6 , and 9 are expected to require 30 min each. The diet will last a total of 30 days followed by sessions 6-9. The total time for all 9 sessions in the lab are 495 min or $\mathbf{8 . 5}$ hours across 9 trials.

\section{$\underline{\text { Risks and Discomforts }}$}

Completion of the physical task may cause muscle damage, soreness, fatigue, dizziness, headache, elevation of blood pressure, heart attack, stroke, or sudden death. According to the American College of Sports Medicine, the risk of sudden cardiac death during physical activity is one per year for every $15,000-18,000$ people. (Siscovick, D.S., Weiss, N.S., Fletcher, R.H., \& Lasky, T. (1984).

- Individual(s) (Hunter Waldman) trained in CPR, AED, and First Aid will be present during sessions.

- Dr. Fountain will oversee the entire diet protocol and is included on the IRB.

- Note: there is no compensation for testing in the instance of an injury. Further information can be obtained from the investigators.

- Needles will be used to collect blood samples, which includes any discomforts associated with needles. There are minor risks of infection with the drawing of blood. Risks are minimal due to the clean methods used for collection. Risk of infection will be decreased by wiping down the site with an alcohol pad. Pressure by gauze will be 
applied after removal of the needle to reduce bleeding. All sites from which blood are drawn will be covered with a bandage.

- Given that this is a CRD but ad-lib caloric diet, hunger is not expected during the thirtydays. However, if hunger pangs are felt, notify the PI and further options can be given.

- Although ketosis is a concern for some, given the amount of $\mathrm{CHO}$ you will still be allowed to consume, the diet will not induce a state of ketosis.

\section{Benefits}

You will have a free body comp test performed by a professional. You will also receive a free graded exercise test. Further, you will be given a full lipid test to monitor and classify your risk for heart disease. At the end of the study, you and the PI will go over all of your personal data and what the results mean if you choose to do so.

\section{Inclusion/Exclusion Criteria}

Inclusion criteria will include: 1) you must be an active duty, male firefighter, 2) meet the American College of Sports Medicine low-risk guidelines, 3) obtain at least 150 min of moderate-intensity aerobic activity or $60 \mathrm{~min}$ of vigorous intensity aerobic activity per week, 4) avoid all supplements that are not acceptable by the National College American Association for the study, 5) refrain from caffeine and alcohol consumption $24 \mathrm{~h}$ prior to the testing sessions, 6) "cleared for duty" after a yearly physical which all FF must undergo, and 7) currently consuming $(\geq 45 \% \mathrm{E}$ ) from $\mathrm{CHO}$ and have maintained stable body mass for the previous two weeks before beginning the study.

You will be excluded from the study if you are found to: 1 ) be currently taking anabolic steroids that are not medically given, 2 ) not following to the CRD on multiple ( $3 \mathrm{x}$ ) bouts when selected for a dietary recall, and 3 ) be current tobacco users.

\section{Confidentiality}

Participation in this study is voluntary. You may drop out or refuse to partake or answer any questions at any time. You will be assigned a participant number. This allows us to remove any personal identifying information from your data. Once you complete all sessions of the study (or immediately after dropping from the study, should you decide to discontinue your participation), your identifiable data will be removed from the file and placed into a separate folder. This will be stored in a locked file cabinet separate from the coded data files. Your identity will be kept in a separate data file after the end of the study. Data on emergency contacts and other health information could be essential to your care should an emergency occur during testing. All electronic data will be protected by passwords and is coded/filed using your number as the identifier. If the data are reported at a scientific meeting or published in a 
scientific journal, only the group data will be reported. Electronic files will be downloaded and deleted from the computer hard drives upon ending of the study. The identifying information will be kept for seven years and will then be destroyed (shredded). Data collection process will be complete by May 2019. Hard data files will then be stored for a total of 3 years. Coded data will be stored indefinitely. The researchers reserve the right to terminate testing if there are potential hazards to your safety or wellbeing.

\section{Questions}

If you have any questions about this research project, please feel free to contact Hunter Waldman (334.596.0824). For questions regarding your rights as a research participant, or to discuss problems, express concerns or complaints, request information, or offer input, please feel free to contact the MSU Research Compliance Office by phone at 662-325-3994, by e-mail at irb@research.msstate.edu or on the web http://orc.msstate.edu/humansubjects/participant.

\section{Voluntary Participation:}

Please understand that your participation is voluntary. Your refusal to participate will involve no penalty or loss of benefits to which you are otherwise entitled. You may discontinue your participation at any time without penalty or loss of benefits.

\section{Options for Participation:}

Please initial your choice for the options below:

The researchers may contact me again to participate in future research activities.

The researchers may NOT contact me again regarding future research.

\section{Please take all the time you need to read through this document and decide whether you} would like to

participate in this research study.

If you agree to participate in this research study, please sign below. You will be given a copy of this form for

your records. 